1245279 


\section{All rights reserved}

\section{INFORMATION TO ALLUSERS}

The quality of this reproduction is dependent upon the quality of the copy submitted.

In the unlikely event that the author did not send a complete manuscript and there are missing pages, these will be noted. Also, if material had to be removed, a note will indicate the deletion.

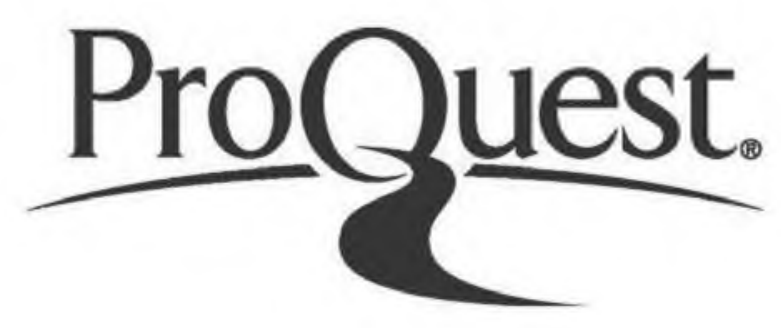

Published by ProQuest LLC (2017). Copyright of the Dissertation is held by the Author.

All rights reserved.

This work is protected against unauthorized copying under Title 17, United States Code Microform Edition (c) ProQuest LLC.

ProQuest LLC.

789 East Eisenhower Parkway

P.O. Box 1346

Ann Arbor, MI 48106-1346 
Learning from Experience in the Community"

an ethnographic study of district nurse students.

ANN E. MACKENZIE

Thesis presented in part fuldilment of the requidements for the degree of Doctor of Fhilosophy. University of Surrey.

December 1990. 


\section{SUMMVIFY}

The starting point for this research was a set of issues originatimg from my experiences in nurse education and particularly in teaching courses in district numsing " These educational issues concerned the learning of student district nurses in the community - a learning environment as yet little researched.

This gtudy gets to gein an understanding of the learning experiences of diwtrict nurses sudents and to examine learning in the prafice setting from the pergpective of the gtudents: Since the research depende upon the changing and differing interpretations of the individualm involved in the naturat setting of the community an ethnographic approach has been aclopted.

The experiences of students are monitored throughout the taught practice element of the district numse course in both jnner oity and rural/umban locations Data a collected through interview and observation: is analysed in the context of theomy relating to adult leaming and learning from experience.

Three major totegories of response are identified and discussed in detail. These categories are sequential and represent the learning process experienced by the students in the pratice setting, as they learn to fit in to a new 
envimonments test out their own ideas and compare the unreality of college with the reality of practicen

Attention is draw to the difficulties experienced by district numsestuents in fitting into new settings and trying out change: to the detrimental effect on learning of rigid practice routines and to the powerlessness of practical work teachers to influence the learning Environment. These issues are discussed in the context of changes already taking place in nurse education as a result of Froject 2000

Suggestions for further research include the development of a package to evaluate the effectiveness of community practice settings as learning environments: and the promotion of teaching strategies based on experience and reflection 
ACKNOWLEDGEMENTS

I wish to record my thanks to the following n-

Dr Elisabeth Clark - Director, Digtance Learning Unit - far encouraging me to embark on this research in the first instance.

Dr. Feter" Jarvis - Surrey University - for stimulating my thinking about adult education and for supervising the project

Dr. Anne Hilton - Ang1ia College of Higher Education - for her advice and enthusiasm about ethography and for jointly supervising the project

Profmsor Jenny Wilson-Earnett and the staff of the Nursing Studies Department and Dr. Sally Fedfern and the staff of the Nursing Fesearch Unit -- King's College London - who provided guidance and encouragement through their enthusiasm for research and their willingness to issten and to share ideas

The participants in this mesearch who gave freely of their time and made the research possible

My riends and colleagues in district nursing who offered understanding and good humour

Finaliy to my husband Terr for believing in my ability and consistently giving help and support. 
CONTENTS

Fage No.

Summary

Acknow dedgements

contente

List of Figumes

TNTFODUCTION

CHAFTEF DNE

THE EDUCATIONAL COMTEXT 3

Introduction

Genera1. Aims of Education

Adult Education and Adult Leaming

Experience and Reflection

Implications for Frofessional Education

CHAF'TEF TWD

NUFSE EDUCATTON

Introduction

Adult Learning Theory in a changing Nurse

District Nurse Curriculun - change and

Learning in the Community Fractice Setting

CHAFTER THMEE

FESEAFCH METHOD

Introduction

55

The Ethrographic Method

Analysis of Ethography - Positivigm

and Naturatidgm

Ref lexivitiv

Ethnography

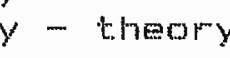

Conelugion

CHAFTER FOUR

RESEAFCH DESIGN 


\section{EONTENTS}

Fage No.

Introduction

I stouses and Froblems

Early fieldwork - pilot stoty

Samping - selection of settings and cases

Sampling across place

Sampling across people

Sampling over time 83

Ac. c.e.sis

Fid dwork: Frotedures

Jnterviews

Farticipant Dbservation

Analysis Focess

CHAPTEF FIVE

"FITTTNG TN"

Intmoduction

Fitting in with col]. ergutes

Fitting in with patients

Strategies for fitting in

Discussion

\section{CHAFTEF $\quad S I X$}

"TFYTNE AND TESTTNG OUT"

Introduction

Dependence

Independence

1.69

Farameters of change

198

Di. gcussion

\section{CHAF'TEF' SEVEN}

"FEALITY OF FFIACTICE" 210

Introduction $\quad 210$

Faralideds of College and Flacement. 212

Integration through comparison and contradiction 2L8

A Discovering Fractitioner 23

Discussion

\section{CHAPTEF ERGHT}




\section{CONTENTS}

Fiage No.

Introduction

Experience and Feflection

Summary of the categories as an experience of

Experience as an individual activity

1. earning

Utilising the process of experience and

reflection

251

The context of reflecting on experience -

The Learning Enviromment

259

The implications for District Nurse Education

Students

Fractical Wort: Teachers

271

Epistemology of college and prextice

Conclusions and implications for future research

CHAFTEF NINE

ETHNOGFAPHIC AFFENDTX - A FOSTECFTFT

281

Fieldwor:

282

Analysis

FEFERENCES

APFEND TCES

1. Distriet Nurse Curpiculum (ENB 1987)

2. Biographical Details - Students 306

3. Research Protocol

4. Research Transcript

5. Glossary of Functuations

6. Extract from Fiesearoh Diary

7. Fecommended Driteria of Suitable Practice

8. Terminalogy - Definitions (ENA 1987) 
Fiag $\mathrm{No}$.

1. Kolb kearning Model

2. The Foud reflection Frocess

3. Study Design - Fattern of Data Collection

4. Practice elements of district nurse course

5. Social. Foles for Fieldwor: 


\section{TNTFODUET IDIN}

Changes in nurse education outlined by the United kingtom Central Councid for Nursing Midwifery and Health Visiting (UkCC 1986) indicate that future numse students will be required to undertake a considerable amount of learning in their prewregistration courses in the communty. These changes will in turn influence post-registration courges.

In reviewing the need for change in numse education the ukco (1986) gtated n-..

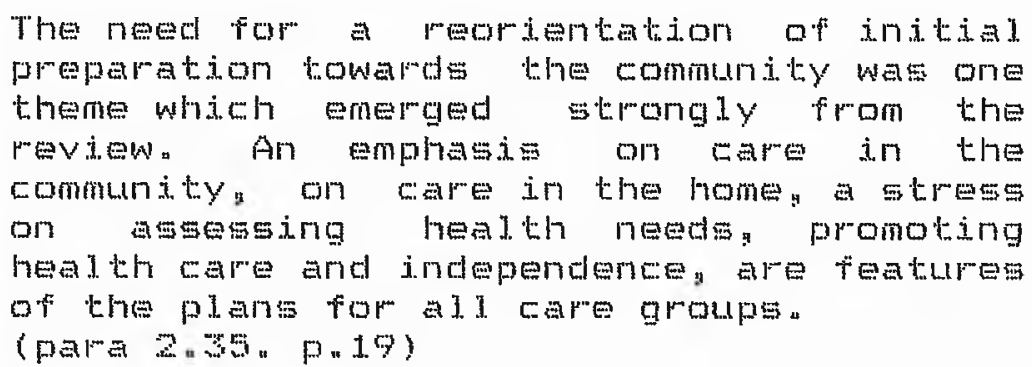

Feomentation towards the community has implications for the way in which nurges wi.l. be educated. It will requime not only a change in teaching ptrategies and curriculum but a change in the settinge in which nurges will receive their experifence. It is quite cleap that many of these settings will be in the community where district nurges, health visitors " community psychiatric numses and others are at present plated for their pratical experience es part of their qualdying courses. Tnevitably these qualifying post-registration courses will change as pre-registration courses provide students with greater insights into comminity and give nurse learners experience in community 
settings that are not generally part of current courses.

Although district numses heath visitors and others have undertalen coumses in the community for many years there has been 1itte researeh into community learning environments the practice setting in which district nurses, health vititors and others are placed during their post registration courses.

This researion examines the experiences of distict nurse students in the learning environment of the communitsy. The community learning environment is defined as all the leaming oportundies that are avalibble to the students while they are placed in the practice setting. The focus of Hhig study arises from questions abouta-

- experiences that help or hinder learning in practice

- ways in which students learn in practice

- the place of prateice based dearning in the curriculum

The aim of the research $i \equiv n$ -

To gain an understanding of the learning experiences of district nurses from the perspective of the students.

The mesearch then is set against a barkground of substantial development in contemporary numse education. Whilst acknowledging the important demographic, gocial and political forces that have contributed to recent changes, the conceptual framework for this research is educationa 
CHAFTEF: ONE

THE EDUCATIONAL CONTEXT

Introduction

This chapter reviews the theorists who have particulariy influenced nurse educatorg and degcribes the educational context in which this mesearch is set. It starts by congidering briefiy the general aim of education and the major conflicting philosophies. It proceeds to a more detailed discussion of adult education and learning and draws conclusions about the implications for professional melucation of which numbe education i.s part.

General ains of eduration

conflicting theories concerning the aims of education have underpinned curmiculum development not only in maingtream school. Education but also in the education of adults of which professional education is a part. The liberal philosophy epitomiand in the andytical approach of Hirst and Feters has been the most influential in the philosophy of education in Britain and has provided the impetus for much of the debate about its aims throughout the whole field of eduration. Liberal education in this sense fan be sajd to characterise the clagsical. view of school. curriculum (Hi.rst and Feters 1.970). 
The concept of liberal education for Feters (1966) is based on the criteria that education $n$--

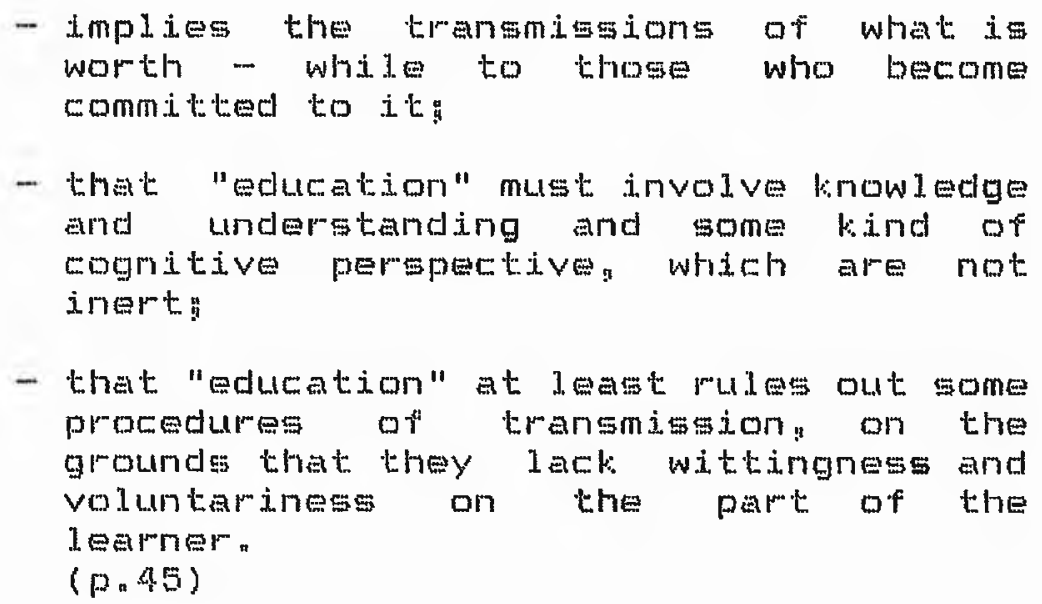

Worthwhileness is related to the development of mind and differentiates between education and training :-

A man with a "trained mind" is one who can tackle particular problems that are put to him in a rigorous and competent manner. An "educated mind" suggests much more awareness of the different facets and dimensions of such problems.

(i.bid p. 32 )

The development of mind through the acquisition of knowledge is a central concept of education algo shared by Fring (1976). However he disagrees with the reductionist definition of knowledge, the now familiar foms of knowledge described by Hirmt (1974) with emphesig on the cognitive, but argues for a broader definition $n-$

Although the development of knowlidge is centraj to the improvement of mind, one must retain a generous definition of knowledge " not confining it to propositional knowledge. Fractical 
knowledge or know - how is of equal significance. Indeed "knowledge that" generally presupposes "knowledge how": and arimes from a systematic peflection upon it.

$(p, 23)$

Fring (1976) argues for a better balance between the two in general education :-

I feel that the neglect of this distinction is responsible for 50 much dead weight in the curriculum. We are so concerned with "knowing that" (possibly because of the greater ease with which it can be examined on a large scale) that we forget that muth of this kind of knowlecge is a very sophisticated reflection upon "knowing how": an attempt to make explicit and put into statements the principles that are already operating in successful practice. $(p .1 .9)$

In an analysis of curriculum planning Lawton (1.975) examines two opposing views of the structure and organisation of knowedge - the classical and Fomantic ideologieg - and summariges their major attributes as follown :-

\author{
CLASSTCAL. \\ Subject-centred \\ Sk. il $1 \mathrm{~s}$ \\ Instruction \\ Information \\ Qbedience \\ Conformity \\ Diseipline \\ $(P, 22)$
}

FONANTTC

Child meentired

Creativity

Experience

D). iscovery

Awareness

Or"iginality

Freedom

Jarvis (1995) relates these two ideologies to two models of education "education from above" and "educatiom of equals"u- 
In the former, the emphasits is upon the socide system and the individuel is prepared to fit into it education is a kind of initiation into society. rather than an extension of socialization: in the latter: the emphasis is placed on the individual and his ability to achieve his potential so that he can act ats an agent in society. (p.50)

He highidghts some of the ideological differences in the rollowing diagram :-

Education from Above

Individual should be initiated or maintained

Aims

objectives

Content

Methods

Assexsment in the social system and its cul.ture. System needs must be met.

Spendic and behavioural objectives employed.

Selected from culture of the social group by those delegated by society.

Initiates individuals into publicly accepted knowledge, its forms and structures.

Didactic. Socratic, when directed: towards specific learning outcomes. Teacher seeks to control learning outcomes. Teacher"s role elearly demarcated and regarded as esgentid to learling

Fublic examination: competitive.

Teachem set tests. Emphasis upon standards.

\section{Education of Equals}

Individual should be encouraged to achieve his human potential. Individual needs should be met.

Expressive objectives

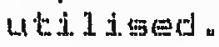

Selected from cuiture of gocial group(s) by learners, often in negotiation with teachers. according to interests and relevance.

Froblem based on knowledge integrated rather than structured.

Facilitative

Socratic : when seeling to stimulate loaming. Teacher seeks no control. over the learning outcomes"

Teacher" role less clearly demarcated and not regarded as essential. to Iearning.

Selif assessment by learner. Feer astessment. Emphasis upon learning. 
Jarvis goes on to draw a parallel between "education of equals" and the humanistic. perspectives of adult educators such as knowles (1984) and, in comparing pedagogy to andragogy: shows that the farmer refers to classical and the corresponding "eclucation from above" while the latter refers to romantic and "education of equals" It is interesting to note that Jarvis (1985) suggests the reason for the acceptance of the romantic philosophy during the nineteen sixties is mainly as a mesult of changes in society "when the structumes or society are malleable, that innovations emerge and social change is possible" "This was demonstrated in changes not only in initial education but also in the professions " For andragogy it was a time when the philosophy of self development, embracing hunanistic principles, was gaining ground. This has since been established in adult education, athough it is still debated (Jarvis 1985).

Adult education and adult learning.

A concern for the learner is the prevailing and common theme in most adult education. It draws strongly on the democratic and progressive ideals expounded by writers such as Dewey (1916) and is based on the humanistic principles that conceive of the learner as self directing extonomous, and independent (Brookfield 1987, Boud 1989). 
According to Gififin (1987) womk undertaken in this field has provided a theory in adult learning

The major point of what might otherwise be thought of as adult education hheomy is realiy a theory of atult learning in a gocial contexta largely constructed as "adult education knowlecige" by the exigencies and ideologies of professional practice. $(p, 198)$

The experiences of practice have driven forward the thimking on adult learning and to a large part provide the basim for methot.

The cument and most obvious aspects of ä "theory in adult learming" ame Iinked to the "adult characteristics approach" of how adults Isarn and the resulting humanistic principles of how acluls should be taught a Both are closely linked in practice but in fact arise from different philosophies and both are difterent again to the 1 iberal and clasical traditions

Dewey $(1916)$ epitomised the democratic idealg of progressive education whith jdentified experience growth and change as major elements for education. He describes education as "a constant meorganizing or recomstructing of experience" (Dewey 1916 p.76) - not just passive expemience but the individual's intemetion with the enviroment. He was [noful to identify the mismeducative experience from educative experjence and the guiding role of the teacher in 
the latter" Frocess, according to Dewey (19.6), is as important as ends in the reconstruetion of experience :-

It means that experience as an active proces occupies time and that its later period completes its earlier portiongit brings to light connections involved; but hitherto unperceived. The later outcome thus reveals the meaning of the earlier while the experience ag a whole establishes a bent or dispositian towards the things possessing this meaning. Every such continous experience or activity is educatives and all education resides in having such

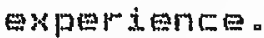
$(p, 78)$

His critics have interpreted his writings as rejecting the intellectual and academic aspects of education for the pragmatic and practical aspects of experience together with limitless but unpurposeful growth. Cross-Durmant (1987) points out that the practical pursuits would be the first stage of learning followed by a sharing and exchange of ideas guided or farilitated by the teamer :-

The third stage is a growing ability to organize analyse and to symthesise : al of which undempin matery of knowledge however defined. $(p .88)$

However it is not that knowledge is regardad as unimportant. It is the way in which knowledge is gained and how it is Lsed to foster further leaming, as opposed to the traditional view of knowledge as facts gained through a study of ecademic disciplines delivered by a teacher" 
The concept of growth ig lese molicit and raises questions about independence and human kind. Growth through education may take various pathen it is not an orderly process and individuals will have gome say in determining it. Even the voluntery nature of adut education does not guarantes consistency in development.

A rumther critjeism hinges on the fact that mueh of Dewey's writing is referenced by school education. However his ideas are contingert with education throughout ife and Dewey (1916) regards education in childhood as setting the foundations for later lifen-

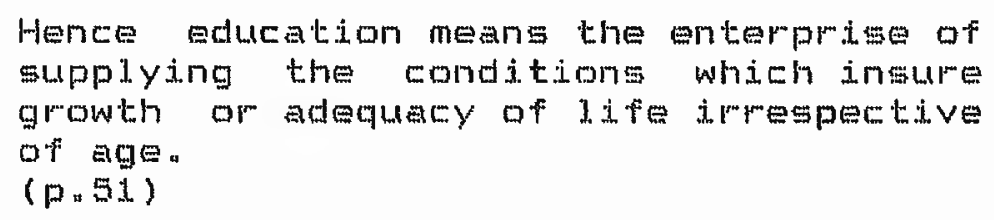

Continuing learning is a welcome concept for most educators in professional education who are frequently faced with remedial action before or as part of a curriculum. Dewey's iteas (1938) are important contributions to curriculum methods :

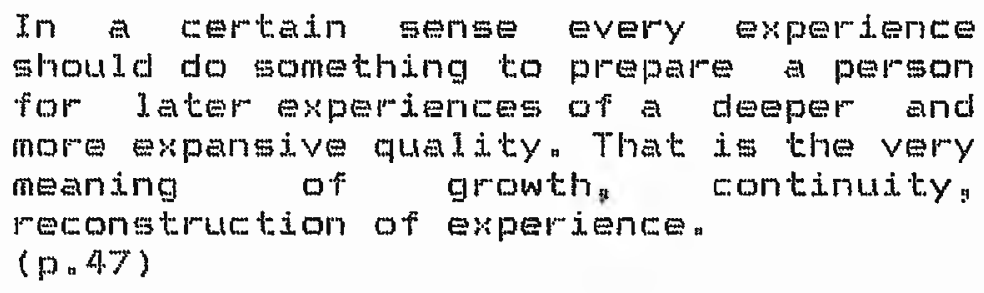
should do something to prepare a person for later experimeng of a deeper and more expansive quality "That is the very meaning of growth; continuity: reconstruction of experience. $(p, 4.7)$

Throughout attention is focussed on the learner and it is this aspect of the American progressive movement that has 
left its greatest impact on the methods of adult eduration. rather than the its social and political emphasis.

The adult learner and the term andragogy have become synonymous with the name of Malcolm knowles who has popularised interest in the learning of adults and made it accessible through his writings and lectures. Influenced by both Lindeman (1926) and Fogers (1969): his ideas refject a humanistic philosophy which parallels and continues the progressive's thinking on the individual. A development of the persom combined with self actualisation, development of individual potential and role are strongly held principles in professional education today whe humanistic approach, drawing from both philosophy and peychology, is the background for knowle's assumptions of self concept, mespect for the individual's experiencen readiness to learn, intminsic motivation and problem orientation and is a dominant influence in curriculum design for professional courses"

An analysig of the wark of knowles (1979,1980,1984) reveals a concentration on the principles of method as the main istue of adult education to the neglect of content and the j.sues of knowledge. It is Jamgely atheoretical and lacks an epistemological base and a rigorous examination of learning theory to which it has most to contribute (Hartree 1584). 
The andragogy - pedagogy debate has been the focus of criticism of his work arising mainly from his assumptions about adults and adult leaming and based on his observations of practice which geen to have been in joglation from other developments in curmiculum. (Eruner 1977" Stenhouse 1981).

While knowles" assumptions have increased to aix (knowles 1989): they have changed Iittle in content, but, in response to criticism, have acknowledged the cioser similarity between child and adult leaming - again without theoretical justification " His assumptions which incorporate many of the principles of humanigtic education may be summased as fol. J.OWE $\because-$

- self concept is an important part of maturation and adulthood and moves adults towards self direction and indepedencenthis assumption implies that adults will benefit from detemining their own learning and own educational. needs n together with self diagnosis and self evaluation. An enviromment that fogters gelf prespotct and independence is therefore favoured.

- related to peif concept is the assumption that adults have a background of experience. reflected in their self respect and part of their uniquerness. This uniqueness and experience should be acknowidged as valuable and uged as a source of learning.

- adults readiness to learn. linked to developmental stages of life imply that relevance in rearning is required. The needs and interests upon which readiness is based a jo asgume an intrinsit motivation to learn. Fielevant material if regarded as important.

- the reality of the learning is related to the assumption that adults have a problem - solving orientation to leaming that is concemed with immediate problems and requires immediate appliceton of learning. In contrast to the subject - orientation and postponement of application of the learning of 
children. Problem - solving techniques and immediate application in real situations are therefore regarded as appropriate strategies of teaching.

While most adult educators can provicle examples of the above assumptions observations will also have been made to the contrary. children who have a problem golving orientation or demonstrate internal motivation and meed for relevance: adults who are not always self motivated but who can display postponed gratification in meeting educational need: are instances that question some of knowles' assumptions.

The social context of learning is largely ignored in these assumptions and the immediacy of problem - solving is at odds with internal. motivation. The complexitiy of experience as a Jearning resource does mot sem to be recognised. nor does its melationship with relevance and self concepts as emphasised by Griffin (1983) :-

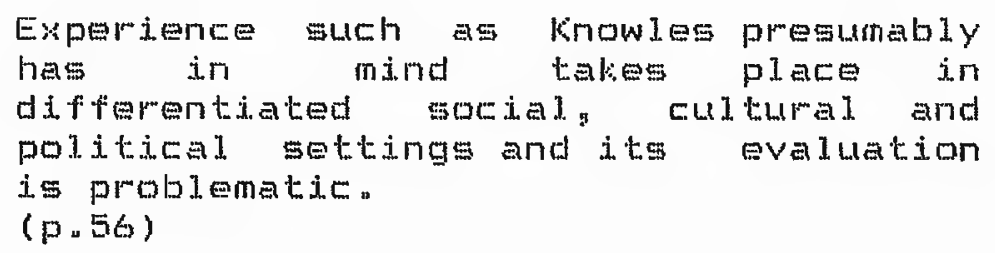

Through an evaluation of experience the learner may gain ingight into relevance and $i t s$ level of effectiveness. The assumption that relevance is an unquestioning reed is too simple Again Hartmee (1.984) has criticied knowles for his lack of conceptual clarity and for his inability to substantiate his claims. 
Despite the criticisns of andragogy the debates have contributed to the principles of teaching and learning in adult education and bring to centre stage the relationship between teacher and learner raising questions of control, authority and context. In these respects the implications are for the practices of adult education and the practice of the educator.

Similar points for debate ame made by Mezirow (1981,1985, 1.988) following ideas of Bruner (1975) and Rogers (1969) in the psychoanalytic field and derived from his own research of women re-entrants to college in the United States.

The interpretetion of Habermas's (1971) theory of lenowledge leads Mezirow to identify three domains of adult learning of which "emancipatory action" provides the besis for his bey concept of perspective transformation and a theory of reflection from whith adult educators may draw some principles for practice.

Mezirow (1981) describes the three distinct but interrelated learning domains derived from Habermas's three areas of primary interest - the technical, the practical and the emancipatory which are grounded in different aspects of social. existence "work, interaction or communicative action and power respectively. The technical interest or learning domain refers to the control of the environment and 


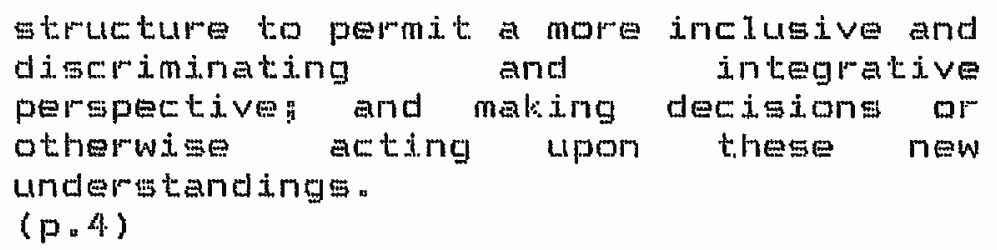

Dr particular interest is the inclusion of the affective domain in perspective trangformation as a form of learning and the process of critical reflection which perspective trangfornation implies. From his study and identification of the possible phases of perspective transformation he concludes that adults are capable of critical reflection but children are not :-

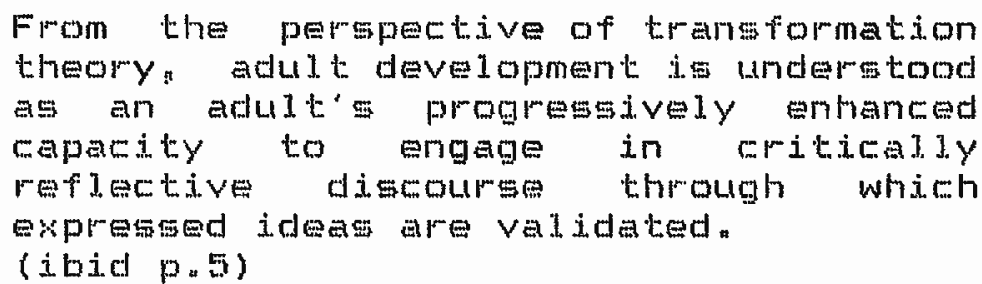

The adult educator"s role then is concerned with "assisting adults to understand the meaning of their experience by participating more fuldy and freely in rellective discourse to validate expressed ideas" "

The theories of adult education that have been reviewed are not exclusivly the domain of adult educators; nor should they be the only theories that inform edueational prectice of adults (Lovell 1980) as is emphasised by Griffin (1987) as follows :-

The fact is that adult educators make a 
Gelection from the total extent of their knowledge about how adults learn on the perfectly good grounds that some kinds of theory are more "fitting" with their practice as professionals in other words, as far as adult learning theory is concerned, knowledge is constructed around the exigencies of practice, in which humanigtic rather than behavioural permpectives are appropriate. (P.186)

In a charter for andragogy (Mezirow 1981) principles emerge for the practice of adult education such a using personal experiences encouraging autonomy in self direction, defining learning needs attending to belf concept and self awareness pecognising the place of relevance and problem golving.

Although there may be differemces in definition, most theomists in the field of adult education would gubsemibe to these prineipless

Experience and Feflection

Experience is a common factor in adult learning and indeed is part: of our everyday existence. The use of this experience would appear to be a central and linking theme underlying the principles identified above and will be analysed as the basis for an interactive process in learning. 
As was noted previously, Dewey,who has had a prevailing influence on adult educationg identified experience as an important apect of learning, the various parte of experience being connected by reflective activity. This dynamic and cyclical process has since been explomed and expanded and has become one of the central jideas in the practice of adult educetion " However it is still embryonic and an analysis of its development will help to assess its use in adult curmicullum "

At its simplest reflection on experience has four stages or learning gtyles - experience as the basis for observation and reflection: observations assimilated into relevant theory" implications and actions identified and tested out incorporation into new and further experiencen This in effect is the kolb learning model (kolb and Fry 1975) :-

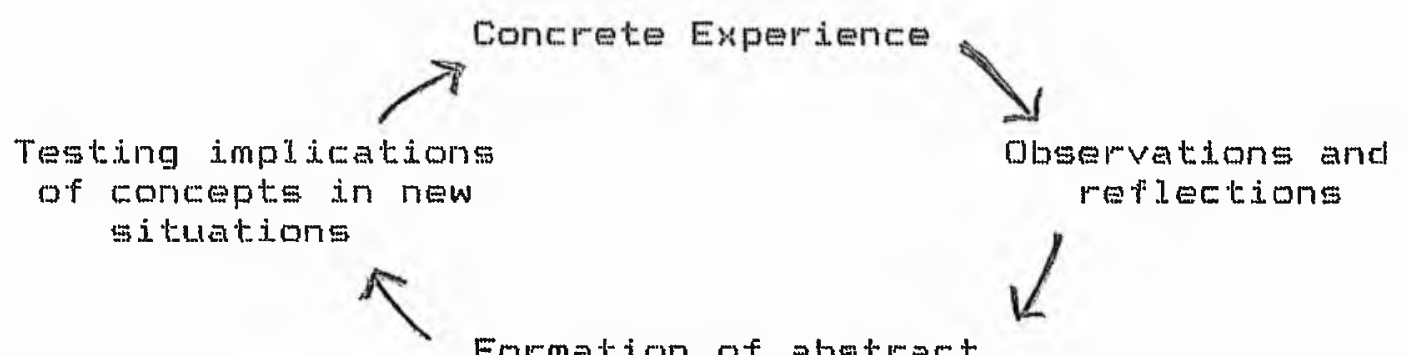

Formation of abstract concepts and genemalisations

$(P, 33)$

Figure I. The Kolb Learning Model.

kolb(1984) defines learning as "the process whereby lnowledge is created through the transformation of experience" kolb (1984) differentiates this type of 
learning from the behavioural and the traditional approaches which define learning in terms of outcomes either as stored facts or as behavioural responses a-

First is the emphasis on the process of
adaptation and leaming as opposed to
content and outcomes. Second is that
bnowledge is a transformation process
being continuously created and
recreated not an independent entity to
be acquired or transmitted. Thirda
learning tramsforms experience in both
its objective and subjective forms
Finally, to understand learning: we must
understand the nature of knowledge.
(p.38)

Learning then is regarded as a continuous process grounded in experience. "knowledge is continuously derived from and tested out in the experiences of the learner" "kolb's learning cycle denotes both experience and reflection as components of learning and in a sense regards adaptation as a process of learning. These are important concepts in professional, education and vital components of the learning process.

Learners require foum kinds of abilitiesn- they must be able to involve themselves fully and openly in the mew experience - concrete experience abilities (CE) p reflect on and observe experiences from different perspectives reflective observation abilities (Fo) preate concepts that integrate their observations into logically sound theories abstract conceptualisation - (AC): use these theories to make decisions and Eolve problems -ative experimentation $\{A E\}_{\text {. }}$ 
The learner moves between the two contrasting dimensions of Jearning - concrete/abstract and active/retlective - in the learning process" from actor to observer. and from specitic involvement to general analytic detachment. Here meflection and action are seen in opposition, implying that meflection cannot take place alongside action and indeed that they are separate tages.

While providing an ideal and rather mimple model of experiential learning, it has complexities that are not explained. It lacks conceptual clarity - for instance in distinguishing between adaptation and transformation. The emphasis is on cognitive processes. Despite a mumanistic. gtance this model tendw to ignore the intricacies of the human person and the changes that may occur to learnems as they undertake their experience and reflection. It also assumes that meaningful learning always takes place and ignores miseducative aspects. However, it is a ueful starting point for analysing learning from experience.

Although Kolb's learning model lacks explanation of the process linking reflection to abstract theory and hence to new situations it $i s$ a useful rimework for the sequencing of content in curriculum design, where $x$ have used it in my work together with another similar model from the further Education Unit (F"E.W" 1981). 
Again experience and reflection are interrelated and learning is a dynamic goal omientated process making use of reflective activity before moving forward to further experience. A more realistic appreciation of the necessary interplay between reflection, experience and any additional. leaming: is shown: acknowledging that the process may not just be cycidcal as displayed by kolb.

The F.E.W. model. includes feelings: attitudes and values as aspects of reflection. It also demonstrates a place for the teacher and underlines the importance of gpecific learning before moving on to further experience. It $i s$ intended as an "ideal format" for curriculum design in the unified vocational preparation, linking young adults from school to work and from adolescence to aduithood.

Boud (1985) argues for a better utilisation of experience and reflection in the Ieaming process. He goes on to argue that refiection is the process through which experience can be turned into a purposeftu activity of Jearning. It is this process that has been neglected and which Boud and hi.s ansociates attempt to develop into a model of reflection in 1.earning. Issues arising from their work in the Australian Consortium have provided the starting point for this model. drawing together the collective ideas from the practice of adult educators. 
The group (Boud et al 1985) take Tough s (1979) terminology of "delibemate leaming" to underpin their own definition a-

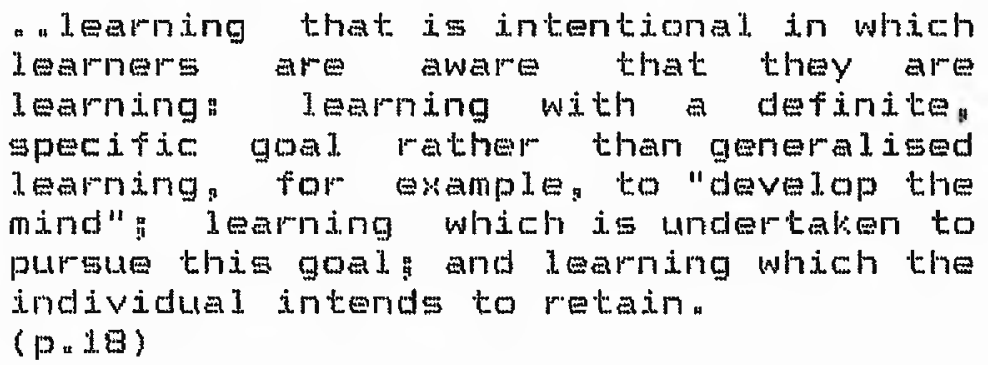

Deliberate learning takes place in institutions as well as an a less formal basis. The focus for Eoud $i d e a s ~ i s$ on experienced based learning rather than elassroom learning which manty concern information assimilation. The following diagram (Boud et al 19g5) summarises the meflection proceses:-

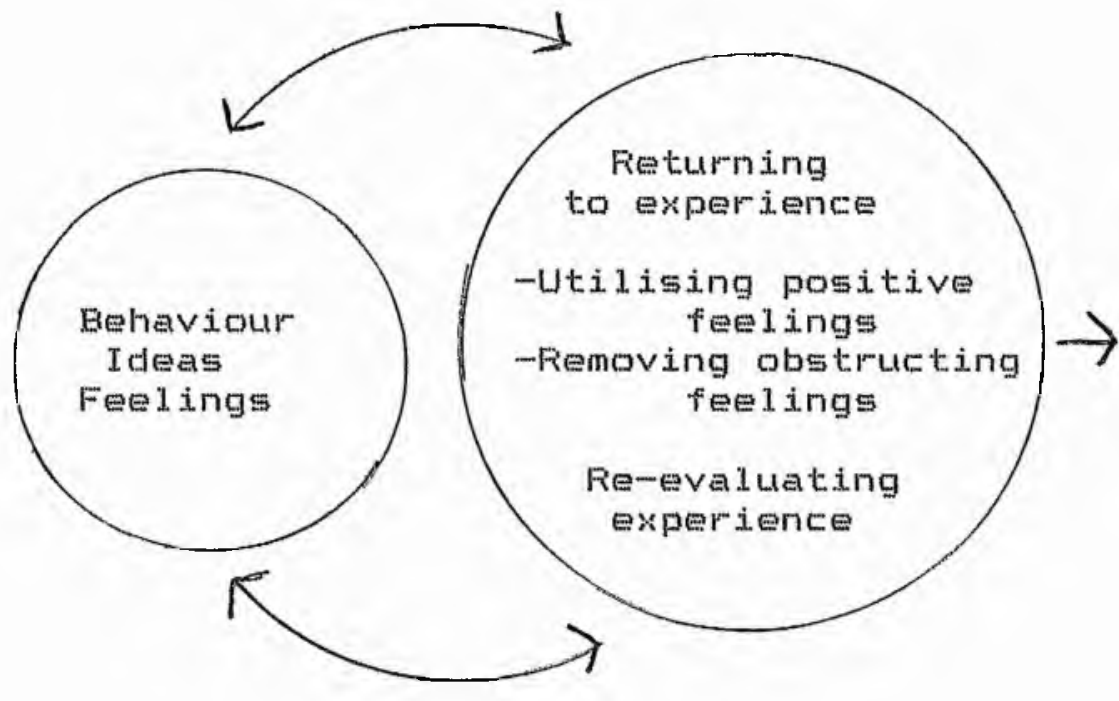

Experiences
Reflective processes

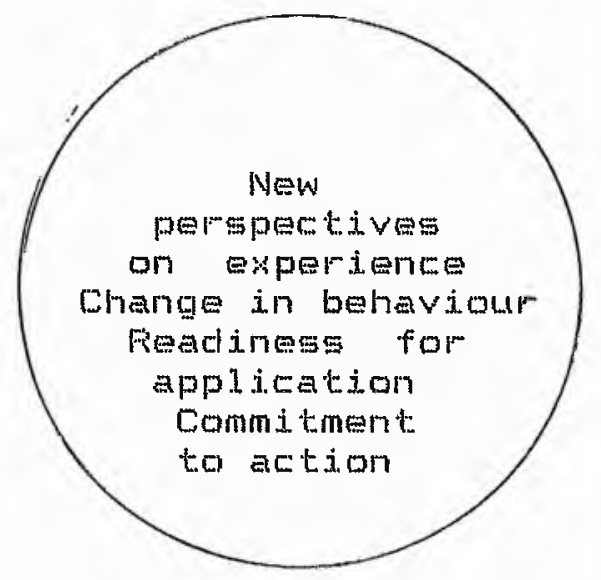

Dutcomex

$(p .36)$

Figure 2. The Boud Fieflection Frocess. 
This model add again to the dynamic process with movement between the reflective process and the experience. The model shows the two main components of meflection - the experience and the meflective activity based on that experience.

Experience is the total response of a person to a gituation or event - "what he thinks; feels, does and concluder at the time or thereafter" (Boud et al $1985, \mathrm{p}, 18$ ). Reflective activity involves recaptuming experience. thinking about ita muling it over and evaluating it. For Eoud the ability to reflect can be developed to different Stages in different people, but for it to lead to learning it involves " those intel lectual and affective activities in which individuals engage to explore their experiences in order to lead to new undergtandings and appreciations" (Boud et al 1985,0.19).

The thmee difterent stages or elements in the reflective process are not regarded as separate or linear and in fact Boud emphasises the sudden insights that might occur "out of the blue" that signal the beginning of a new level of refiection. They may be "instantaneous or intuitive appreciations of an important truth, or enriched descriptions of the events"(Boud et a 1985,p.29) and cannot be planned. However for most reflective processes the three Elements of reflection tollow each other as: returning to 
experience - recollection, replaying of initial experience in the mind or recounting to others attending to feelings? - involves two aspectis utilising positive feelings and removing obstructing feelinga remevaluating experience -re-examining experience in the light of the learner's intent, associating new knowledge with that already possessed, integrating new knowledge into the learners conceptum 1 framework. This final stage is the most important as it leads to "appropriation of this knowledge into the learner's mepertiome of behaviour" tested out either mentaly or through action" Boud cautions against moving through these stages too quickly or missing out the first two which he thinks are premcursors to re-evaluation.

What Boud (1985) does not consider in depth is reflection at a later time; through written material perhaps in the form of a diary. This revisiting the experience would aid re-evaluation and particularly the integration of new knowledge into the conceptual framework and into the Iearner's affective and behavioural repertoiren

A further important point for Eoud is that all the stages are influenced by the intent of the learner who is central to this process and determines the level of analysis dependent on the the learner's goals or intentions. Some experiences lead to learning others are better forgotten. 
Other work has helped to illuminate Boud's discussion. af particular relevance is the complex double -loop learning that Argymis (1982) has identified as being the jdeal level of leaming to bring about change and action, and Mezirow's devejopment of the concept of critical reflectivity as a vital part of perspective transformation.

Boud : work then, concentrateg on the learner as the initiator of Jearning, determined by his intent and stimulated by positive and negative experiences but needing the help of another to assist in the process of reflection.

It is interesting to note that the starting point for rerlective activity is seen by some writers as uncertainty (Dewey 1916): critical consciousness (Mezirow 1981) conecientization -- to enlighten men about the obstacles preventing then from a clear perception of reality ( Fmeire 1972):-a11 of which imply the megative connotations of disharmony as the impetug for reflection rather than positive experience. The reason for reflection then becomes emancipatory action in a social and political context rather than just an individual activity change is the intended rewat of action in either case one is conceived as bringing about change in society the other changes in the individual which largely ignores the mocial and cultural context. Kemmis (1985) is criticel of the individualistic emphasis $:-$ 
This insight, that reflection is a political process in which we locate ourselves more or less explicitiy as agents in the historical struggle againgt irrationality, injugtice and unfulfiliment, denies that refiection i. quidet contemplation primarily of significance to the individual and her or hi. own interests.

$(P P=146,147)$

This statement is a challenge at the theoretical level as argued by gurch as Griffin (1987). Some may say that the concentration on process and on the individual, independent of the gocial group, is counter-productive to development of a theory of adult education. It is of courge an issue for professional education and one which will be referred to in respect of the womk of Brownhi1. (1987) and of Schon (1985): both of whom recognise the influence of the professionel group and of society in shaping the nature of professional know 3. edge.

Schon (1985) in particular recognises the importance of meflection in professional practice and examines the process in what he terms "reflection-in-action" "This type of reflection its learning which is based on an epistemology that challenges the technical mationality model of applied theory to practice and advocates that professional knowledge is drawn from our actions . Schon (1985) equates it with what Polanyi (1967) cal1s "tacit knowledge" and Fyle (1949) refers to as "procedural knowledge" n- 


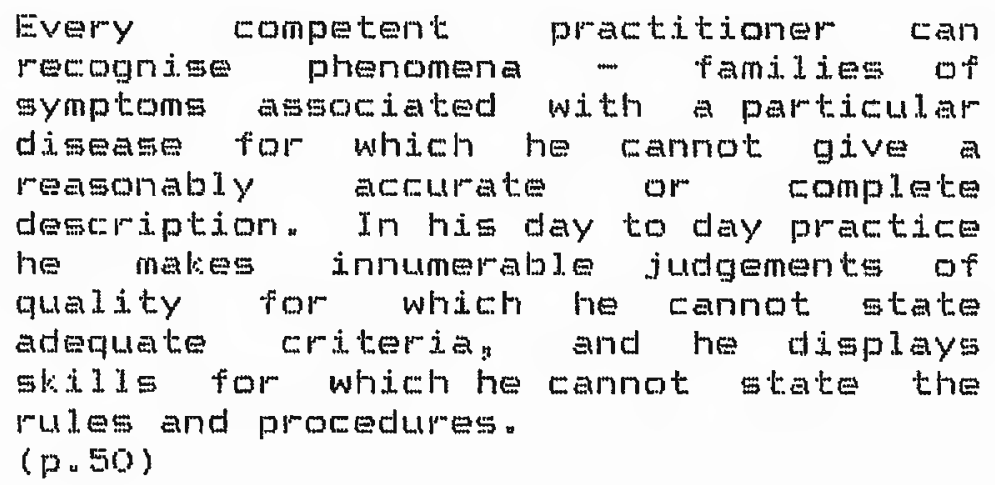

This "knowing-in-action" is the characteristic mode of ordinary practical knowledge the "thinking on your feet" which suggests that we can think about what we are doing while we are doing it. This capacity is regarded by schon (1983) as reflecting-in-action and is degeribed as follows:-

He may reflect on the tacit noms and
appreciations which underlie a
judgement, or on the stretegies and
theories implicit in a pattern of
behaviour. He may reflect on the feeling
for a situmtion which has led him to
adopt a particular course of actions on
the way in which he has framed the
problem he is trying to solveg or on the
role he has constructed for himself
within a larger institutional context.
(p.62)

The modes of reflection are not presented in any hierarchical or developmental form but ma vary in timen which may be rapid: minutes! or stretch over weeks or months. Timing is "bounded by the "action-present" the zone or time in which the action can still make a difference to the situation" (ibid p.62). Frequently the reflection-in -action is stimulated by surprise

When intuitiven spontaneous performance 


\begin{abstract}
yields nothing more than the results experted for it, then we tend not to think about it. But when intuitive performance leads to surprisess pleasing and promising or unwanted, we may respond by reflection-in-action..." In such processes: reflection tencl to focus interactively on the outcomess of artion, the action itself: and the intuitive knowing implicit in the action. (ibid pusb)
\end{abstract}

It would appear that thig process of reflection is expected to be more interactive with the experience and the learning than in some of the other models such as those of kolb and Wezirow. Schon (1983) also implies that routine practice does not result in meflection. This is perhaps an aspect that professional education needs to consider, as much professional. practice ig routine and offers opportunities for peflection which could result in changen The role of the teacher or facilitator is important here in helping the practitioner to meflect-in-action - a point taken up in 1. ther work (Schon 1987).

Schon (1993) could again be oriticised for ignoming the organisational or political constrainte that the practitioner is under and therefore taking an individualistic approach outside of the social context.

Clearly learning through experience and reflection is very relevant to professional education where knowledge and practice are of equal importance, as a consideration of the aims of professional education will illustrate. 
Implications for Frotessional. Education

The philosophical arguments of "worthwhileness" and "value" are as rejevant to professional education as they are to the school curriculum. It is still a question of balance between intellectual development and preparation for a specific role or as Feters (1981) puts it "-

"there is a constant tenmion between
the pursuit of personal and public good
and that this manifests itsel in the
type of emphasis that emerge as
educational aims
(p.47)

Feters does not deny that cognitive development is fundamental to learning or that the development of the mind through various forms of experience $i g$ an aim of education. as discussed earjier in this chapter: but rather gives a broader definiton of knowledge :-

what people do: their attitudes: actions and habits; are as important as what they know and believe.

(i.bid p. 5 )

The aims of professional education cannot deny the importance of cognitive development but have also to accommodate professional practice. "knowing how" and "knowing that" are both important concepts in professional. education.

Faterson' (1979) philosophical malysis of adult education sees liberal and vocatiof a education as quite separate 
entities. "Being educated" and having a liberal education in Faterson's terms are the same vocational education can only hope to have "kinship ties" with liberal education :-

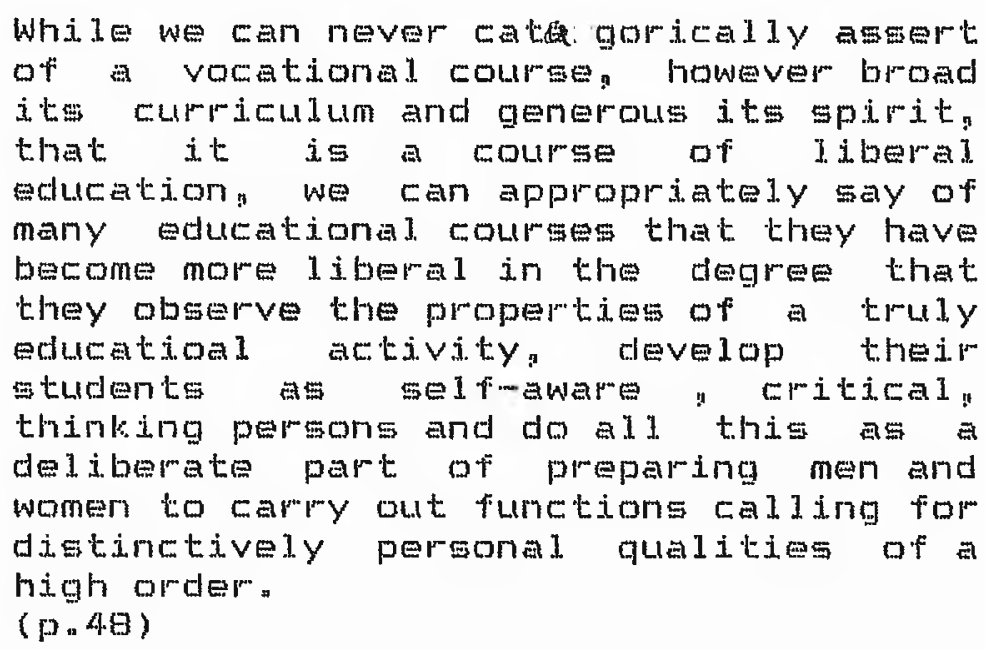

This distinction between liberal education and vocational or role eduction sems to emphesise kmowledge as an abstract commodity and gives little ingight into what constitutes worthwhile knowledge for adult or professional curricula. In common with other proponente of liberal eduration it treats education as velue free or neutral ignoring "pumposes" and to some extent undervaluing pragmatic and utilitarian forms of education.

It is clear that the liberal view of education characterised by developing worthwhile states of mind and an emphasis on the cognitive has had its influence on professional education albeit in a rather piecemeal fashion. The introduction of subjects that are intellectualiy stimulating though not specificaliy vocational, and a 
concerr for persomel and intellectual development. are reflective of a more "liberal" philosophy.

While the philosophical arguments surpounding the genemal aims of education raise important questions about professional education the forms of knowledge requimed by the professional are not the distinct and irmeducible forms of knowledge described for indtial education (Hirst and Feters 1970). The knowledge is chosen as being worthwhile because an understanding of the concepts involved contributes to both cognitive and professional growth (Hostier 1982).

Notwithstanding the philosophical arguments gurrounding the aims of education, the professional group will determine what constitutes professional knowledgen Erownhill (1987) outlines the gituation in his exanination of aesthetic education as a wrientific mtudy

The intellectual communities with their interpretive frameworts and decision procedures litimately control how a subject is developed and what can be classed as knowledge in a mubject. For instances the scientific community clecides how seientists are to look at the worldy what are the appropriate methods: what is acceptable evidence, and what is taught in a subject. (p. 38 )

Cleamy this rases questions for all professional groups 
jus as it did for asthetic education. The aims of education may be determined by the professional group but not without pressures from others who have an interest in shaping its future. They may be social or economic or political interests and may come from within the professional group or from outsicle. In this context the questions about educational ains frequently centres on knowiedge and on what constitutes an appropriate knowledge base. Indeed in any analysis of education the issue of knowledge is a central one.

The debate about professional knowledge - arequacy: relevance and applicability is arqued by Schon (198s) under the label of technical rationality :-

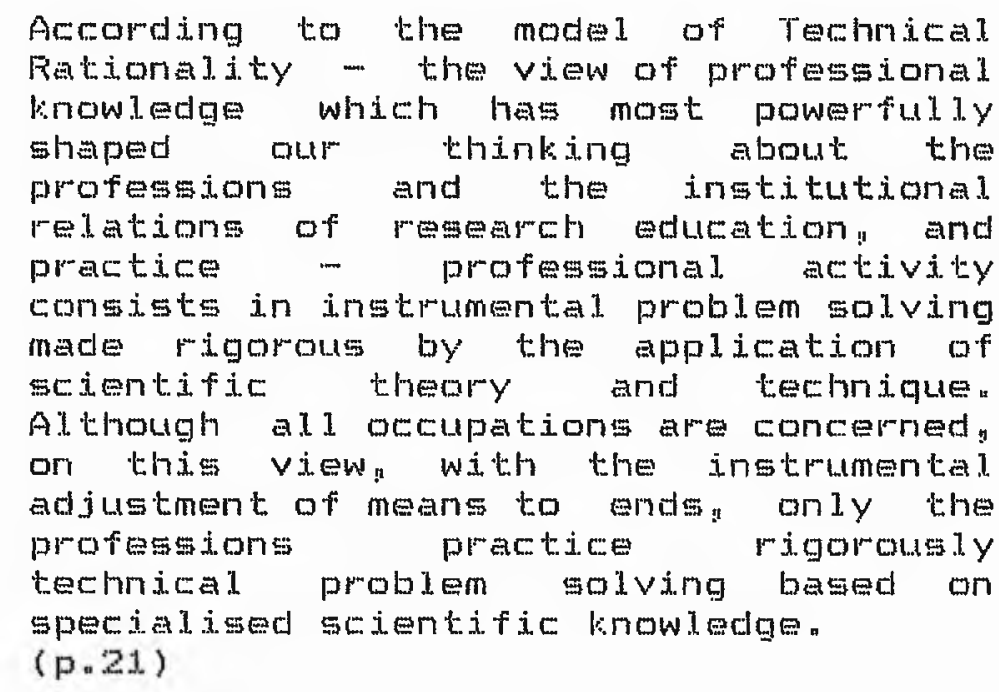

The prevailing view of geientific knowledge is drawn from the positivitic school epitomiged by the natural sciences and based on the assumptions that human beirgs can be 
studied according to the application of 1 aws through experimentation and rigorous application of empirical method to explore the physical world. According to the narrow definition of the natural sciences scientific knowledge is objective. testable, public and open to scrutiny. The opposing non-positivist approach is that knowledge is subjective, meaningful and individually focussed.

Positivism assumes that there are clear cut ends to the profesgional's work that can be achieved by the rigorous appication of systematic knowledge. Schon (1983) sums up the views of proponents of Technical Rationality thus :-

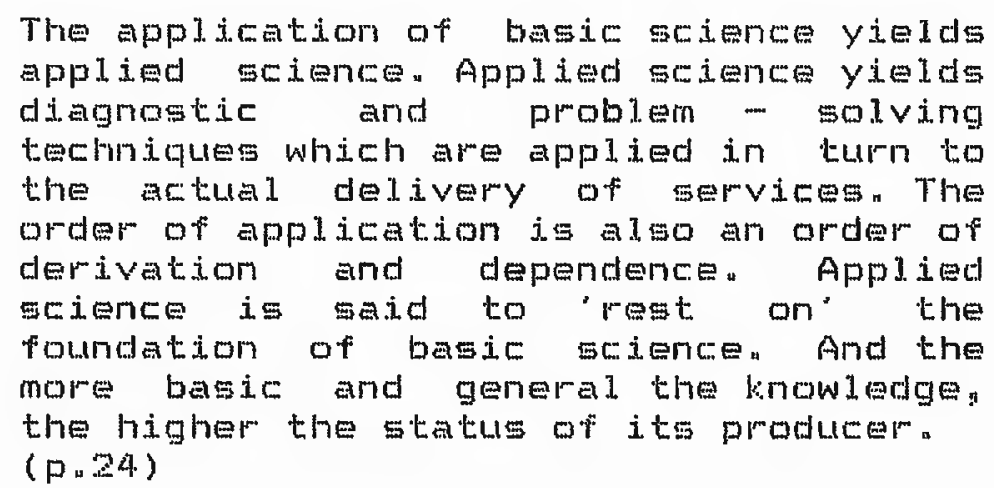

The status and power of the professions is intrinsically bound up with their body of knowledge and perceived expertime (wilding 1982). Frofessional educators must. work within a social and political context and recognise that educational decigions ame influenced by political ideologies m well am educational ideology " with resulting tension for both student and teachem" 
According to Schon (1983) the discrepancy between the expertations of society and the effectiveness of the professional is causing a crisig of confidence in the profeseions :-

Is professional knowledge adequate to fulfill the espoused purposes of the profesgions? Is it sufficient to met the societal demands which the professions have helped to create? $(p .15)$

If the professions are to overcome the crisis of confidence as described by Schong which is afflicting many of the professions not only in the United States but also in Britain (Boodlad 1984) it may be timely for professionals to re-appraise their body of knowledon the development and dissendnation of this knowledge through educational practice and its utilisation in professional practice.

A debate within the professional field which identifies the philosophy that directs activities and provides inspiration for protice would make clear the basic philosphical differences and expose the cantradictions between educational aims and educational practice in order that they may be better understood and discussed.

The important issues of professional education may be brought into greater cilatity by an exposure and an exanination of the underlying philosophy of why actions are 
taken and what the consequence of these actions might be.

It is in these respecte that philosophical analysis can make its most useful contribution to an undergtanding of professional education and curriculum design. In terme of adult education the conclusions from analysis of philosophical approaches is well summarised by Griffin (1985) thus:-

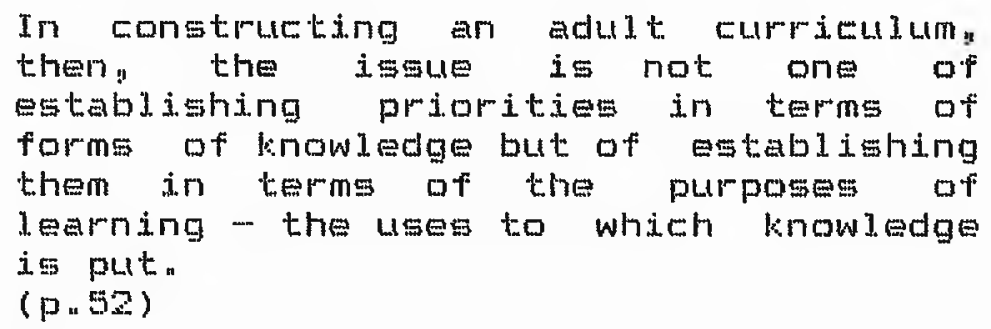

This eriticism of liberal philosophy serves to remind educators of the professions that they may develop a "gabre - toothed" cumpiculum, abstract and irmegant, if debates about educational aims are not made public and linked with debates of practice"

In any curmitulum the aims: content and method are inextricably linked "Frofessional courses have the added complexity of learning environments stradding both academit and practical and therefore contradictions within the curriculum are more likely to arise. However adult education has directed its efforts to the activities of learning and to curriculum method and in this mespect has made its 
greatest contribution to curriculum design in profesgional educetion "The increasing influence of adult learning theory on nurse education is becoming evident and will now be examined in more detail. 
DHAFTEF TWO

NUFSE EDUCATTON

Intimoduction

This chapter examines the influences of adult learning theory upon nurse education in general and upon district nurse education in particular" It reviews recent changes in curmiculum and training and noves towards more specific consideration of the community learning environment which is the focus for this research.

Adult Learning Theory in a Changing Nurse Curriculum

Aclult learning theory, the theory arising from the practices and methods of adult education and drawn from the humanistic philosophy of education, is evident in the cumrent texts in murse curriculum (Allan and Jolley 1987, Eradshaw 1.989, Kenworthy and Nicklin 1989). These texts are part of the implementation of the greatest change in nurse education since the new syllabus for general nurse training was introduced in 1952. They demongtrate the different and often contradictory epistemological approaches that are prevalent in nurse education and which lead writers and mume eclucators to advocate an eclectic approach (Eeattie 19a7). To some extent adult education theory has not helped 
to clarify the situation as it is itself engaged in epistemological debate (Emight 1989).

It is understandable that curriculum planning in nursing appears to lack direction. The study of education is relatively new in nursing and has only begun to establigh itsejf since the Nurses, Midwives and Health Visitors Act (DHSS 1979), which resulted in the constitution of the United Kingdom Central Council (UKCC) and the four national boards. These new statutory bodies have enabled change in nurge education and have focussed debate on educational issues. As the chief executive officer Mude storey (1985) gtated:-

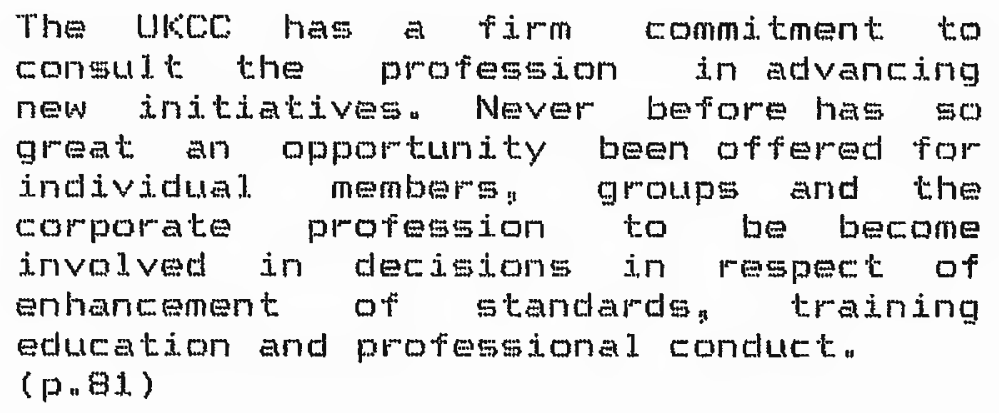

The review of nurse training which resulted in many new proposals and initiatives: will change fundamentally the pre-registration and post-registration programmes of nurse education. Not only will it substantially change the content and structure of the courses, but also it will mean that students will no longer be part of the work force but wi.1. be supernumery. 
These proposals collectively known as Froject 2000 (UKCC 1986) are in response both to pressures from within the profession and to changes in society. For some it is a further step towards the professionalisation of nursing. For others it $i s$ an eduftional enterprise. Froject 2000 (UkCC 1986) represents education as pursuing both "personal and public good" and it is here that the aims are often obscure and contradictory. The question of whether murse education is preparing competent practitioners to meet the demands or saciety or whether the preparation is for individual growth through free thinking and gelf direction, is one shared with general educational philogphers and Is perhaps a question that is a lwass open to debate. As Feters (1981) states "the type of mphasis will emerge as educational aims" assuming that the aims have been debated. Nurse education is in danger of not giving enough time to the debate of aims even on an individual institutionai basis. Ferhaps this would be a more worthwhile debate than that of the role of the nursen

However the short timescale over which these extensive changes have been enacted has also brought with it confusing and confused innovations with little time for debate about curriculum issues, curriculum evaluation and dissemination. Indeed at times nurse educators in thedr attempts to kepp up with the demands of change: have been able to do littie more than respond to a plethora of papers; not only from their own national bowds but 1 as from the heateh 
authority or health board in which they are located.

This demanding plogramme has led to some innovative ideas but may also result in validation driven courses without allowing eclutatorg to debate or clamify epistemological issues. These are the issues which underpin all curmiculum planning and if not aired may sumface as competing and contradictory aims between intention and nethod. The considerable efforts of curriculum planners an result in a submisfon document that meets the dimand of validation but remains inert and impractical as an initial blueprint for an educational programe and accompanying evaluation "The added complexities for a practice based proression such as numsing are thase of straclding the two learning environments of the eductional institution and the practice setting.

District Nurse Curriculum w- change and contradiction

Anelysis of district nurse education as part of the generaI rhanges in pre and post megistration education will demonstrate some of these difficulties and set out the context in which this research has been undertaken. The district nurse curriculum (Fanel of Assessors 1978) is currentiy used throughout the United kingdom as the basis for planning courses which lead to the certificate in district nurging the mandatory qualification for practice. 
The introduction of a new curriculum was a major innovation in district nurse education. In part it was the result of demands for change in district nursing and in part a result of changes within nurse education in general.

In 1978 the training of district nurses was based on a syl3abus that bore strong resemblance to that implemented twenty years before. These in-gervice courses were variable in quality: organised by dedicated; but sometimes untmained, tutors and were in need of major meview. It was obvious to many peopleg particularly the Panel of Amsestors. - the certificate awarding body for district nurge training that district nurses were not adequately prepared for the role that they were expected to undertake. Th some cases this was because they had received no training since initial registration and in others because the training they had received was not appropriate. Feseareh supported this poor atate of affairs (Skeet 1974 , Cartright et a 1973) and made suggestions for change, one of which was a new curriculum (kratz 1978). The changing pole and function of the district murge in responge to changes in mombidity and health denands eventually resulted in the setting up of a working party (Faned of Assessors 1976 ) to produce a new curriculum.

The changes in general numse education which occurped at this time involved district numsing in a political arena hitherto unknown to them. (DHSS 1979) It was important that 
a small specialised group such as district numing had statutory status within this new organigation of the United kingdom Central Councij and four national boards if it was to control its education. In order to achieve a joint committee within the new structure and ministerial approval for the new lengthemed mandatory district numse course, recommended by the working partys a national district nursing campaign was started. District nurges had never been so united or so militant. Their efforts were rewarded in geining a new curriculum, a mandatory qualification and the District Nursing Joint Committee to advise the central councit on matters concerning district nurse education. ine luding the new curriculum.

The curriculum therefore, represented quite a landmark in district numsing "Set within a political context of change it. was a symbol of status and achievement as well as an innovation in education. It marked a turning point in district nursing by offering a new type of preparation to meet a changing role.

One further upheaval for those concerned with the new curriculum was the recommendation that all coursess should be offered alongside health visitor and social. work courses in colleges of further and higher education. For many district nurge tutors this represented the greatest change of all, because the majority of the fifty five existing teaching 
centres offering district numse courses were based in health authority premises. The curriculum was fully implemented in September 1981 afer two pilot schemes and the opportunity for al1 district murse tutors to attend ane week updating Course.

The pamallels with changes in general numse education are clear and raise the same curriculum ifsues, namely the different epistemological appraaches that it seems nurging has to accommodaten The district nurse curpiculum (Fanel of Assessors 1978) later adopted by the four National Boards (English National Eoard 1983) (See Appendix 1) demonstrates these different aproaches:-..

- The move into educational establishments hes emphasised the application of knowledge drawn from the digciplines of the natural and social sciences and with it comes a liberal philosophy and a technical rationality model.

- The importance given to acquiring competencies to practice emphasises a behavioural objectives approach to the cumpiculum and with it a skills based model and to some extent, again a technical rationality model.

- The requirement that distófet nurses should be able to take responsibility for evaluating the standards of their own performance implies independent practitioners who are able to monitor their own practice Here it geems the approach is one of encouraging self direction and selv assessment and an adult learning approach to teaching methods. The problem - solving approach aligned to the nursing process implies an interactive humanistic stance in kepping with person centred fare.

While it would be inmppropriate to assume that courses do not change or that nurse educators in district nursing have not developed their curriculum to meet change it i.s fair to 
astume that all courses are influenced by the national boards' curriculum documents to the extent that they have to accommodate the three appraches autined above. The differences between courses will be the result of each educational institution incorporating the different approacheg of behavioural, humanistic and liberal. philosophies into one curriculum. One such example of this change comes rrom surrey University (Eattie 1989) where a further aim was added to those distilled from the national boards" curriculum following their digtrict murse pilot course and reads thus:-

To create a learning environment where students can benefit from the echlicational processes; by extending their knowledge in community nurging studies and related subjects and further their personal and professional. development. (P.27)

The district nurse curriculum has been analysed in relation to both the objectives model of curmiculum design beibson 1980) and the milis based model ( Spicer 1983), meither of which, in an ideal form, take into account the humanistic principles which underpin the individualised care that charactemises district numsing practice (Mackenzie 1989) or the development of autonomous practitioners who are able to monitor their own practice. Indeed spicer (1985) concluded that the uniqueness of district nursing knowledgle was inherent in the way in which district nurses applied their knowledge to care in the home it is knowledge that 
arises and is developed in practice and has to be monitored in the context of practicen District nurge course evaluation (Battle 1999) identified autonomous practice and close relationships with patients, including holistic and continuous care, as a highly valued aspect of distict nursing. It is therefore clear that athough the district murse curriculum is explicitly objectives and skills based: it also has to take account of the context in which district nursing is practised "that is" as an activity which is essentially humanistic and which requires the humanistic principles of personal development and gelf directed enquimy to ensure professional competence.

Any mvaluation of the district numse curriculum has to take account of the climate in which the cupriculum was launched, which to some extent was a time of uncertainty: when far reaching decisions had to be made without any indication of the implicatione this would have in the new structures "It appears that the working party from which the district nurse curriculum was developed used procedural methode (Feid 1978) of problem solving in relation to distmict nurse curriculum. These are methods of problem solving used by those who support plenning by objectives the problem is solved by applying a comtain technique and often used in matters of public concern or large scale importancen

However: it may be more appropriate to apply practical 
reasoning to the practicad tasts of developing the disterict nurse curriculun rather than procedural principles. According to Feid (1978) the problems for curriculum planners are those of "uncertain practical problems" which require practical reasoning to atempt a solution. For fieid (1978) uncertain problems aro:-

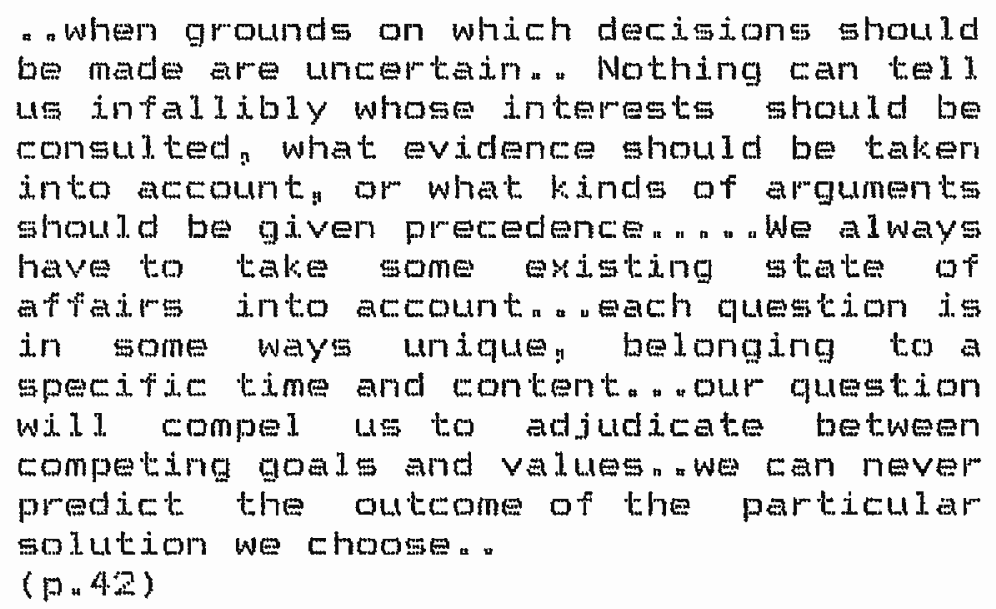

As pert of such remsoning we should not be afraid to consider the underlying values and beliefs or philosophies on which curriculum decisions are made. We should recognise that in district numsing the humanistic principles which promote growth and progressive professional development rather than the behaviourist principles that revime competency: and skiljs based learning should take precedence. The basis for this approach has been ladd by the proposals for specialist practitioners in project 2000. Nurses will be competent to work in both a hospital and a community etting as a registered practitioner. "Therefore nurseg entering district numsing will be well prepared to develop their expertise as a specialist practitioner 
but where increased eritical awareness and ability to recognise and develop good practice is an appropriate principle on which to build educational experiences. Nursing has recognised that the experiences gained in practice are fer from based on good educational principles. it is in the arena of leaming from experience that adult learning theory has become most epperent in the recent literature in nurge education.

A group of hospitaj research studies conducted between 1975 and 1981, have been very influential in bringing the problems of learning on the ward to the fore (Lathlean 1988). The studies exanined the ward as a setting for students: experience from two main permpectives the role of the ward sigter (Fembrey 1980, Ogier 1982, Funciman 1983), and the activities of teaching and learning (Orton 1991 , Marson 1982: Alexander 1983). The coordinated efforts of this group highighted the main themes to amige from their mesearch studieg (Lathlean 1988) as being related to the ward sister who is a "key to the ward learning climate" (ibid paz). The students" learning is affected by the varying teaching and management abilities of the ward sister to infulunce the learning "climate" and bring together theory and practice. These conclusions were not new but confirmed previous concerns about the ward as a setting far teaching and lemining (Dodd 1975,Fevans 1964) and in turn resulted in further worl: to examine the continuing education of qualified numses (Rogers 1987) and ward 
sisters (Lathlean et al 1986). The quantitative measurement of inuliple eriteria for assessing the ward as suitable for Iearners (Feid 1985, Jacka and Lewin 1987) demonstrates another development in the increased awareness of the importance of the practice setting as a Iearning resource for nurges.

These studies provide strong evidence for some of the deficiencies in the education system of nurseg in hospital settings: particularly the influence of service demands on the students. learning and the lack of meaningful integration between school of nursing based teaching ard ward based experience. Both have Ied to changes (UkCC 1986) which will be implemented by the froject 2000 programmes in the form of supernumery status of students and training for qualified ward staft in teaching and assessing gtudents. They also raise questions about the nurse educators" umderstanding of adult learning: athough this is given little explicit attention by researchers who, on the whole, have concentrated more on sociological and organigational theories than on learning theories as theoretical frameworks for their research. Howevem there has been some recognition that learning theory is important in relation to the "theory, practice gap" (Alexander 1985) and the attributes of good teathers (Marson 1982).

While the hospital based studies have alerted nurse 
educators to difficulties of dearning from the practice setting they have done Iittle to examine how students learn in melation to adult learning theory" It would seem important at thie stage that numse education does not accept uncmitically the adult dearning theorists without close evaluation of their contribution to the curriculum. Already adult learning theory is intuencing cumpiculum methods. For instance the use of mentore or preceptors for Learners in the chinical, areas is causing a degree of confusion (Morje 1990) mainly because the aime underlying this innovation have not been made (elear (Farry 1990). A further introduction frequently attributed to the work of Malcolm knowles is that of the learning contract Here agin the objectives approach of identifying competencies which leaming contracts can emphasise are at odds with the facilitative style of teaching advocaled for thage involved wi.th learners in the prectice setting (Marson 1982).

It is not that nursing should dimegard an ectectic approach to curriculum planning but that the aims of each approach should be debated in order that al. involved in solving the practical problems of the curriculum can consider the appropriate balance of each approach that professional courses require. It ig clear from the hospital researsh that one of the most valuable but least effective resources for learners is the practice setting of the ward. It is here where curriculum planning becomes most challenging and where some of the issues for nurge education have been gtarliy 
identified.

If numse educators are to benefit from examining some of these issues, then the issues need to be examined within an eclucational context. Adult Jearning theory has been utilised in a fairly ad hoc way by nurse teachers and it therefore seems appropriate that it should provide a framework for further studies in the practice setting of the community which will, in future provide the starting point for nurge learners and will be the leaming context for the advanced practitioner in district nursing (UkCC 1990). It is also appropmiate that the learning experiences of students in the different setting and circumstances of the community are exanined "

This research! therefore: will invegtigate the learning experidences of student dictrict nurses during their practice placements in the community"

Guidalines were issued (Famel of Assessors 1982, Engligh National Eoard 1987 ) for practical placements for district murse students which concentrate on the organisational aspects of the placement such as siting within a general practice and the provision of private areas of study. The "Jearning environment" is described in terns of the role of the prectical work beacher, who has responsibility for the management of the placement: and of iclentifiying the type of 
"instruction" and "opportunities for observation" "There are no criteria related to educational principles. These appear to be left to the practical work teacher who "wi.l. assume responsibijity for planning the student's practical work programme: allocating a wontrolled caseloads and teaching the skills of district nurging within a primary health care toam" (ENB 1987 p.2). It is in the practical work teacherg' course (ENB 1987) that reference is made to principles of education for ingtance "the nature and aime of objectives" and "theories of adult learning". This course of six weets extending over nine months is the qualifying course for practical worls teachers and aims to "prepare the experienced district numge to acquire and apply the knowledge: gkils and attitudes necessary to teach and Evaluate the practice of district nursing" (ENE 1987 P.26) However research into the preparation of practical work teachers (Maggs and Furr 1989) has highlighted inadequacies in practical work teacher coumses to prepare them for teaching in the practice setting and raises questions about their continuing education as teachers. It is interesting to note that practical work teachers together with other teachers in the community practice setting wild be called community practice teachers emphasising the commonalities of the teaching role and so encoumging joint courses with others in health visiting mental healthy mental handicap and offupational health (ENB 1990).

The differences between district nurse students and the 
students in the ward studies are most obviously thet district nurse students are already qualified nurses. They have supernumery status and are therefore not part of the worlejoad and they have a one to one relationship with the practical work teacher, who is not expected to have responsibility for more than one student at a given time. It is from these areas that the man dificulices for ward learners arose and indeed that provided the impetus for some of the major changeg in Froject 2000 (UkCC 1986).

However the differences in context between communty and hospital setting remain and will have to be addreseded by all students who enter this environment for purposes of learning how to practise in that setting. Here nurses practise in a patient controlled envimonment, where immediate decimions have to be made without recourse to consultation with either nursing of medical colleagues. Apart from these basic differences for any murse working in the communty there are further differences for those who are aspiring to be district numes (Mackenzie 1989) ory in the future: advanced practitioners in district nursing (UkCC 1990). These difterences will be further enhanced by policy changes in community care (Foss 1990) and by what Eeardshaw and Fobinson (1990) Eald the challenges in community of the "new nursing" "

Although nume educators are aware of difficulties in the 
practice setting it is clear that the community contexts are different in a number of ways outilined above "However" the rocui of this research is not on policy change and organigational influences but on learning and adult 1.earrers and on the community setting as an environment and resource for learning, where as yet ititue is known. The issues to be addressed are those that arige from the processes of Iearning and from the students experiences of learning in the complex and uncertain environment of the community.

These are issues that do not Jend themselves easijy to large scale quantitative analyis. The adoption of a more appropriate research method was therefore crucial to this study, as the next chapter wi.l. describe" 
CHAFTEF THFEE

FESEAFCH METHOD

Introduction

jt is a generally held view that the reseerch method should be appropriate to the purposes of the research (Munhal. and Diler 1986, Fayne te al 1.981) " In discussing methodological implicationg for educational qualitative research Fope and Denjobo (1986) advocate :-

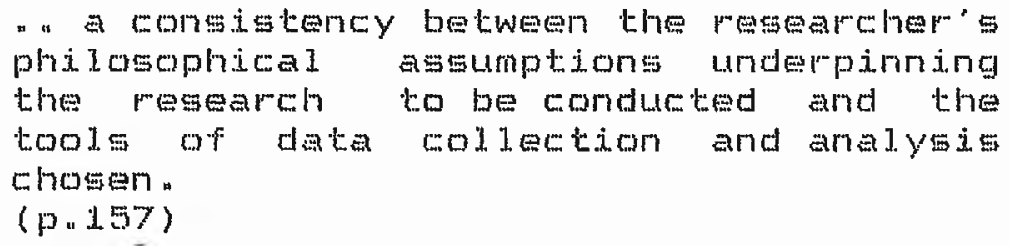

This educational study geeks to gain an understanding of the Iearning experiences of district nurse students and to examine dearning in the practice setting from the students" perspective " The learning environment provided by the practice setting of the communty is complex and uncertain: as described in the previous chapter" it involves the Student in relating not only to the practical. work teacher but also to other members of the primary health tare team and to the patientu. These relationshipg will change as the student regularly visits the placements throughout the first gix monthes of the courson 
As well as learning to be a distritet nurse the student has to find an acceptable role within the group in which the placement in located " pportunites for learning are many and varied and may be formally offered and organised by members of the primary health care team or informally taken by the student in the many different and unpmedictable cireumstances in which district nurses work. While there may be common features across placements there are also specific differences. The reality then of the distriet nurse's working envimonment provides a rich and changing experience for djstrict numse students and is largety unekmined as a Jearring envi.ronment.

The Ethrographic Method.

In the absence of any parallel work in nurse education the work of ethnographers in the sociology of education encapsulated by the approach of Hanmersley and Atkinson (1983) provides a useful framework for the ethnographic method Lued in this pesearmh"

The purposes of this research are made explicit in the previous thapter and represent a particular epistenological stance conteined in the set of astumptiong outlined below. The underlying assumptions of the ethnographic method described by Hitton ( 1987 ) have provided a starting point from which to consider the appropriateness of such a 
qual $\mathbf{i}$ tative approach for this research :

- a person's behaviour is inextricably linked with the meaning thet the situation has for her"

- a person's unclerstanding and hemce behaviour, changes as she interacts with others

- within any situation there will normally be different perspectives.

- a person's behaviour and beiliefs can only be fully understood in the light of broader aspects of orgarisation or intures.

- the group or culture must be studied "as it. is". $(p P, q-1 ;)$

It is with this set of assumptions that I have come to examine the learning experiences of district murse students in the practice setting of the community. These assumptions can be regarded as a set of orientations which guide ethnographic researchers in their research strategies and design (Atkinson 1979). They underpin methodological principles - the distinctive methodological ideas that feed into the ethnographic method. The ethographer then is concerned with meaning and understanding: recognising that individuals interpret situations and act in accomdance with their interpretation and understanding of each situation. As situations change so do the interpretation of the individuals involved: negotiating roles and changing perspectives are part of a process of interaction and can only be fully understood by investigation in the natural setting or social context. A holistic approach provides a 
view of people within their social group or environment. There will. be different perspectives in each situation "The ethnographer wi.l try to comprehend thege perapectives and perhaps hypothesise about differences and similarities without attempting to determine it there is a correct one w

Ethnography is. according to Hammersley (1984) "--

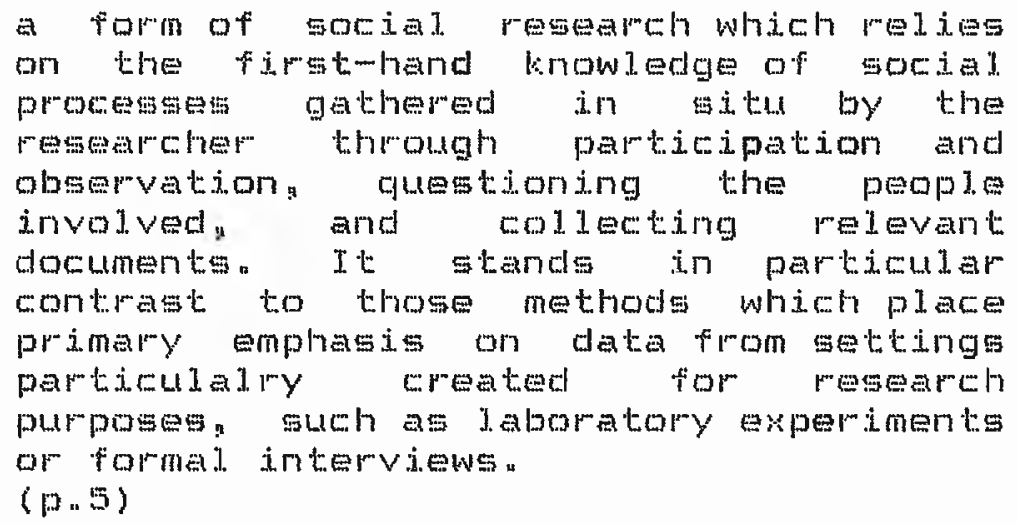

A particular setting is chosen for the in-depth investigation which may be a Eingle case such as a hospital or school or a small number of cases such as wards or claserooms or as in this study: the practice getting of the community.

The move from the dominant approach in educational mesearch: popularly known as "political arithmetic" - the quantitative analysis of oficial statistics and survey datan to looking ingide the "black box" of the school (Hargreaves 1967: Lacey 1970, Ba1. 1981) heralds a move in general education that has provided userul materials for methodologital analysis in ethography. 
Analysis of Ethnography - Fositivism and Naturalimm

The polarisation of social science theory and research and the consequent arguments defending extreme positivism and naturalism are counter-productive to edther quantitative or qualitative mesearch. (Hammersiey and Atkinson 1.98: Bryman 1988). However this does not mean that ethography should become complacemt in defending or making clear its value in social science research (Fayne et al 1981).

Naturalism and positivism are methodological frameworks through which ethnography can be examined. Naturaliam is seen as embodying the underpinning methodology for ethrography athough Hammeraley and Atkinson (1985) point out :-

"that once one recognises the reflexive
character of social. remearch that it is
part of the world it studies many of the
issues thrown up by the digpute over
positivism become easier to resolve, and
the specific contribution to be made by
ethography emerges more clearly.
(p.3)

Central to positivisin is the concept of goientific method modelled on the natural sciences which ig concermed with the testing of theories and with accumulating a body of scientific: knowleclge "-

The most important feature of scientific theories is that they are open to and subjected to. test" they can be confirmed or at least faleified. This prosess of testing involves comparing what the theory may should occur in short comparing it with "the facts". ". "In 
particular every attempt is made to eliminate the effects of the observer by developing an explicit. standardised set of experimenta d. or interview procedures. (ibid p. 5 )

Feplication and assessment of reliability by others is thus made possible. Positiviste have Iittle time for the nonstandardised procedures of participant observation as they gee no way in which responses can be interpreted reliably if there are no procedures to ensure that we know what subjects are responding to as with for instance the specifications in experiments or interview schedules.

In contrast to this view maturalism would say that standardiged procedures in no way ensure the comparability of data. Interpretations of procedures are impossible to eniminaten . Individuals will respond in reaction to their own meaning or understanding and therefore the social. world should be studied in its natural state " undistumbed by the researcher "-

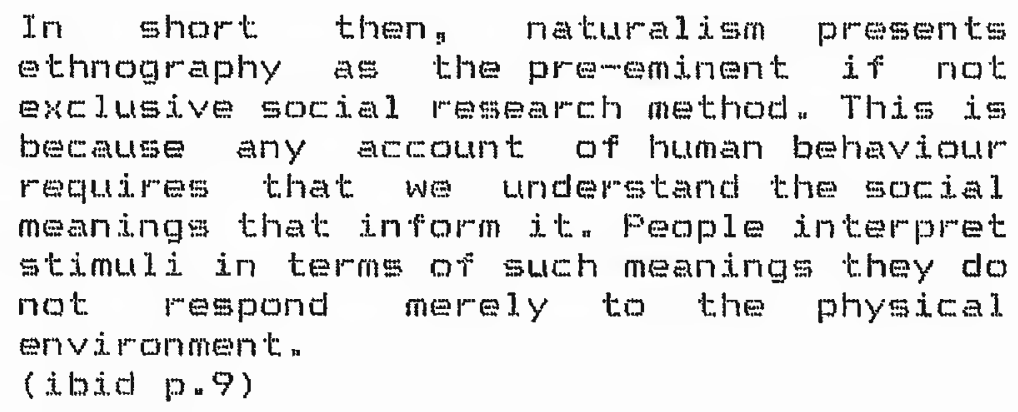

Hammersiey and Atkinson (1983) go on to state that this can only be done by learning the culture of those under study: a cultural description which does not impose the researcher's 
own "arbitrary and simpistic categories on a complex reality" (p.9).

The dichotomy between quantitative and qualitative research arises mainly out of the debate about epistemological issues of what constitutes gcientifice knowledge and the corresponding appropriate methods "Fositivism as ideally portrayed encompasses the philosophy of the natural sciences: Which in turn ig taken to be the benchmark for all scientifit research including that of the social sciences. This position has meant that positivisan has become a perjorative term and is often regarded as the underpinning philosophy for all quantitative research. The iajor concerns of research in the natural sciences such as numerical measurement, causality: generalisation and replication (Brymary 1998) do not easily fit the assumptions identified as appropmate for this regearch. However" in the reality of carrying out research: it is less easy to be so eategorical about the distinctiveness of the techniques and procedures which make up the method and research design " Compromises have to be made in the light of time restrictions and the limited capacity of a single mesearcher.

The problem of generalisability and of inferring from artificial settings to everyday life is one not only for experiments and surveys but also for ethnography (Hammersiey and Attinson 1983). The intluence of the researcher on the 
getting and the implicatioms for ecological validity holds not only within ethrogmaphic settings but across temporal cycles within gettings (Eal1 2983 ) " On this point naturalism makes a misleading ditinction between artificial. and natural settings and becomes confused in its own whetoric of criticiang positivist assumptions. To assume that theme is a Elear digtinction enforces the positivist videw that one can observe settings from outgide when in fact the whole force of the naturalists argunent is that people, however studiecl are involved in social interaction and that even experinentg are social occasions.

Reflexivity

The argument then for both naturalism and positivism $i$ s that the effects of the mesearcher must as far as possible be eliminated from the data as emphasised by Hammersiey and Atringon (1983) :-

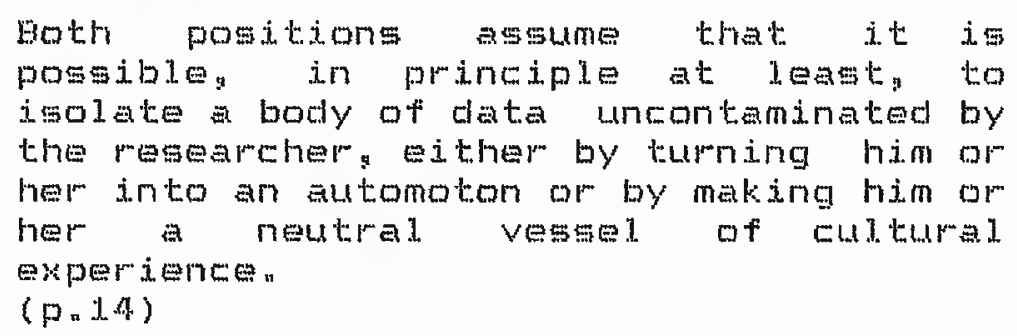

Reflexivity ig the answer to thig problem $\rightarrow$ the recognition that we are part of the world we study :

Neither positivism nor naturalism provides an adequate framework for gocial restarch. Eoth reglect its fundamental. reflexivity, the fact that we are part of the gocial world we study. (P.25) 
If one accepts the arguments for peflexivity and the implicatioms for research practice" the role of the researcher becomes as an active participant in the regearch process. The influence of the researcher on the setting is made clear - data i. used to make inferences and identify hypothesis which might be "tested out" using elifferent research strategies and theories are made explicit in order to test their limits and assess alternatives from thig perspective hypothesis testing "plays a major role in the process that naturalism places at the very heart of gocial research " undergtanding the action of others" Hanmersiey and Atkinson (1983) :

In observing peoples behaviour we
derive hypothesis from our cultumal
knowledge to descibe and explain their
actions and we test these out agdinst
further information.
(p.ib)

Fietlexivity challenges the epistemological assumptione at extreme haturalism, implying that ethnography should incorporate other models alongside naturalism such as grounded theory (GIaser and 5trauss 1969,1979), analytic induction (Denzin 1978) and the work of Schatanan and Strauge $(1973)$

Ethnography : theory development and theory testing

The extent to which ethnographic research concerns itself With theory development or theory testing will depend on the 
analysis of data (Hammersley 1979). Although analysis begins with a description of the perspectives and meanings of the actions of those involved it can go on to develop analytical concepts and to move from being a selective and inferential concrete account to abstract categorisation which explein actions, intentions and motivations and relate to other categories leading to theory generation. If a form of the comparative method, in which a systematic search for falsifying evidence and modification of theory is lised, the theory may then be tested.

This is a Jong road to travel in ethography and is not possible in small scale research or may not indeed be the desimed intention. There are many gtages at which the research can userulity be completed dependent on the purposea of the research. For example the purpose may be to describe the assessment processes in the bureaumatic organisation of a gchool of nursing or at the next stage to make comparisons between the aims of assessinent procedures of a courae as perceived by the students and as perceived by the teachers "At a further stage models of different amsessment perspectives may be compiled and compared or developed into a hiemachical typology"

Q1aser and 9 truss (1968) emphasise the importance of theory development and the use of systrmatic comparison in thejr model of grounded theory which by definition "is based an 
systematic generating of theory from data that in itself $i s$ sytematically obtained from gocial research" "(Glaser 1578 p.2). In the early stages of fieldwork when ideas are emerging and analysis becomes more systematic the process of theoretical. gampling is used recurrentiy to digcover and develop categories. It is essentialiy a process of multiple comparison of different groups or settings - initielly minimising dirferences between comparison groups to draw out basic properties and subsequently maximising differences to discover the more universed uniformities. In minimising differences: the researcher is collecting information about restricted phenomena. Maximising differences between comparison groups involves wide ranging data about particular themes or concepts. Both activities will, if used as the blager and strauss (1968) model suggests : involve the researcher in making conscious decisions about the choice of fieldwork settings in order to seek out new cases with the intention of developing and modifying the theory as the research progresses. Theoretical sampling is a form of comparative method that provides control over the comparison groups for the purposes of theory generation and contrasts shapply with the sampling and control of other research approaches of a quantitative nature, well demonstrated by Atkinson (1979) in hit illutration of statistical and theoretical. Sampijing :-

Statigtical Sampling

Ferformed or the basis of categories which are taken as given.
Theoretical Sampling

The purpose is to discover and develop categories. 
Usualiy a one-off exemcise to identify the targets for the date callection exercisen.

Dnce the sample has been drawn every tase in that sample mut be investigated and analysed.

$(1.54)$
A recurrent process in which at a number of pointo in the rieldwork samples are chosen which seem most Iikely to clevelop the theory.

Cases are analysed only until new categories and properties are no longer appearing - to the point of what Giaser strauss saturation.

Here we have an example of the differences in method that arise from different assumptions of epistemology a it is also an example of the flexibility of ethnography where the meseamch design is not predetemined but in which strategies and direction can be changed quickly to pursue theory development in an effective manner and subsequenty where theoretical sampling can be used as a basis for theory testing by the process of analytic dinduction (Denzin 1978).

While the advantage of ethnography is most obvious in theory development it can also be utijised to test out theory Woods (1986). In this respect theoretical Eampling is not regarded as a rigorous or mystematic enough process for the purpose of theory testing and therefore for this later stage of ethnographic analysia the rom of comparative method called malytic induction is sometimes used. At this stage the ethnographer is involved in a "systematic search for faleifying evidence and modification of theory until no further disconfirming can be found" (Hammersley 1979 pu.29). 
The work of Lindemith (cited Atkinson 1979 p.s6) on opiate addiction is often quoted heme to demonstrate the use of analytie induction and the formulation of generalisations on the basis of negative cases Lindsmith reformulated his hypothesis and was able to clain that the evidence he found about opiate addiction supported his theory in all cases. A more recent example of the research application of the logic of analytic induction can be found in the study by Dingwall and Murray"(198\%) They modify and extend Jeffrey's (1979) model of doctor"s categorisation of "good" and "bad" patients in accident departments through their own research with children.

Analytic induction may also give researchems mome confidence to move from substantive theories - those concerned with concrete areas such as mentally handicapped children or ethnic groups - to formal theories - those concerned with a higher level. of abstraction and generality and the ability to explain processes in different subatantive areas. For instances stigma would be a formal theory in relation to the two examples of substantive theory mentioned above. The distinction between these two lypes of theory are detailed by Glaser and Straus (1969) and wan be usefully aligned to "topical" and "generic" problems (Lofland and Lofland 1971). Again moving along a continutum of levele of abstraction from topical to generic. 
Ethography provides flexibility of method al lowing changes in direction as the research proceeds "It may be used to develop a well as tegt theory (Hargreaves 1967, Lacey 1970, Ball 1981). If we accept that ethography does not just encompass the extrene views of naturalism or is merely an alternative to the positivist paradigm.

Conciusion

Wnderstanding, process, naturalism, holism and multiple perspectives (Atkinson 1979) are terms umed to summarise contemporary ethography described aboven although its rootg in early anthropologited research are evidenced in the Iiterature by Malnowsís in his much quoted phrasen cited in Fayne $(1981)$ :-

The pertinent goal of which an
ethographer should never loose sight is
briefiy to grasp the native's point of
view hig rejation to life to realige his
vision of his world.
(p.gy)

The extent to which his writings reflected his experience is debatable (Fayme 1981) but the chamaterigtics of naturalism dimect the ethnogmaphir.: method" since the advancement of ethnography under the influence of Malinowski in the 19205 it has become

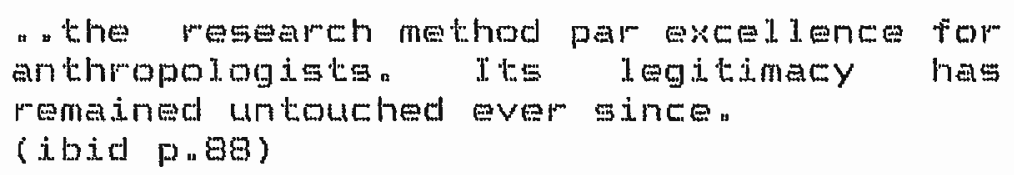


This has not been the case in sociology and in education where ethonogaphy has had a precarious position in establishing its place as an acceptable mesearch methodology - athough ethnomethodology has gained a foothold.

Sociologists have adopted ethnography in varying ways dependent on their perspective or school of thought phenomondogy: ethnomethodology or symbolic interactionism a1. having common characterigtics of relevance to educational researchy as descmibed by Cohen and Manion (1999) :-

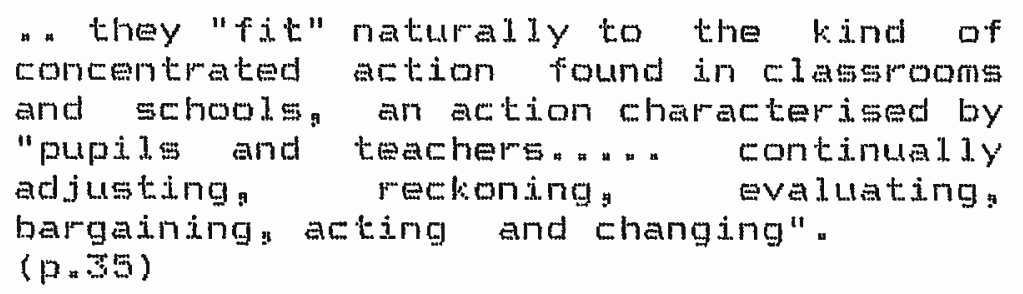

The "fit" can also be applied to the Jearning environiment in the community where students are ecting intentionally as a result of their understanding of what is expected of them as learners and as inembers of a group: negotiating: adjusting and changing as they progless through the placement. This interpretive approach is intent on studying situations by understanding the actions and the meanings of actions rather than explaining behaviour by seeking causes and has been used in nursing reserach to study psychiatry (Towed1 1975), health visitor education (Dingwell 1977) and 1.iaison between hospital and community (Melia 1983 ). 
It is not the incention here to examine sociological pergpectives but to treat ethnography as a research method within the qualitative approach and to consider sociological perspectives only as they impinge on the ethrographic method.

The philosphical assumptions of iny research are therefore soundly based upon those epistomological assumptions already stated (Hidton 1987) and upon the acknowledgement of the reflexive nature of ethnography (Hammersley and Atkinson 1983). This stance has implications for the analysis. interpretation and presentation of data as described by Fope and Denicdo (1986) :-

First of all one must acknowledge to oneself that the situational context and one's own personal intuitive theories colour interpretation " " "Secondly: and almost contradictory: one must provide prospective readers with an open, frank and detailed discussion of the procedures used in analysis and interpretation of data . ...... Those who present their deductions with no acknowledgement of their provenance are doing a diservite. not only to the reader: but also to the particj.pants. (p.155)

It im with these cautionary notes in mind that I have detailed the research design and andysig findings in the subsequent chapters. The issues that are raised in using ethnography as a method for this research are those of sampling, actess field relations data collection and analysis and are examined in the next chapter. 
CHAFTER FOUF

RESEAFCH DESIGN

Introduction

It was pointed out in the previous chapter that the design of ethographic: research cannot be totally pre-detemined. However this does not mean that there is no premplanning: nom that ethnographic presearch is a haphazard activity (Hammersigy and Atkinson 19a3). Whilst there is flexibility in the study design allowing change in direction as the research problem is refined and re-defined and theory i.s developed there ig a 1 go need to identify and select the area for study and the broad setting in which it will tale placeg and to treat data collection and analyais in a systematic way. Moreover my own experience in carrying out this ethnogmaphic research has shown that compromises in small scale studies lead to a demand for prem planning and less scope for changes in direction, although the refirement of the research questions and theory development still remain an integral part of the process.

This chapter gives a description of the research design for my study and provides, in part, a reflewive account of the research methods in the ight of selected literature from ethmographic research. To complement this account a cliagram of my study design is shown in Fiqure 3 overleaf. 


\section{STUDY DESIGN - PATIERN OF DATA COLLECTION AND ANALYSIS}

Inner City Placoment - Year 1

Interviews with FWT Interviews with Students Observations College

$\downarrow$

2nd placement

$\longleftrightarrow$ 2nd placement

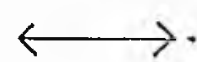

2nd placement

$\downarrow$<smiles>C=CC</smiles>

Ongoing Analysis at time of interview

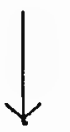

3rd placement

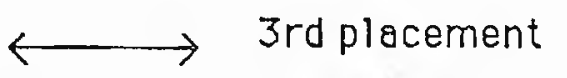
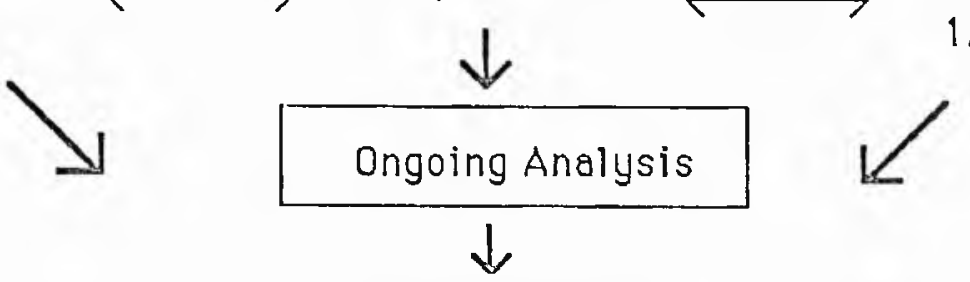

3rd placement

$1 / 2$ day with student

End of course

Group interview in College

Urban and Rural Placements - Year 2

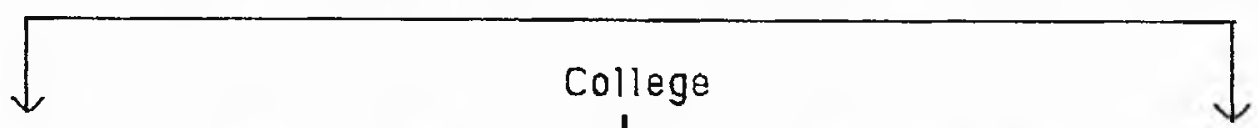

$\downarrow$

2nd placement

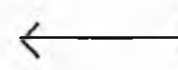

2nd placement

$\downarrow$

3rd placement $\downarrow$

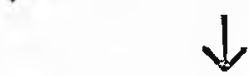

Ongoing Analysis

3rd placement

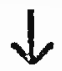

Ongoing Anelysis

$\downarrow$

Final categories 2nd placement at time of interview<smiles>C=CC</smiles>

3rḍ placement $1 / 2$ day with student

Figure 3 
The starting point for this research was a set of questions about the learning of etudent district nurses in the practice setting of the community" The questions raised originated from my experiences in teaching, and particularly in teaching courses in district numsing. These questions have been considered in the light of significant theoreticad ideas from the literature of adult learning and district nurse education

In Malinowski*g terms (1922) these questions: or "foreshadowed problems" are the starting point for fieldwork rather than a set of "preconceived icleas" to be proved :-

Freconceived ideas are pernicious to any seientific work. but foreshadowed problems are the main endowment of a scientific thinker, and these problems are first revealed to the observer by his theoretical studieg

$(P P, B-q)$

In the first instance my research was concerned with the issues and problens of what constitutes a "good" or "bad" learning environment s stimulated by research gtudies in the haspital. settinga (Fretwe11 1982, Ogier 1982, Drton 1981) and in district nursing (Eatile et al d.985) and by the reported experiences of students in the community. 
In some of these reported experiences the geographical placement and variation in experience seemed to be melevant: in other the teaching of the practical work teacher and in others the difficulties or attitudes of other staff. Evaluatione of district nurge courses with which I have been associated over the last five years evidenced problems, but no pattern emerged to give clear guidance in assessment of placenents as suitable learning envimonments .

Indeed the education institution has had little influence on the placing of gtudenta which in England is largely undertaken by the seconding health district. Ferusal to use a particular practical work teacher is usualiy the ondy and rather negative option *

The main influence available to nurse teachers on the practice setting has been through the qualifying and post quelifying courses provided for practical work teachers. These courses draw heavily on adult learning theory and emphasise facilitation and support as a major teaching and learning strategy in the practice getsing. Clearly the practical work teacher has a major impact on learning in the practice setting, but there are other factors to be considered in the learning process experienced by the student. These ractors started to become evident in the pijot study. 
Early fieldworl: - pilot gtudy

The pilot study drew attention to the difficulties and complexities of trying to identify the characteristics of "good" and "bad" learning envirommente in the community. Asking outright questions about what helped students to learn, quickly exhausted topics of conversation simply becmuse students were not able to describe whit helps them to learn. It is through the students deswribing what they have done that instances of learning and their possible gtarting points or determents are identified. As a result the problems of learning in the community changed their focus. Therefore exploring how students learn became the initial. focus of the questioning and observations rather than looking directly for characteristics or indicators of "good" learning environments.

Frior to the pilot atudy I discusaed the research independently with two practical work teacher support groups that had been set up in local health districten I asted them for examples of topics or guestions they would consider appropriate in exploring the experience of gtudents in placement. Some of the topics were used in the interviews in the pilot study and in the initial interview in the main study to explore ideas such as relationshipg with practical. work teachers: time available for study and variety in cameloads. As the researeh progressed these topics came up as unsolicited information, which to some extent was a 
validation of the data. In this respect the early fieldwom Was an integral part of the study. It becane apparent during the pilot study that students spent less time than I anticipated with the practical work teacher and that the inajor part of their time was spent in the patients homes. It was therefore important that observations of students in this latter context should be continued into the main study.

The pattern of interviews and observations carried out with these wudents and their practical work teachers, from an institution which provided both inner city and urban and rumal placementsis followed the same pattorn as that adopted in the main study (see Figure 3 on page 72) "The sampling procedure was also continued into the main study and both are detailed below.

Sampling - selection of settings and cases.

The starting point then was the recognition of the issues relating to not onjy where the student was placed but algo what happened in that placement. Both of these aspects were taken into account in selecting settings and sample cases in the main study.

It is during the first part of the courge that gtudents are placed with the practical work teacher for what ig termed taught practicen Tn the second part of the course the 
students then move to another location for supervised practices as i.lugtrated below:-

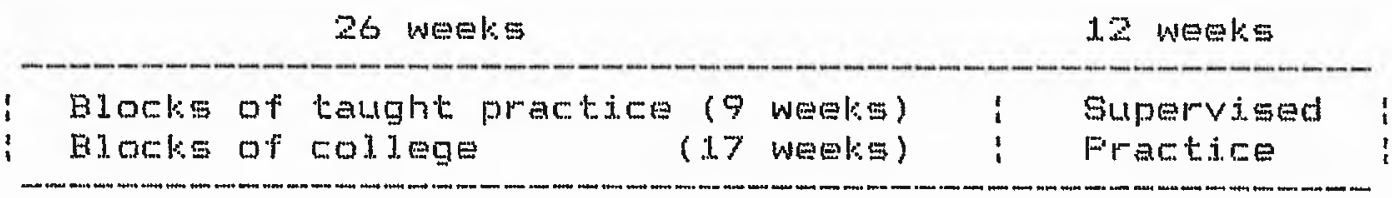

Figure 4. Fractice elementus of district nurse course.

It was considered important to investigate a number of different geographical settings. Thus the jocation of the piacement was the indtal determining factor for the seting and subseguently for the sample cases within the settings. Two education ingtitutions were chasen for thejr ability to provide on the one hand placement settings from inner eity Iocmions and on the other placement settings from urban and rural locationg. In total pourteen heasth authorities were involved eight in the first year providing inner city locations and six in the second year providing urban and rumal locations.

Feactivity of the researcher on the setting and on the intervieweeg was a further aspect in selecting the placement setting. Placementg were eliminated where I knew the practical work teacher from a previous tutormstudent relationship in order to minimige this reativity af course this $i$ only one aspect of the more general effect of context and the recognition that all data is context related and should be interpmeted as such. It is not an 
acknowledgement that data can be free from potential bias or indeed that it is desirable to make it so but that this unnecessary threat to ecological validity was reduced in order to minimise reactivity - an efrect that requires monitoring in ethnographic research as much as in any other (Hammergley 1983).

It is important, in this context, to note the distinction between settings and cases "The setting is the placement in which the students undertake their pratical experience durimg the taught practice part of the course and covers the geographical area in which the practical work teacher Lsually worbs and is based and from where the raseload is drawn. This may be a GF surgeryn a health district elinic or a health centre. The cases for study are the individual students chosen who are plated in the setting - or more precisely the experiences of individual students which pertain to learning. This uistinction between setting and case $i s$ important and $\dot{i}$ often used in a misleading way " As Hammersiey and Atrinson (1983) point out they are not "isomorphic" n-

A setting is a named context in which phenomena occur that might be studied from any number of angles: a case is those phenomena seen from one partjcular theoretical angle. Some features of the setting will be given no attention at all. and even thoge phenomena that are the major focus wiIl be looked at in a way that by no means exhausts their rharacteristics. Moreover, a setting may contain several casesa " "Conversely a case may not be contained within the 
boundaries of a setting, it may be necessary to go outside of the setting to collect information on important aspects of it. $(p, 43)$

Further congideration in sampling cases was concerned with place: time and people. This aspert of sampling within cases is again an important consideration in gaining information and is again a selective process for the purpose of discovering and developing categories (Eurgess 1982)

Sampling across place

Sampling in relation to place might sem straightorwara in that the study is investigating the gtudent"s Jearning experience in placement. However the placement setting has a number of contexts , such as the cilinic, health centrea or surgery and within these there may be a nurses' meting room or a more public reception or general staff meting room. Fatient contexts such as private houses or residential. accommodation are further aspects of the placement where Iearning takes pIacen

Variation in context is as important in sampling as is time and people. One might expect that different opportunities for learning are available in these different contexts and thet the student utiliges the contexts in a different way. 
Therefore it may not be possible to assume that ali aspects of the placement will mesult in the same opportunites for learning

It is also a question of ecological validity which in ethnographie research ig ugualiy high. However there are always threats to validity which should be recognised. The fact that ethographers work in the "natural getting" does not mean that people will act consistentily in the different contexts of the setting. Generaligation even within settings may not be possibles as Mammersiey (1985) points out:-

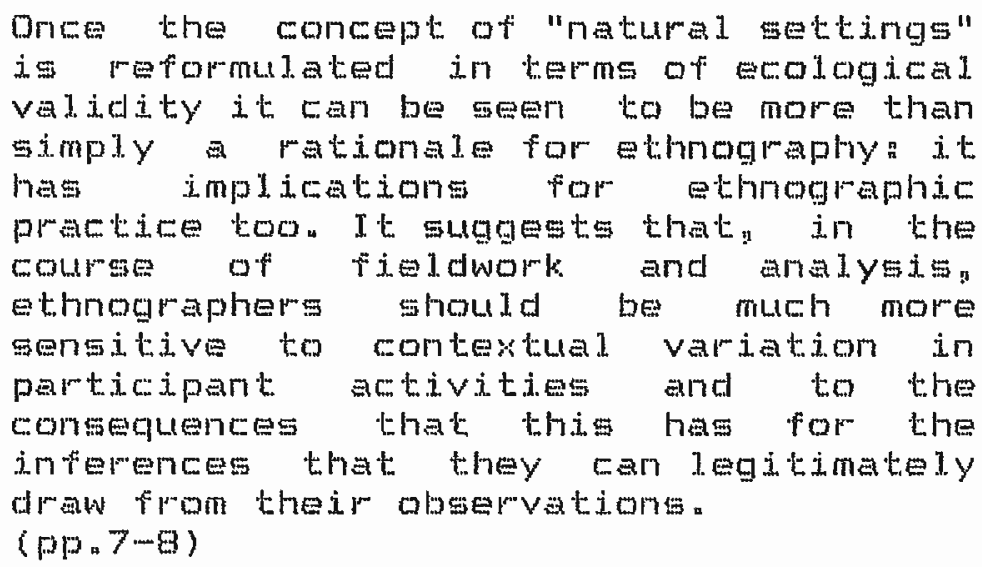

The concern with placement settings meant that the educational institution was largely ignored. Although visits were made to the institution for access and in order to interview students at the end of their fime placements it was not the intention to investigate the setting of the institution in relation to the learning experiences of the student. However" the institutional influences are apparent 
in the piacements through the experiences of the students and in this respect are part of the research.

Visits were made to the placements to interview gtudents as they progressed through the course. During these visits observations were made and recorded in field notes and tape recomdings were made of all the interviews. Although the visits were pre-arranged and were determined by the practical. work teacher I was able to arrange varying times of day when it was possible to see diffement aspectes of the routine and to mest other people such as nurse managers. doctors, and other nurses from the primary health care tean. Various formal and informal meetings were observed on this fairly ad hoc basis and the student was seen interacting with people in different contexts. As the student progressed through the course and the categorieg from the analysis began to emerge I was able; to some extent, to observe wituations which helped me to develop and analyse the categories further" This often involved me erriving at the Iocation early or taking any opportunity ortered to stay on. However it was not always so straight forward and on more than one occasion plans were suddenly changed, either by the student or by the practical work teacher. On one occasion I arrived too late. was refused an interview and had to repeat the eighty mile journey to return on another day" 
Sampling across people

Sampling people may seen to be obvious in this research and indeed it was clear that the "key informanto" would be the students. This term may be regarded as referring to those people who are able to give an inside account and to contribute to a better understanding of the participants. point of view (Lofland and Lofland 1971) "Informants" are distinguished by their ability to give information in mesponse to questions that arise from their own culture: whereas "subjecti" and "respondents" are distinguished by their response to questions that arise from the researcher' culture i.e. responding to questionnaires couched in terms of social. scientists. As Spradey (1979) notes :-

Ethnographic researchy on the other hand, depends more rully on the language of the informant. The questiong arige out of the informants culture.

(p. 31)

The sixteen students who were selected "ight from each education institution. were selected with the aim of gaining as diverse a spread of plecement settings as possible in terms firstiy of geography ine heath distriets and secondly of location i.e health centres. cilnics and surgeries. In the event: of these aims being fulfilled the length of community experience of students was taken into account and the resulting Emple contained a mix of "direct" and "non direct" entry students. Direct entry gtudents were 
regarded as those with less than one month's community experience prior to the course, non-direct as those with more. (Student biographieg are detailed in Appendix 2 )

As Lafl and warns it is not wise to depend on the information of one type of informant. The practical woms teacher who worked with the student was also a main source of inforination but provided a different viewpoint. However this research is concerned with the students experiences and therefore it is those experiences that are the starting point for data collection and for analysisa taking inko account other sourceg of data that help to gain further undertanding of the learning environment and the students' experiences.

Sampling over time

Timing for the students" placements is governed by the academic programme of the education institution, nomalisy two or three week periods in the placement interspersed with college blocks. The activitios that students are engaged in and their expectations are rejated to the timing of the placementsa For ingtance the first placement is taken up with "getting to know" the area and the people and is by way of an introductory experience" whereas the subsequent placements are used to develop the experience and increase expertise. 
Timing acrose the placement day is governed by the normal activities of the practical work teachers working day and can vary across placements. However there are routines that prevaid. armos all pidcements which mean that the majority of visites are made in the morning and the afternoong are usually free for extra visits or meetings "This might be regarded as a cycile of routine and deternines when the student meste with other members of the team or with the practical work teacher: or when people ame available for interview. The timing of these events has therefore some predictability and has enabled me to assess when I might boserve sone of the routines of the placement. However I was M.so invited to attend some exceptional events such as a practice meeting involving members of the primary health care teann.

Sampling within cases on the basis of timing should take account of what Ball (1985) callg temporal cycies. In relation to pesearch in general education a

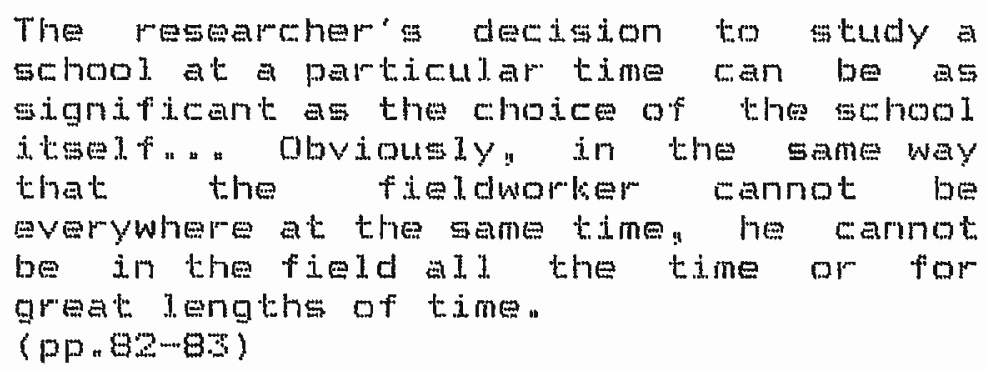

Sampling across time must therefore inevitably be a compromige" 
In this mesearch the decision to visit students during theim second and third placements and not durjing the first was based on the assumption that development would take place as the student proglessed through the course and on the belief that the first placement: though important from a researeh point of view: was much more important as the sensitive introductory period of negotiation between student and practical. work teacher" Moreover it wa felt that issues arising from the fipst placements could just as appropmitely be discussed with individual students duming the init. ial interviews in the education ingtitutions.

The reasons for reaching the above compromise as regards visiting gtudents in placement were explained fully to health authority representatives when seeking acress "It was hoped in this way to essure the gateteepers of the researcher': appreciation of the sensitive nature of the exercise. In fact the research revealed that negotiation that starts in the first plecement is a continuous process throughout the whole of the first six months of the course.

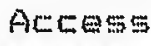

Having selected the setting and the cases: taking account of place, people and time : access became the next consideration. Ag Hammemstey and Atkingon (1983) note:-

The problem of gaining accegs to data is 


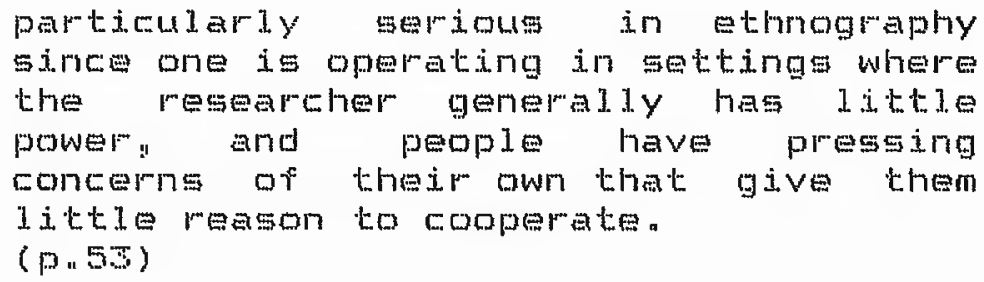

My research was no exception: problems af access were varied but in the main derived from peoples pressing concerns of day to day work rather than their concern for the research.

The education institution was the fipst point of access and posed few dificulties in either centre. In the first year the inner city institution provided the chodes of placements and in the second year the urban and rural institution. In both situations permisgion was gought and received firgtily from the head of department and then from the district nurse tutors.

The digtrict nurge courmes in both of the higher education institutions were in a department of social. sciences with two district nurse tutors responsible for each course. On the first visit to the ingtitutiong the project was explaimed and discussed with the tutoms and a research protocol agreed. (See Appendix 3 ) During the first week of the course I visited the college again to discuss the project with the students and to ask for names of volunteers who would like to take part in the research. In congulation with the tutor who was familiar with the location of the placements ejght students were selected: 
using the criteria described above i.e. diversity of placement settings. The selected students were offered the choice of withdrawing at this stage "None did so and from this point my contact was directly with the students.

I wa able to gain access to the jnstitution in the summer in readinese for courses gtarting the following September However the time between the students gtarting the course and subsequentiy gairing access to their mespective health districts was around a month - very short particularly where problems of access were encountered,

Gaining accese to health districts was quite complicatedn In the first imstance it was not ciear who the gatekepers were. Health authority himrarchy is such that it is easy to offend by overlooking someone and so bring about a refusal of access. Also news travele quickly in the distritet grapevine and not always accurately" Therefore any request could be mistepresented by senior mangers to their fieldstafi. It seemed there were three levels to accessa the manager at district level, the manager at community unit level and the practical work teacher" However even it this Was farly gtraightforward it was not always easy to find the named person in these posts and changes were frequent. Even the institution's records, on which I was reliant, were not always up to date. 
The short length of time available meant that initial contact by telephone followed by letter detailing the research protocol (See Appendixs) semed the most effective way. In the first instance access might have been facilitated by my knowledge of local heath authority organisation and my personal contats "Moving away from local mealth districts meant this path was not open to me and a Ball (1984) describes! is now always useful " In the best tradition of regearch $\mathrm{I}$ also wanted to ensure that informant"s acceptance was based on informed choice - a principle not always upheld in an organigation such as the health service. Despite the intention of good practice one cannot be sure that subordinates have consented and various presgures can be applied to maintain involvement coingwall 1980). This principle cost me the loss of one informant in the second year and demanded continuous contact and negotiation theoughout the two years of fieldwork mainiy with the practical work teachers who: once approval to enter the health district had been gained, becine the main gatekeppers "

The generaj. protocol for health gervice management is that. the most senior are approached first: followed by the next in line and then the fieldstaff. Having once gained approval from the senior manager I followed up the other personnel as quickly as possible in order to curtail the grapevine effect. This process worked well in the inner eity placenemts. In tact all Jevels of mangement accepted the 
research with ijtte enquiry into purpose or method" Ferhaps this uncritical responge was due to the fact that they were familiar with research activities or that they had experienced good research practice in the past and therefore did not see the need to ask questions. Or it may have been due to jack of interest or to lack of understanding about what research entails "Whatever the reason for their passive acceptance I cannot assume that it was the due to the access procedure as the very same procedure in the second year with the urban and rural placements resulted in two refugels.

Access and maintenance of access was more dificult in the urban and rural placemente with managers, practical work teachers and students. It is fair to say however that I was carrying out the fieldworl: at a time when health gervice staff at al l. levels were undergoing the trauma of clinical grading. The burden of clinical grading was the reason given for refusal to enter one placement and in another ingtance a rather harsh refusal. came from the senior manager who had been called from a clinical grading interview to answer my phone call. On reflection a different paterern of access promedure such as a written request first may weil have been better, but the constraints of time still applied.

Because of difficulties in gaining access to health districts in the second year the eight placements in the 
second year were spread across six health districte rather than eight as in the first yeam. .

A further complication in the urban and rural placements was that I had to compromise in one health district about the observations I wished to undertake with the student. This involved agreeing to meduce my obsemvations to the visits to the clinic only and not to accompany the student on any other routines or patient visits, the arranging of which was felt would put pressures on already overworked practical worl teachers. The maintenance of access was also compromised when one tudent withdrew before the end of the fieldwork. Fefusal or excuses about convenience and work10ads which necessitated changing appointments with pratticat work teachers: adso complicated the maintenance of access in the urban and rural placements.

Access is not just about gaining permisgion to enter the field. It $i$ also about making relationships with people who might help, hinder or stop the resemen. The way in which the research was presented to the community managers and the practical work teachers had much to do with the expectations about the research and the role of the researchem "It also meant that the role of the researcher was always precarious. I was made to feel quite vulnerables and at times isolated and ankious "Small numbers of cases and limited time means that a minor change congtituted a major disaster for the 
researcher" Fejationships are buid. tu over time and often access may be prohibited or curtailed in a way that would not have occurred once trust had been estabijhed.

Hammersley and Atkinson (1983) suggest that too much information can be given at the first point of access and. with a trusting relationship not having been established a a refusal may result . Later in the research however" when clatekeepers recognise that information is used responsibly and confidentiality is honoured, they mey agree access that earlier" would have been refused. This strategy was used in a limited way in the urban and rural placements where agreement about access was based on twenty minute interviews and no agreed observation time. However once a relationship had been established with the practical work teacher observation of student routines was allowed over two houms and interview times were extended. However there is $a$ dilema here, beceme the researcher wished on the one hand to demonstrate good practice by trying as a matter of principle to adhere to any agrement made with health districts so as not to jeoperdise future research" and on the other hand to take every opportunity offered to gain as much information as possible in the time available.

With the short time available in which to build up any relationship: it was perhaps unrealistic to expect managers to give permission for a researcher to enter situations where people were already under pressure of varying kinds. 
Fieldwork Procedures

Maintaining access to enable the researcher to coliect the data $i s$ clependent on field relations which may take varying forms according to the nature of the data and the method of data collection.

The methods of data collection for this study were informal or unstructured interviews and observations. Three interviews were carried out with each gtudent and two intervitws with their respective practical worle teachers - a potential totel of eighty interviews over two years. In actulity seventy six individual interviews were completed over two years and one group interview at the end of the first year. observations were made at each placement visit including" in the third placement, accompanying students on their normal moutine for between two to four hours. This extended observation was thought to be most appropriately placed in the third placement as I would by then be more familiar to both student and practical work teacher. A period of "acelimatisation" is mutually desirabje in participant observation - particularly in patient care contacts (James 1986. Field 1990).

In the second year this extended observation was curtailed in the rural and urban placements, edther by the manegers in the health districts or by the withdrawal of students. 
The establishment of relationships with students gtarted at the beginning of their course whem I tajked to them about the research. At this time I explained the research aims and briefly outined my biography as a researcher with a background in district nurging. practical work teaching and college teaching and therefore an interest in finding out more about the student a learning experience in practice. Something of the method was described and an estimation of the time that would be required from the students was made. I. also told them that the results of the research would be submitted for consideration for a doctorate. For bome this had negative conmotations of personal gain rather than "real research" and theretore prevented their participation. I ajso promised to circulate a written meport at the end of the research. Confidentiality was emphasised and also independence from any of the health districts or from the eduational ingtitutions This was remenforced by the fact that I. was not known to any of the health district managers mor to the practical. work teachere " However, ag previously described. my lack of local contacts did make access more difricult in some health districts.

Contact with the students then followed on the premdetermined plan of interview at the educotion institution after the first placement, followed by interview and observation in the second and thipd placement. In the first year I met the inner city students as a group at the education institution on the last day of their course. 
However this was not possible in the second year due to a different programme at the urban and rural institution.

Continuity of contact with students was maintained throughout the course by letter reminding them of our meting times and showing interest in their progress similarly contact was maintined with practical work teachers in order to ensure continued interest in the research and continued access - msential to the success of a project such as this (kratz 1979).

It is difficult to gauge the impression students had of me" Although all knew my district nursing and teaching background they seemed to regard the researcher role as my main reagon for being there. However there were quite a few instances when studentis acknowledged my background by either asking advice or expressing a shered understanding, such as "weld you know what its like on the district" During the longer periods of observetion: al th of which included patient contact g sudents distused theip decisiong or in fact asked me what they should do as if I were a practical wort teacher or college 1,eturer" Field (1.985, 1990) regards this es an indication that the informants accepted my presence and that reactivity and threats to validity had been minimised.

clearly presentation, including dress and demeanor: is important and has been described by authors from both 
nurging (k゙ratz iq7B) and education (woode 2966 ) as being part of the creation of an appropriate role. Tr regpect of practiond work teachersy with whom there had begn lesw time to mate a melationghip: it was important that I was $5 e$ en as a researcher not as a teacher and not ms a member of the education establishment . Despite by best efforts I could not be sure that practical work teachers had given informed consent or that they had not felt obliged to conform to the studentes: wishes. Ciearly my wole and my intentions were not always clear. For example in one interview a rather mostile practical work teacher kept referring to me as "you people at the college" "When $\mathrm{l}$ reminded her that I was not from the coljege she coumtered "well you are a tutor perhaps it doesn't happen where you work" "

Making use in the initial interviews of "natural" or "mundane talk" rather than direct questioning about research interests was another strategy used to estebligh a good relationship and indered this frequently led into the mesearch topics. The semingly "mundane talk" of describing their experiences was a truitful starting point for the intervidews

Interviews

Apart from the student interviews after the timgt placement and the group interview at the end of the first year all 
ather interviews were held in the placement settings. Gettings varied across general practice surgeries, health centres or cinics! and venues within the settings varied even more - from the privacy of an office to the public thoroughfare of a large but quiet corridor. Despite these odd venues intermptions were infrequent and only once did the interview have to be curtailed for this reason.

A1. the interviews were tape recorded to reduce the distraction of taking comprehensive notes: although terms and phrases were sometimes noted - more as an "aide memoire" during conversation than for mecording purposesi Tapes were usuldy trangcribed within one week of the interview. However a backlog did occur particulary after the third placement when the urgency of summarising and interpreting in preparation for the next interview was no longer present. Length of interview varied from twenty to forty five minutes dependent upon time available to the informant and upon the amount of information volunteered " (See Appendix 4)

The interviews then were unstructured and informal. As Burgess (1982) say the unstructured interview appears to be without gtructure but nevertheless "

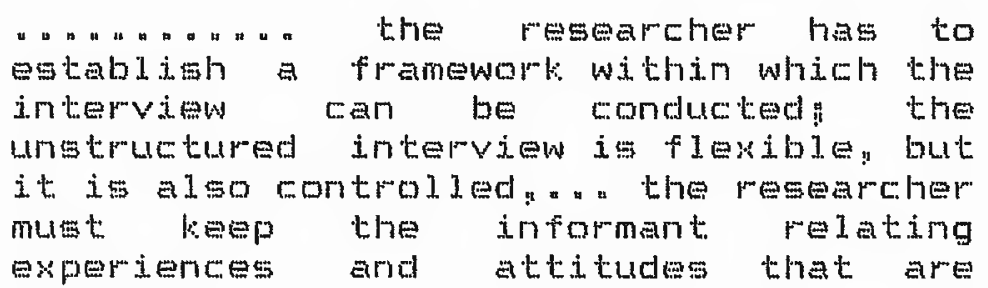


relevant to the research problem and encourage the informant to discuss these experiences naturally and freely. ( $\beta .107)$

Dpportunites for talking to students and practical work teachers and to a lesger oxtent others in the placement occurred at each placement visit, not just during the set time for the interviews but during the whole of the time I was present. Each visit to the placement then could be regarded as participant observation of which the juterviews were a part ( Hamersley and Atkinson 1983).

Participant observation

There were two main contexts for learning in the placement settingn - the patient context. for instance home or residential accommodation, and the colleague context, such as cindic or health centre

observations were recorded in fieldnotes which were either entered into a small notebook or dictated onto a inicrotape to be written up more fully or transcribed at the earliest opportunity. Two or three times I forgot to tale the notebook and so ended up with loose bits of paper which were then stapled to the motebook"

A further record was made of the whole process in the form of a diary" In this confidential dimy $I$ recorded my 
feedings, thoughts and prustrations about the research in an honest account of learning about ethnogmphy (See extract in Appendix 6) The diary covered to some extent the three major elements identified by Burgess (1984a) as -a chronological mecord of events informants and locations an autobiographical account of the resegrch process and the researcher's involvement in itg an outine of the stages of the research and "hunches" and "insights" pelating to the data In short a substantive, methodological, and analytic account.

The fiejdnotes I made were open to the students scrutiny but none took the opportunity to read them. However they were used as a reference point at the interviews in an atempt to validate my interpretation of the meaning of the behaviour I had obgerved. It was not my intention: or indeed ethically desimabe, to keep fieldnotes confidential from the respondents (Dingwa1] 1980 ).

As many observers have noted it is not easy to make field notes without detection that casses anxiety to informants. It was quickly apparent that taking notes in gtudents cars was unnerving for them, except at times when they were describing patients to be visited. At such times $\mathrm{T}$ was able to mare a few extra motes of students' comments or phrases.

of course not all visits were made by car particularly in the inner city placements where walking or using public 
transport was preferred.

I carried my notebook into the patients' homes - in constant fear that I might leave it there - and used every opportunity when I was not invited to be presents a a. when patienta were taken to the bathroom: to make detailed notes. Publice trangport, snack bars! the student'b car and my own car when used, all provided opportune places for note taking.

A further dimension to observation in placement settings was ramiliarigation with the geographical environment - the housing industry and locel facilities which are all part of the community in which the district nurge works. Time gpent walking around the locality before or after the metings with students and practical work teachers was valuable in helping me to gain a better appreciation of the placement in its community setting.

During my overt observations" when t. accompanied the students in their norna routine patients, I was acting as an "observer as participant" in the terminology of Gold's ( 1958$)$ ideal types. I was known a a researcher to the student and introduced to the patientg if at all in a number of ways - banetimes colleague n sometimes visitor " gometimes researcher depending on the discretion of the student. lt ig difficult 
to assess the effect of an extra person on the obgerved interations in any setting and particularly in intimate surroundings of someone's home. Dyadic and triadic relationships have been discussed in this mespect by Luker (1978) "Kratz (1978) and Field (1983). They noted no change in the dyadic nature of relationghip between nurse and patient - the observer being viewed by the patient as one with the nurse. Fratz (1975) also digcusses nurse patient meactions when a fourth person: the carer, is present. Again she notes few changes in the relationship due to the presence of the observer, one reason being as stited above that the observer is seen as being one with the rursen another that in the presence of a carer, the interaction was of a more trivial naturen kratz (1975) expleins this level of interaction as being due on the one hand to patients acting as non-persons - neither performers nor audience because of their age or illness - and on the other hand to patients conforming when they do participate to the expected behaviour $i_{u}$. acting nomally and not acking maudlin questions about health or eventual recovery.

In situations where I visited patients without carers I was generally ignored or else included in the discussion in a similar fashion to the nurse, who was not always wedl known to the patient. The addition of carers" as kratz (1975) observed, frequently centred on trivial interactions: but in some instances centred on patient concerns about iliness and treatment: the patient: usually elderly: frequently being 
the main performer.

It is even more difficult to agsess the effects of the observer on the relationships between nurse and carers important relationships which the district numse builds up in the home and ones which are easy to ignore (kratz 1975). I. an unable to say that I found evidence to gupport all kratz's arguments about relationships. However this is not surprising as my observations were not concentrated upon the district nurse's care of the patient in the home, but upon the opportunities for learning that were presented. A further complication in drawing parallel conclusions with kratz is the fact that the students did not have overall responsibility for the petients who memeined on the practical. work teacher's caseload. The student's transient status was often a point for discussion during the visits to the patient's home.

When I visited placements for shorter periods perhaps for two hours or so to carry out interviews $I$ obgerved in a covert manner. This did not necessarily involve obmerving just students and practical work teachers but others within the setting. Ferhaps while wating in the reception area or in the nurses room until meeting had finished.

There are varying dimengions to participant observation acting overtily or covertly are not dichotomous roles and 
often depend on the open or closed nature of the system in which the study is being undertaken (Eell 1969). They are evident in several binds of research activity as gimply described by Eecker and Geer (1962) a.-

The researcher may be a member of the group he studies he may pose als a menber of the group. though in fact he is not: or he may join the group in the role of one who is there to observe. (p.239)

Participant observation varieg from total participation with no abservation to observation with no participation. The participant observer role is therefore likely to change dependent on the atuation and oold's (1958) ideal types to overtap (cited Hammersley and Atkinson 1.983), as illustrated DE IDW :-

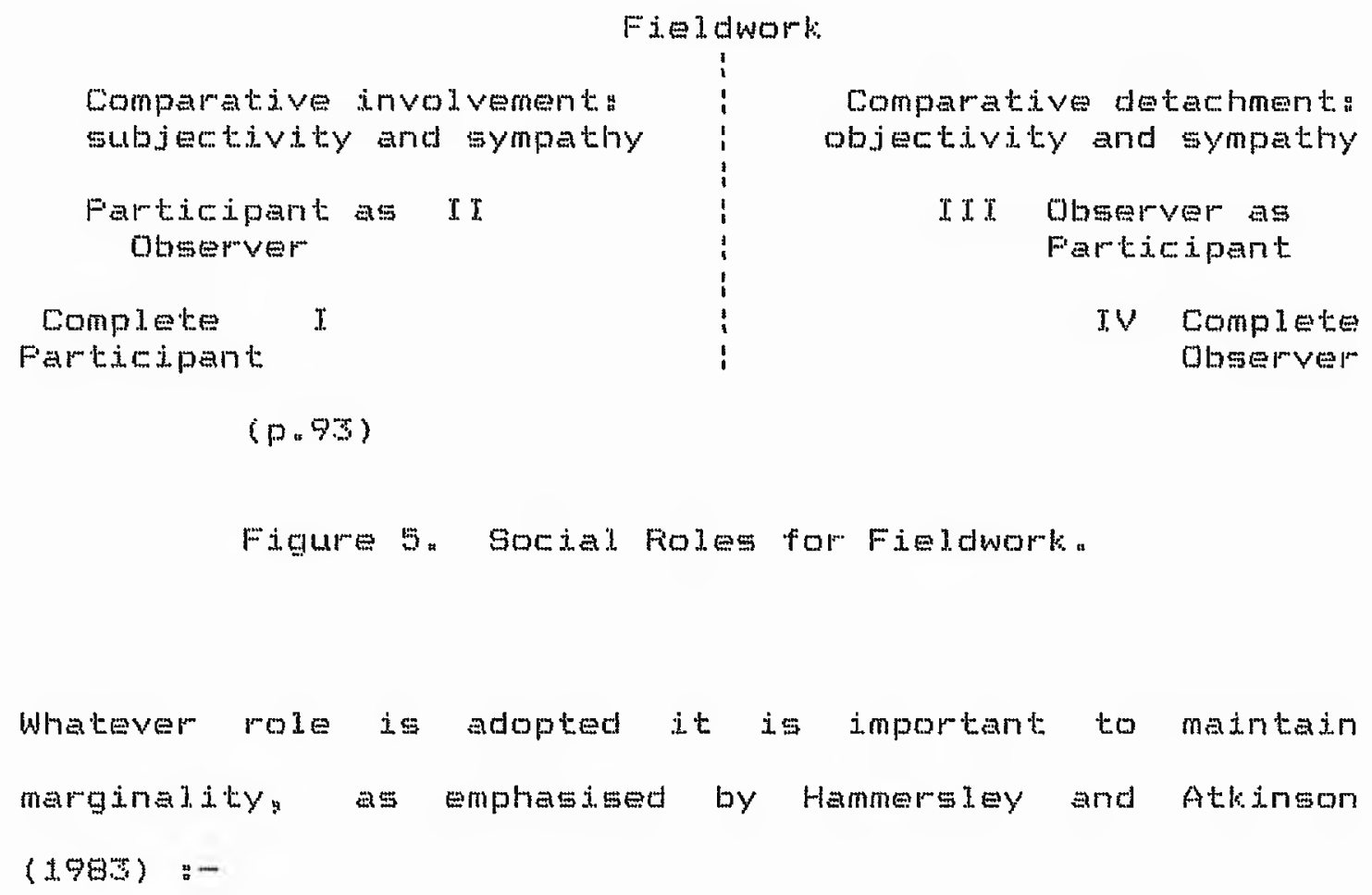


There can be no question of total commitment "surpender" or "becoming" . There must always remain some part held back: some social and intellectual "distance" "For it is in the "space" created by this distence that the analytic work of ethnography gets done. ". the point is that one should never surrender oneself entirely to the setting or the moment, In prineiples one should be constantly on the alert; with more than ar eye on the research possibilities that can be engineered from any and every social situation.

$(p p .102-103)$

Moving between "ramiliarity" and "strangeness" and between "gtranger" and "friend" $d$ s not easy and can result in isolation and disillusionment with the project (Malinowski 1982) " Even in this mall gcale project it was easy to feel isolated and as the informants became faniliar there was the likelihood of forming likes and dislikes with the danger of skewing the data (Gans 1982, Field and Morse 1995).

The participant observation was discrete and sequential usual. ly amounting to half a day at each visit - rather than contimuous and therefore al lowed greater detachment but cut down the chance to change direction and to take oppomtunities for "pesearch possibilities" in many situations. It would not have been advantageous to increase the length of visite "Indeed there is an optimum time for which observers in the field are able to memain alert (kratz 78, Field gis. However the frequency of vigite could have usefulity been increased. 
The process of analysis, although discussed here as if subsequent to the data collection, is part of it and not a distinct stage of the research. By its natume there are no sets of procedures or rules to be followed in ethnographic analysis which may account for some of the critiejsm levelled at ethnography conceming its lack of rigour and clarity. It is a combined process of reflection, imaginative thinking and systematic sifting and analysig of evidence from the data.

The broed gteps in the process of andysis, outlined by Hammersley and Atkinson: (1983) underpin much of the ethnographic research in education and have provided a guide for this study :-

- the identification: formulation and clarification of research problems beginning in the pre-fieldwork phase.

This ciarification of the research ploblems resulted in a redefining of the research questions beginning in the pilot study when it atarted to become evident that the problems were not so much a matter of what constitutes a "good" or "bad" learning environ ment but more a matter of how the students learned from their experience in the environment. As the study progressed this learning process became clearer and emerged as categorjes which demonstrate a developing process of leaming. This process is described in detail in 
the following chapters.

- careful reading of the data to gain familiarity with it, using jt to think with and to identify any interesting patterns or features that are puzaling or surprising. "Formally it starts to take shape in analytic notes and memoranda informal ly it is embodied ethnographer" $\mathrm{g}$ hunches, and emergent concepts " (ibid P.174)

Analysis has centred on the student interviews" with data from other sources and from other techniques being used not only to check out the inferences that are being made from student interviews, but also to provide a richer and more compremensive picture of the practice setting.

After each interview transcripts were made together with brief notes of interesting or obvious icleas arising which stimulated thinking during the transcribing.

At the end of each placement the student interview data was read through and individual notes were made with coded reference to the trangeript. Words: phrases and patterns were noted with cross reterence to other student transcripts and to the fieldnotes

It quickly became apparent that one of the first steps in this systematic process was to get some sort of order in 
the data. With regard to the transcripts this was a matter of coding each idea which gerved to identify the respondent: the placement, and the year. "The codes could them be grouped into concepts enabijing references to be made across all twanscripts.

The data from the research diary and fieldnotes was more difficult to distinguish. The purpose of the research diary was to record all the events throughout the thmee years" including the pilot study: and also to record personal notes about my feelings, atkitudes and reactions to events and people I came across in the reseapeh. Not only did it aid rewall and hejp me to reflect on the methodology, but it also contributed towards a more valid account of the inferences from the analysis (Field 1990). For instance some respondents were mome helpful than othere and some settings were emier to enter than others. Any mesulting bias or error in the data analysis was easier to detect in the light of the diary evidencen (See extract in Appendixs)

The fieldnotes were notes on observations and also contained some bitg of verbatim comments that I was able to write down. However I found that the diary and fieldnotes sometimes overlapped particularly when first meeting new situations and people "For practical purposes I carried the tield notebook only when observing. It therefore semed a good plan to try to distinguish in the fieldnotes between 
observational notes " methodological notes and theoretical motes (Schatzman and Strauss 1973), all of which appeared occasionally in the diary. This system of ordering data was successfuldy adapted by Melia (1981) in her analyses of forty interviews carried out on student nurses.

Schataman and strauss (1973) describe the ordering of data inko distinct packages thus:-

- ov: Observational. notes are statements bearing upon events experienced principally through watching and listening. They contain as little interpretation as possible and are as reliable as the observer can construct them. They do not go beyond the "facts but record verbatim or paraphrase as accurately as posidibu

Data from the vigits to plecement and the routine visiting with the students which I tried to contain in the fieldnotes rells into this category. Frequently it was paraphrasing with occasional recorded verbatim words or phrases"

- TN" Theoretical notes aro inferential notes "The observer as recorder thinks about what he has experienced, and makes whatever private declaration of meaning he feels wil bear fruit. He interprets, infers, hypothesises, conjectures: develops new concepts" links these to older ones.

Such data was mainly recorded in the research diary and 
related not only to placement visits but to my reactions to interviews and to sudden 'insights ' of interpretation.

- Min Methodological notes ame an instruction to oneself, a reninder: a critique of one"s own tactic timing , sequencing, and stage setting.

These noteg which are clogely related to TN again arise out of the interviews and contribute to the reflexivity aften the end product of a TN becomes an instruction to onese 17 and therefore results in a MN.

When I started to use this systen I used the notations indicated aboven However this was abendoned in favour of just using the concepts and indicating differences in my recording. For instance all MIN and TN were bracketed in my fieldnotes " It was the provision of a franework for the Iogical. ordering of data that was most useful y rather than the application of the exact system.

An extract from fieldnoteg during rautine visiting with the student in the third placement of the second year gives an example of how the framework was used "n-

On to the next patient. FT describes Mary Jones "Long standing CVA "very sweet lady, husband will have some pithy comments about me being late - he j.jes you to be on time " " 
FT says she is very frustrated by the situation and feels annoyed that all. she seems to be doing is relief. No continuity with the patients.

She takes in equipment for catheter insertion - not sure what is in the house by way of equipment. Leaves car on the moad. Enters house - spacious private bungalow in own garden, wetached -.. without being let in, calls out and goes into bedroom.

Curtails any comments from Mr. Jones by saying "I expect you are going to tell. me off for being late" "He says "yes another black mart:" "I am introduced as tutor and decide to stand in the corner of the room away from bed and where FT is working " Mr J.says git down - athough no chair- then a few minutes later "stand where its warm near the radiator" - I decline mainly because FT is working there.

FT washes Mary: changes dressing on buttocks and puts in catheter. Mary talks generally - good rapport. General chat about the weather, visitors, other nurses who will be visiting - has twice daily visits by day and evening otaff Husband gets wife up later. He stays in the room and joins in the conversation and general banter about cooking and Mary bossing him about. Trying to memember where FT lived -Mary remenbered - she chips in "Questions asked about other murses - whether still of sick and in the treatment room. Discussion about catheter size- Mary has said its 18. FT gays "you were right I asked Joyce" "Mr J. Says "T thought ghe was on holiday "FT "yes but she 
popped into surgery" not there ver"y long"

[ FT seems to be doing what she is told by other nurses. Follows the treatment of others. How can ghe be learning for hersel. "How melate to $T$ and $T$ eategory. No ecope for innovations]

FT is empathetic and perceptive with Mary and husband. Includes me at one stage to show me the dreseing for the buttocks - pressure areas a Calls me over to see "how well it sticks" Mr J.involves me in conversation a few times what do you think of the numses - I say fine [ tutor moled. Later he saye "FT is a very good girl - sorry when she goes ".

Mar"y im left in bed on her side until. Mr J goes shopping. He drives into fi. one mile.

[FT copes well in this situation? but there are great opportunities for teaching here in both techniques and communication ski1Is and health education - FWT]

Vigit. taken 30 minutes.

[ Check out how FWT might discuss or visit to do this teaching]

While driving along $\mathrm{I}$ ask FT if she would make any changes in the caselom. She says she would cut down visits to Mary and put in social service care asmistants. Explains the family visit every weekend, he is active they have private cleaner and nurses could visit three times a week: to observe catheter and Fins "Should not be daily. I ask 
If she has suggested thisa she says no "I don't think that would be welcome" "She had already asked why daily visits and been told-because the family need support. FT Feels equivalent support could be given but at less cost to nursing resoumces.

[1. feel. sorry no opportunity taken by FWT to discuss thiswhy is this so?]

This extrat ilustrates the mix of mainly observational notes with odd theoretical notes about learning and with methodological. notes arising from initial analysis of transcript. Fieference to the category of "Trying and Testing Dut" was possible at this stage because it had emerged as a well defined category and it was therefore fairly easy to recognise and focus on.

There are algo other aspects about my role and the relationships between numse and patient which could be orm out from these notes and used in the analysis. In addition there is evidence to contribute to inferences about the situation in which FT finds herself. WeIl established routines would be difficult to change here. FT is expected to "fit in" - mother strongly emerging category at this Stagen Dpportunities for teaching, in this very common gituation in the homen do not seem to be used by the practical. work teacher. The idea of 'go and get on with it. as a way of learnimg expressed by the practical work 
teacher in her interview is at variance with what FT would Jike.

Ordering of data from the observations and simple coding of the transcripts together provided the beginnings of data anelysis. (See Appendix 4)

- noting any links between data and expectations on the basis of common-sense knowledge, official accounts or previous theory" Also noting inconsistencies or contredictions between individuals and between their expressed beliefs and what they do. Identifying "sensitising concepts" - " the germ of an emerging theory" a starting point that provides the focus for further data collection.

Apart from individual transcript notes any general ideas or themes were noted and these together with individua ideas were picked up in subsequent interviews this process not only began the progressive focussing of ideas but was also a way of validating mespondents accounts. It did not take the form of written accounts or formal feedback but rather a noting of points that I had drawn out of my interpretation of the previous interview and which later provided evidence for the emerging categories. Fespondent validation resulted in confirmation of the point, or expansion, or explanation. Ther"e was no outright rejection but some re-interpretation as a result of discussion. For Ba11 ( 1983$)$ :

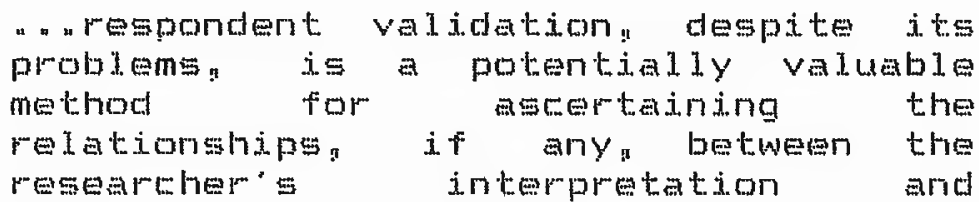


partrayal and the respondent 5 experience's of their social world. $(p .99)$

Wnce ideas had begun to emerge, after the student's second placement, they were discussed not only with students at subsequent interviews but also during observations and formed the focus for the participant observations noting any confirmatory or unusual activities. It is at these points when categories are emerging that constous decisions gtart to be made about where to look for confiming data in other jnterviews and in observations. It is not the theoretical sampling of multiple sites used by the orthodox grounded theorists (Glaser and strauss 1965) but the theoretical sampling within sites" within the student interviews. between the student and practical work teacher interviews and between fieldnotes and wudent interviews. This is an approach for smal sole research such as this that al lows utilisation of the concept of theoretical samping (Strauss 1.987) The concept has been used and modified not only in education but also in nursing (Melia 19g1 g Luter and Chalmers 1990 )

At this stage it was obvious that there were same fairly consistent concepts emerging which could be tentatively explained by reference to the adult leaming literature and which were familiam from the research on the ward learning environments. It would have been easy to begin to develop 
categories prematurely at this stage and as a result to draw spurious inferences.

Sequential stages of analysis during fieldwork are identified by Becker and Gerer (1982) as follows :-

(1) the selection and definition of
problems concepts and indicesa
(2) the check of the frequency and
distmibution of phenomena and
(3) the incompration of individual
findings into the model of the
organisation under study"
(p.24l)

Of particular relevance is the second gtage in which the researcher i. looking for evidence of inferences and conclusions. These may be armived at by checking the number of respondents giving infommetion the frequency of such numbers pertaining to a particular category whether the information was volunteered or given in responge to direct questionning by observing respondents" behavioum in

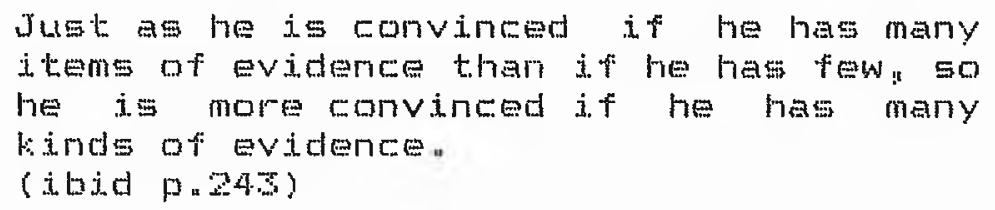

For instance the category of "Trying and Teating Out" was devised from the conclusion that it was important to students in their Jearning to check out their actions with others they regarded as experts. Evidence for thig conciusion came from a variety of soumeses it was found in a11 students" transcripts and confimed in interviews with 
the respective practical worle teachers that this was a strategy in which they were involved and whith they encouraged: it wes stated voluntarily by gtudents during conversation and observed in their behaviour in both first ancl second year students across all placements.

lintegral to the process of analysis is the question of construct vadidity - the validity of the lines of inference running between data and concepts however far down the road towards theory testing the researcher is intent on moving. As Hammermiley and Ateinson (1983) state there is Iittle point in developing typologies and models if they provide littie purchase on the date n-

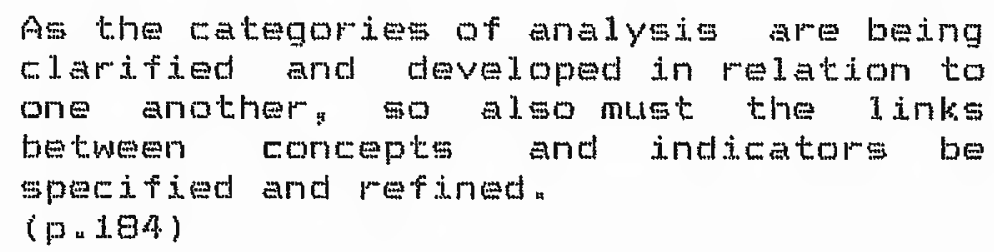

They stop short of adopting quantitative methods of asesesing construct validity as advocated by Evans (190s) which they considered as misconceived if applied to ethography. They argued that not untid the analysis has been written up are the reletionehips between the concepts and the indicators apparent and only then does evidence of the indicators become elear in supporting the validity of the claims made by the concepts. The important process here im the "inductive reflexive character of ethography where the process of analysis involves the simultaneous 
development of constructs and indicators to produce a 'fit' between the two"(ibid P.lBs). The question of identifying standardised indicators that concentrate on the stimulus response model with no consideration of the researoh process is again not an appropriate qualitative neasure. Here the requirement for standard meliability measures to support construct validity becomes erroneous and the need for standard indicators influenced by the assumptions of the behaviourigts is unnecessary. This type of reliability measure as a component of construct validity ignores the differences in context and the "presentation of a standard set of indicators is not an essential feature of theory" (Hammersiey and Atkinson 198s):-

What is required is that the theory be explicit in its preclictions of what will occur under given conditions. The question of whether and when those conditions hold can: and indeed must, be a matter for subsequent investigation, $(p, 186)$

Fossible threats to validity in analysis can be reduced by triangujation. Degpite the complexities of triangulation and Varying teminglogies particularly in nursing (Mitchell 1986 Duffy 1987 Comer 1990 ) its use in this study has been restricted simply to "data - source" and "technique triangulation" (Hammersjey and Atringon 19gs) " In the former: data is analysed from different times in the study and from different participants and in the latter, data iz examined that has been collected through two different 
methods - in this study through interviews and participant observation

- clarifying and developing the concepts om analytie categories into "theoretical schemen finding links between concepts and adding new ones" through the constant comparison method.

Throughout the first year there was a rather loose frarne of ideas and hunches with some fairly consistent themes which inight regarded as concepts and the start of categoriesn

During the gecond year the same process was carried out. However as concepts became chear they were matched against evident categories from the first year and in this way the interviews and the participant observations became progressively focussed. Also during the second year it became possible to Elarify and to refine some of the categorims and to compare data against these categories as it was coljected. In this way it was possible not only to check the relevance of data to the categomes but also to identipy and wetch a particular category in the data.

It was clear that not all the interesting jdess and leads could be followed up it was those concepts that were becoming conceptual 1 y weld. integrated that were concentrated on and others had to be left behind, what strauss (1967) 
cals the pain of severances When decigions are made about the focussing of data collection on the basis of fit with the cotegories.

Analytic notes became more prolific as progressive focussing continued. These notes ean be likened to the process of memoing demeribed by GJaser (1978) as "the theorizing of ideas about codes and their relationships as they strike the analyst while coding"(p.es). The theoreticaj notes used to order the data were the beginings of such notes" As the written notes continued they were kept on sheets separate from other data and were concerned with the conceptual level of analyos centrating on relationships and on writing about ideas that were sparled of at any stage of the data collewtion and the analysign

- continuing the systematic sifting and comparigon to devejop a typology as part of the energing theoretical model.

It is important to gtate that my research is not seeking to develop a theoretical model but is drawing on adult learning theory in order to analyse and explain the student: learning experiences and to reach a better understanding or learning in the practice eteting. In the wordg of Melia $(1981):-$ 
of the work makes a detailed description of the mode of the analyais medundant without the attendant data and interpretation. (p.1.4.

The conceptual categories which emerged are mapped out in sequence in the following three chapters. In analyaing them I draw upon the research data for the evidence of the concepts involved and upon adult learning theory for an interpretation and explanation of the protesses of learning involved in becoming a district nureen

The categories arise in the first place from an analysis of the trmacripte of the gtudent interviews "Further evidence for the inferences made is drawn from the observations with students and the interviews with practical work teachers. This variety of evidence provides a range of different perspectives on the students Iearning process.

There is a sequence to the evidence as it emerges from the data that closely follows the learning process being experienced by the student. The sequence is evident acrose the categories and it is around this process that the integration of the categories has been developed. The overlaps therefore are confirmatory rather than contiradictoryu 
Categories in this study are thus defined as groups of concepts linked together logically in tems of adult learning theory. The rationale for linking the concepte reflects the learning process of the students as they progress through the course. The categories then are the end part of this study 
CHAFTEF: FIVE

"FITTING IN"

Introduction

The learning process involved in becoming a district nurse is characterised by as mueh uncertanty as the community itself portrays. Although all the students are qualified nurseg they have to start at the beginning and one of the first chalenges is fitting into the learning environmentnot so much a physica] enviponment such as health centre or general priatice surgery but a social environment of colleagues and patients and routines and accepted practices. In this respect this category tan be said to be inextricably Iinked with district nursing pratice. The learning here is driven by practice whether good or bad. Not that district. nurse students are uncritical of the way district nursing is practiged but in many ways thig eriticism has to be set aside until the course is finished. It is postponed in order to be able to maintain some sort of fitting in.

The gtudents recognige that this is where they leam about real district nursing and it is in this environment that they have to make the most of this brief ppportunity of nine weeks. Which to some extent gives a sense of urgency to the fitting in process. 
Becoming a district nurse is like piecing together a jigsaw. of getting to know what is acceptable and what js not. It is as much to do with being accepted into the group of which patients and professional carems play almost equal parts. as about learning what djetrict nurses do.

It starts on the firgt day and is continuous throughout the placement experience: athough the emphasis ateris as responsibidity increases from observing the demonstration of basic competencies to decision making about caseload manegement.

Fitting in with collemgues

Just getting to know the geographical area and finding the clinic can be a part of this fitting in process "The firgt moming feeling was graphically descmibed by a sudent who was a direct entry. It was a feeling I was able to share with her as I had wandered round the streets trying to find meeting places and sometines feeding the insecurity of an unknown area $"-$

$A M$

We were taking about the strangeness or the situation: how difficult it is to come into a new gituztion ..."

Student J couldn't get in! I didn't have a key, I couldn't find the door and I couldn't get in. Then I met one 
of the district nurses who brought me in and in fact made me a cup of coffee. But it is this thing of having worted in a hospital, knowing where you're gaing to some extent - what's expected of you and then a very different gituation of not being able to assume anything at al gand of having no past experience.

$1001,2,2,1$

The practical aspect of finding the way around the placement added to the strangeness, but it was something that students knew they would be able to deal with. It was just a case of learning the local geography and applied to al s students whether direct entry or non-direct entry. However it all added to the strangeness of the situationg not on ly looking for a clinic or health centre but also looking for patients. homes "knowledge of the local area is extential to finding. at the very least the patient'g house, and more comprehensive knowledge is required" for lockting low servicesis It is therefore closely associated with what is expected of a district nume and with working alongside coldeagues and is referred to by students throughout the placements

The wider environment of the locality may appear to be simply a mater of using a mapg and indeed it was; but it loomed 1.arge on the student's agenda at the beginning of the course "Finding one"s way round a maze of streets, tower 
block or estate in some areas of the city or town where viglence is not unknown, can be difconcerting and much different to finding one's way round an institution.

However fitting in to the routines and pratices of the group was much more of an unkmown quantity and as described mbove is something akin to the experience of a stranger entering a new group (Schutz 1964). The lack of experience gave the above student and others: both direct entry and non-dimect entry, the feeling of "a man with no history" (ibid p. p7)

The newress of the situation was relevant to ali students but the experience students had had before they came on the course was influential. The ability to draw on previous knowledge about the situation athough not exactiy the same eased the way in. But for those students with hospital work ae previous experience it was different. They were acuteiy aware that they were in a different social environment but their background knowledge of hospitals was mot easily transferable.

Further comments from the previous student reflects again mush of what sohutz refers to as lack of status and Iack of rules for guidance as to what serves as normal practice. It touches on colleague and patient interaction and highights some of the student' needs. Ald these things are relevart 
to thim category a-

$A M$

Did it (placement) meet your expectations?

Student Not particularly.

$A M$

$$
\text { In what way? }
$$

Student In two areas. I thought I would gpend more time visiting in homes, and I hadn't ervisaged all the other things a PWT had to do. Um " " I spent a day with gocial services I spent half a clay with the home help service.

Al Did that help you to put into a frameworl the things that happen in community? It must be one of the thimgs thet are different in community and make if difficult for you to know what services are available and who does what in relation to distomb nupsesn

student Yes" I think it's essential informetion, and for people who have already been out: they have accumulated this infomation over a length of time: I found it stressul in the sense that I had to go combanty meet new people, go to new places and find my way round. Lin. Meeting new peopleg not knowing who anyone particularly was always being on one's guard: not being mble to relax. I was worried about getting to places on timey beating the traffic. 
AMI

Is it a faniliar area to you anywy geographica J.J.Y?

student No not especial1y"

AN

What about your FWT was that a stable factor for you, at least that was one person you could alway go to: whatever their feelings they would always welcome you?

student on yes" um, Yes. She knew everyone. She had been there quite a while and as I am sizing then up: so they are sizing you up all the time.

Aly

What will you be expecting from your next placement? Fresumably you will know where you ere going this time and therefore it will be lese stressful in that way? (mm)

Student it will be gtressful in a way - to have a different role not to have any responsibility really. Not to have any continuity for patients for care. I think it's very difficult for a FWT to know what to give student who has no experience whatsoever. I would like to have some respomsibility without making the FWT a nervous wreck.

$A M$ I expect they have to fird a balance between giving you enough responsibility and not giving you too much responsibility" Were there any 
experiences that were new to you when you were visiting patients in their homes for instance?

Student It's very different going into a new environment and very tiring, because your mind is alway being bombarded with information, a new persong a new personality. Trying to cope with the new environment, trying to work out their problens for the elderly. It was quite hard for them. I was surprised how hard it was and not knowing what to offer. (nm) \{bause?

AM

What about the nursing teamg what about redationshipg there?

Student I think they were very careful about what work they took on. There was a lot of digcussion between those specific groups: nursing groups about who should do what " the thing that very much supprised me was that the person who went in to look arter the patient: who was acting as relief accepted the standard of care, the detision making and the planning was accepted, and that anything other was regarded as intertering "This could be a problem for some patients. Not just for leg ulcers but for others who were more serious where there needed to be sone changes. $k 01,1: 1,1$ 
The hospital experience at this stage does not transfer easily the past experienee which is " thinking as usual" (Schutz 1964 B.98) is not so relevant in the community context. In this new envimonment the student is enquiring and probing trying to make gome sense of what is happening in order to understand the situation. She is very aware of some of the things that others familiar with the seene would take for granted, such as the work practices of district nupses in respect to a cageload. The students do not feel. they can easily take a part in the care planning despite the fact that they are qualified nurses and in some cases have had management responsiblitieg as ward sisters" This may cause problems if students are not prepared to relinguish their role of authority which a senior nursing post incorporates. The practical work teacher referred to these difficultes as continuing throughout the early placenents, recognising that they were related to changes in status and setting. "for somebody who is very experienced and who has been in nursing for a long time "u. "for then to change from ward sister to the district to be under somebody - thats the crucial bit". cicarly thare were expectations here that the students would also recognise their more subordinate role.

A further example comes from a student who had been a ward sister. Here again she i. concerned with trying to fit into the practices of cistrict nursing and into a new role :- 
Student I didn't have break from being a ward igter" so it took me some time to fit into the student roleg so I think everyone knew me as a ward gister. so maybe I had high expectations of what I should be doing. Therefore I think: I was doing things thet maybe I shouldn't Mave been doing. Do you see what I mean?

A Mmm. Do you have any examples?

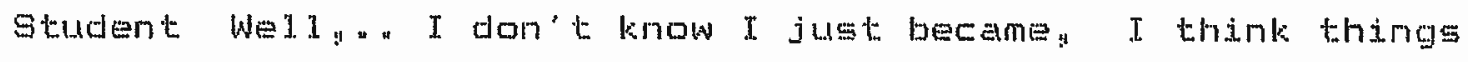
Iike leg uleer dressings: I found it diffirut because people were going in only every other day to do things that I thought should be done every day I could understand the reason, um but: seeing things that i thought should be done.....

AM

So really you were carrying your experience directly into the community without any sort of discussion about whether there needed to be any sort of modification or any difference in mpplication?

Student That's right. I felt that sometimes there were things that were lacking and that I felt that I should have been seasing to. mabe that ig wrong! I cilon to know

$F M: 1.1: 1,4$

This settimg in to a new role was dealt with by students in various ways and indeed some found it a very easy process; 
maleing the transformation with little difficulty. Where it was an easy transfer the students were made to feel that they were "welcome" and the expectations were that they should act 1ibe studente and ask questione and not undertake the work of a district nurse at this stagen Time for learning was emphasised and to some extent the practical work teacher took control of students leaming rather than allowing experience to be determined too much by the workload. They were protected. Such students enjoyed the new role and to some extent the protection this gave them. As one said "it allowed me to ask silly questions".

How well thig early fitting in worked had much to do with learning need; how they were identified: how they were interpreted and what impact this had on the learning opportunities for the student.

There is an accepted routine for students to work their wa through the placement experiencen It i.s a well established routine sarting with carrying out tasks and basic nurging surh as dressings and general caring of patients who need bed baths to the more highly prised areas of delegating and organiging the caseload which comes in the third placement. Without exception all students follow this poutine and it ig one that all practical work teachers explicitiy describe as the desired way of teaching the studente how to practise ditgtete numing. 
Throughout this time the student has to fit in to each stage of this process. In the beginning that is during the early stages in the firgt and second placements, the increase of responsibility varies according to how the practical work teacher percedves the tudent's capabilities in taking on increasing responsibility and the student sontidencen

Assessing gtudents' meeds is an espoused theory of practical. womk teacher"s who all adhere to this way of identifying what students need to be taught and in what order. Having said this it appears that practical work teachers already have a sequence of events in their heads - that is moving from task to management as it in a hierarchy of leaming. The Inarning needs of studente merely anend that sequence but do not: reworder it.

The identification of learning needs is nomally a joint effort between studiant and practical work teacher. Concessons can be gained by the student for instance according to the planned programme of the practical work teacher a visit with the evening service was planned. Ag the 5tudent already had this experience it was agreed a different visit could be arranged. This negotiation was regarded as "showing respect" for the student's past experience and was linked with being accepted and increased confidence. 
However competent gudents feel they are at some activities they still have to go through the routine. For some this leads to dimillusionment and a feeling that learning needs are not being taken into account and that their competence en nurses is not accepted. The routine is described here by a student who has had previous experience in the community:-

Student To start with as in all cases we didn't do much the first day. It was just a case of getting to know each other and the area "Then we did go out and do a very sinali caseload and once I had been to one or two of them I wes able to do them on my own "

I find being watched all the tine fairly hasgling: I don't ike it at ally i know everyone has to go through this and I appreciate $S_{-}$- has to do it. I. must admit in myself I teel a bit mesentul that after so many years working $I$ am having someone see that I can do a dressing property. KUI, 1.1 .2

This poutine is adopted by all practical work teachers and for some students it is a reassumance that they are doing thinge "properly" -- a dressing technique correctly or updating in techniques that they had not uaed recentiy. Although at leat half the students found it difficult and annoying being supervised in basic nurging it was tolerated in the early stages of the coumse. One of the problems seems to be that the techniques that sudente might want updating 
in are not just dealt with geparately" it appears to some students that until they have demonstrated their competence they are deemed to be incompetent and therefore past experience is of no value. Prior leaming related to practical knowledge and skills seems to be ignored. Indeed practical work teachers say that they are concerned to ensure the students in basic numsing cares and can only do this by direct supervision. Although they are all concerned to do this without making the student feel inadequate and in fact the practical worl teacher for this student describes how she tries to be unobtrusive and talk to the family while observing the student carry out tasks in the home. Fractical worls teachers volunteered this information about concern for students. There was no direts questioning on thig gubject. but clearly practical work teachers were gengitive to the student's reelings

Another practical. work teacher" sadd "I took her round with me for a bit which she doesn't like. She likes working on her own completely. She hates being overlooked and she hates me watching her do dressings and thingsi but she knows she has to do so" "The reason given for watching the student: undertake basic techniques was to ensure competence and adaptation of competencies in the home.

The attention given to the needs of the student relates directiy to how they feel they are being accepted by the 
practical worle teacher and by the group. In describing her increasing move towards more responsibility for patient care one student sees this as an acceptance of being a member of the digtrict nurging team :-

Student But yes I mean it's great and $x$ mean it's hellos how's college, and my tace is being known, and the secretary at the health centre and the receptionist and that. You know they res talking to mes sort of including me in the conversation. Although they did that befores but now it's questions dimected at men I'm becoming part of the rurnituren itss quite nice.

$E X, 2.2: 2,6$

The feeling of security which is associated with meeting meds is described by a direct entry student :-

AM

What did you peel that you needed to gort of find out considering you madn't had community experience, what were the sorts of priorities for you when you went out?

Student for the first two weets? (yes)" It was important for me to see that it was the job that I thought it: was I felt it important as well to see how the actual. job was done, where you get the equipment from. How the commuication was done between difrerent disciplines: between the numses - the practicalities of the job. 
It didn't worry me about going in and looking after someone in their home Yes it's different from the hospital but it's just adapting your basice skills to the environment. I. think it was more not feeling that I would be in total control. knowing if I wanted a ripple mattress how to go and get a mipple mattress.

But I reel that we identified that at the beginning of the first two weels. That was my learning needs for the pirst two weeks and they were reached.

KT $2.1: 1.9$

This student meiterated this point throughout the course together with others who felt that, although some of the thinges taught or concentrated on were too basic for qualified nures particularly if they becane repetitive, there was a need to have early and continuing support. The development and feeling of moving forward was important otherwise the learning became pedestrian and no new things were learnt. This is clearly demonstrated in the "Trying and Testing Dut" category and is closely linked to the extent to which students take up the leaming opportunities on offer.

The interpretation of learning needs by the student is not just a case of adapting basic nupsing techniques as deecribed above it is to do with being "in control" and Eeeing the whole picture or fitting the known competencies 
into a new setting. Simijerly another direct entry student describes her needs as having purpoge and dimection "-

Student oh yes. J. feel a lot happier. I'm not quite such a spectator, you know everyone's involved, one's care is valued it restores ones self estem. I do know a Iittle bit in which direction I'm going and another thing is I think the planning: you've got some input.

AM Is thet important to you - the direction?

Student I think it is becauge youre floting, nothing's $\tan i \mathrm{i}$ iar

AM You feel you ve got that structure now?

Student Yes, I reel I have, before there wasn't such a purpose to the day.

AM And now you ve got that purpose?

Student I think so. I ve got a caseload and it doesn't mean to say I'm not in a learning position and there isn't moom for change: obviously I value others apinions very muchn but I'm very much involved myself now. It's a big transition from being a gister in a hospital. Feeling that one's just being observed really and not feeling in any sense at home.

$\mathrm{KOL} .3: 3.1$ 
Many of the assumptions about adult learning that knowles (1984) identifies are relevant here. Clearly there is a Iink between self esteem and the attention that is given to Etudents" needs. On the face of it if gtudents expectations are met the learning is relevant and therefore valued if it is not seen to be melevant " such as meviging techniques then it is not seen as relevant and as a learning experience is ignored However this does raise questions about identification of leaming needs - how they are interpreted and how they are met.

knowles (1984) advocates the learning contract as a device to identify and to monitor students. Iearning needs. However his main eriterion for the identification of learning needs is the extent to which these needs met. the required competencies to be achieved. The contradicticn however is that learning needs are interpreted as competencies and pre-set in objective terms and $i$ what the practical work teacher has in mind to teach. The felt neede of mtudembs are ofter about how they fit in with their colleagues or the system but are very difficult to express in terms of an objectives; sills model such as the district numse currjoulum. This is not to say that students do not wish to be competent and indeed many of their expectations of what will be taught coincide with the practical wark teachers ideas. However the timing and the method of identifying needs are closely associated with how the gtudents feel about the experience. 
It is not difficult to see how knowe's work could be very influential. here, because it has a simple appeal in its structured approach. (knowles 1.994) for the student melevance is not just competency based, but has to clo with acceptance by the group and until this is demongtrated learning is postponed or at least intermuted.

Needs are also concerned with feeling in control and with having a purposie a more abgtract requiremert than something that can be quantified against a competence for the role of district nurse. They are personal needs rather than professional needs "The daily meetinge with colleagues are one measure of the way in which students feel they are accepted. It is a time when work is shared out and when al I. members of the district numsing team meet with each other and with colleagues auch as general practikioners or health visitors" An extract from the fieldnotes duming a rural and urban vigit in the third placement describes this activity :-...

As I arrive ku(student) is just going out to see a diabetic patient.

I am welcomed by $E$ (FWT) who is busy sorting through notes and taking to another" district numse about patients that have to be seen today.

This is called the community aurses" room, - small. with central table, chairs round filing cabinet and phone.

E tells me about some of the patients I shall see with ku and describes them as "a good galection". She explans that most of them know KU well and will give 


\begin{abstract}
us "good welcone". $E$ explains her colleague $i s$ of ${ }^{\prime}$ sick and therefore she is "running two caseloads" here and at -D another surgery in the town. All the time she $i$ somting through files and looking at her diamy.

Nursing auxiliary arrives. RU discusses patients she has to visit - apologises for giving her a "heavy patient" "ku arrives back and gives brief comment on the patient she has just seen. E says the night staff have reported that Mr 5 has deteriorated who is on kU's visiting 1ist. E asks about the wife. kU says that she $i s$ arnious but "doesn't want you to do anything"
\end{abstract}

During this interaction it is clear that the student is expected to take part in the ustal activities of this district mursing team. she is becoming familiar with the routines and is recognised as being an appropriate person to visit an ill patient. This pattern of meeting and talking together about patients and workloads is evident during at 1 my observations. The group may be smali with one nursing auxiliary to help the practical work teacherg but in some placements there are three or four district nursing teams working alongside each other in one large room.

It is also appament that the relationships that the practical work teacher has with other members of the team influence the student's entry into the team. One student acmitted that she felt estranged from the other menbers of the group because her practical work teacher did not carry a caseload of her own but "borrowed" patients from other groups to give broad experience. To gome extent this meant 
that the student did not belong to any particular group and at this surgery there were a number of district numsing teams working from the same health centre.

It is in these settings where students experience the patterns of district numsing work. The day to day experience of the students theng forcesi them to think about how they are accepted by the group it is present every time they interact with colleagues and with patients n

Fitting in with patients

As stated at the beginning of this section fitting in is am important in relation to patients as it is to colleagues. It is Jinked with the status of being a student and of feeling part of the workforee "Doing the work means working with patientis. The contact with petients is the mison detre for being a digtrict nurse. Five of the direct entry studente said they had moved out of the hospital to get back to the patient.

How petients perceived the student depended on the introductione and this affected the amount of control the student felt they had over the care and therefore how much they were part of the team. Studente wanted to be well known to patients: which again was part of being accepted as a member of the numsing team and therefore learning to be a 
distrit.: nurse.

The initial introduction to the patient was important and at its best included gone somt of explanation of the students past experience of being qualified nurses. Although eventualiy patients knew the stutents were on a course from the students point it was important that patients knew they were capable of carrying out nursing care. Jn the first placements when students were being introduced by the practical work teachers this was a sensitive subject - particularly for those who felt that the "student" label. was emphasised too much. It wes regarded at this stage as one of the measures of the practical work: teacher's mensitivities and how much students fitted in. The word "gtudent" was often geen by the students as a derogatory term - to denote inck of knowiedge and expertise and was closely aligned with lack of mecognition of past experience.

Al1 prectical work teachers mentioned the stuclents qualification as a nurse as something that had to be recognised and emphasised to patients. However some practical work teachers deliberately chose to send students to less complicated patients because of their lack of experience in district numsing which for some students was interpreted as 1 ack of recognition of expertise. 
The transcience of the student's role was often a point of interest to the patients and the comings and goings between coliege and placement was a point of conversation as I observed during my visits with students it provided a shared interest.

The relationships with patients were highly valued and good relationships were regarded as achievenents. Indeed it ars the patient's home that provided the main learning environment :-

student This is a little bit scary - how the patients feel. Because I'm with the FWT she does try to explain I. am a trained nurse. How the patients react to two of us there because you find that as my fwT has her own list of patients they know her very well " they talk about their own 1ittle things - you know there are their own little chats going on.

TFL $: 1,1.2$

Another student highlights the importance of relationships and their links with having a caseload and thus working as a distirict nurse $n-$

AM So you didn't actually have a caseload of your own? Student No, ghe'E working that out for me next timen $A^{|N|}$ Is that something you want to do?

Student Yes: I feel very happy to do it. It will be great 
going out on my own. I enjoy going with other people to see how they work, but obviqusly its much nicer out on your own ereating your own relationships.

$U E=1,1,1,11$

The following student: unlite the previous twon was a direct entry and was very positive about her experiences. In the first placement her comments about being a student were related to acknowledgement of previous experience :--

Student I don't feel. as if I'm a student when I'm with $A_{\text {a }}$ It's nice. (is it) Yes. As far as being a student the only time I've felt my back prickle is because I"vecrossed from the hospitid to the community and just in the first few weeks in college a couple of times when people would criticise the hospital. I would feel like jumping up and saying its not al ways like thet. (Ves)

But apart from that I've adjusted quite weII" Eecause you re not treated as if you bnow nothing. Its been stressed to us through college and A the PWT have stressed - we respect that you are a trained nurse in your own right. You've had valuable experience in the past and we are jugt giving you that post basic experience or a very specific speciality*

KT2.1:1.18 
Such positive experiences were often associated with being included in the discusion about care in the early stages which eased the way into caring for patients even when the student had mo previous community experience to draw on. Another student describes her first visits to patients in the first placement :-

AM

And how much were you involved in all. that? Are you realiy on the margins at the moment?

Student very much on the margins, I get the impression that was my fortnight for getting in. I mean I had a morning with the GP that was quite good. But for actual treatment and doing anything un." I mean I. helped get people out of bed and that, but if there was anything specific to be done I tended to be on the sidelines. I "yet $x$ was verbaliy included if I didn't do the acturi nurging. Because you can't herp it your fingers are itching to get in anyway.

But they'd ask my opinion you know - you've done a lot of orthopaedics - what do you think to thisbecause we had a hip replacement that had got a wound problem. so I felt part and parcel of it although I was standing on the sidelines looking in. I didn't feel like a spare part. I felt I was part of the ". "I was always introduced not as a student; - she is a staff numse y you know: to help her" work: in the community" whith I thought 
was rather nice. Father than being clased -this is my student. sort of thing - you could be anything.

In a lot of places they just introduced me as $E$ she is working with me, you'11 see her about for the next number of months. So I didn't feel like a lemon at the end of the bed I felt as though I was contributing something. There's a limit, if you're going in to do a bjadder washout you can't al. have your hands in. I really enjoyed it and $I$ felt as if l'd got a lot out of it as well. EX2.1:1.6

A further example was a student with experience in coungeling in terminal illness. Here in her second placement she destribes the experience :-

student Gome things we discussed. In some situations she was happy for me to take over -- in the case of a teminal patient where she actually sidid that I had more experience with that sort of thing. And I thought that was brilliant because not many people that I've come across wiIl do that.

Al' This was the first time you were out in placement?

Student Yers and I feIt that was very good. And I noticed that the patient was very relaxed with sister, and I relt relaxed and it was a very melaxing situation and I think they benefitted from it. It 
must have made them feel better to think that somebody with special. knowledge -..' not that sister hagn't got special knowledge - saying that I will know more about this. when it was quike a senmitive situation.

FT2.2.2.2.16.

Not lnowing the system presented particular problems in fitting into the expectations of patients:-

Student well, I will feel far more positive about knowing about the system to start with -one particular area was notes. Fatient' motes were kept in the nurse's drawer in the cinie. If it was my PWT' day oft and $J$ had to go in to see a patient I found it very stressful having to go into a patient without actually knowing anything about them. I think the patient expected me to know things about them that I didn't. Now that I understand the system a bit more and know what quetions 1 carn ask to find out about the patient it will. be a bit easier having heard the other people in the group talking: but there are go many unknown factors

$1601.1: 1.9$

Strategies for fitting in

Students developed varying strategies to cope. With fitting in, which for some meant acting ijke a student or at leats 
showing the expectatione of a tudent n-

Student It's not too long ago that I was a student midwifen and so I have learned actually to abolish my responsibility and I. have done the same coming out this tine. I always think being an elderly gtudent you are a threat so I. always make sure that I do git back and just listen rather than voice an opinion. Especially this fortnight because M doesn't know me and $x$ don't think there would be anything worge than me trying to take over.

AM. So that has been a deliberate ploy on your part, has it?

Student Yes I. have purposely bept a low profile unless she Mas gpecifically asked my opinion and then I have given it.

$N[2,2: 2,1,7$

Every student made reference to strategies used to gain acceptance and to maintain their place. The fact that students preferred not to make comments or to ask suitabie questions and kepping a low profile were common. Also trying to act. like an interested and positive learner was seen as appropriate to the gtudent role :-

Student I was slightly dubious to start with because of my previous role and I knew that she didn't like the presence of the hospice because she feels that she can do it. so to start with we were on sightly 
iffy ground. I think she felt that I might pretend I knew everything.

Aly How did you cope with that?

Student Ey not being deliberately ignorant but by asking lots of questions and not.. "She said something funny to start with she said $\mathrm{r}$ hope youre really kean about this coume. This was just as we were going into a person's housegand $I$ said, of course I wouldn't be doing it otherwise. I was quite firm about that. I'm not usually " " I'm a pergon who grins my way out of things, But I did feel quite strongly about that. So after that she was fine.

AM So you fieel you have got over that?

Student I think so. Yes. She gaid you know all that and $I$ said no I dor't, I asked her to tell me things. It was just finding out where we were I think.

Aly

Ard that was about the first week was it: what about the second week? Did it settle down?

Student second week it settled down." ". in fact it was the first day when she said that. When we went into the first patient (laughter). Heme I am going through this course and not being paid and she braaches that, but yeg it was al i right. $N Q 2.1 .: 1.11$.

Another student in her second placement thinks through how 
she will negotiate to get the best experience and still be an acceptable student :-

AM

$$
\begin{aligned}
& \text { Now you've only been here on what - two days on this } \\
& \text { block? (yea) It's very garly.do you think it's going } \\
& \text { to be different in the way you do establish a } \\
& \text { moukine this time round? Last time round it was a } \\
& \text { bit of getting to know the patients and not being } \\
& \text { given such a lot of respongibility perhaps just } \\
& \text { to go and visit? FAuse w. (yes). Do you see any } \\
& \text { difference this time round? }
\end{aligned}
$$

Student I think I shall be more positive about regotiating what is actually expected. I think I didn't really know. I was hesitant about itn I think people saw me as somebody who could be threatening and $\mathrm{I}$ didn't want to be: and therefore I stood back a bit. But thinking overali it doesn't mater who you are, you need to be positive and if you are seen to be threatening then its just too bad.

$A M$

$$
\begin{aligned}
& \text { Have you had any negotiation at the moment with the } \\
& \text { group, or particularly with your FWT: or is it too } \\
& \text { garly? }
\end{aligned}
$$

student well, I think I've startedy I think it's too eamly to meally tell.

A

And have you set in your mind the sort of experience that you want out of this block? I mean have you identified quite cinary for yourselfo 
Student I know what I would I ike, but I don't know that it will actually happen. I would like a smal caseleat. I'm not quite sure how possible that is. I can feel. the difficulties with the job. Somebody is not there or somebody is away, the question is raised, what is J doing on Friday "um $t$ "m not sure how supernumery I rea as a student. I'd like to be their student? although I'in very happy to work. "um I'in my own worst enemy probably" if in very keen to learn so I want to take al the opportunities that are availableg I don't want to miss them: sometimes experience doesn't come every day" if you see it you've got to grab itg and you ve got to be adaptable. I saw that on the first day actual1y. I saw the opportunity to go out with one of the qualified district nurses to interview a new patient - I hadn't sem that I felt I feIt I wanted to. She said she'd take me: go I sajd - yes please.

$101,2: 2,7-9$

In the first placements it was arting like a student and being taught: asting questions but not being too confronting As the responsibilities increased and students took on more of a management role it was related to change and a sensitivity about making changes. It was unanimously accepted that the petients belonged to the practical work teacher and that no change would be made without asiing. In some instances these changes were not even discussed if it 
was thought that it would upset the balance of fitting in. For the sake of mantaining this balance opportunities were at best postponed until after the course or at worst lost.

Fractical work teachers had $i d e a s$ that stuclents should be both interested and motivated" atributes recognimed as contributing to a good student. As previousiy noted students should also act in a fairly subordinate role taking on responsibility as the practical work teacher felt appropriate. One practical wort teacher had a stated strategy which she told all students and which was that she agsumed they knew nothing about the community and "etart from scratch" and for her previous six students it had worked - all had had previous community experiencen it is clear that deviating from the established routine of teaching would be difficult.

It was not the stated intention of practical work teachers to restrict students leaming in this way but even where there were very good and trusting relationships there was reluctance to challenge fundamental ideas about practice such as how work is organised and delegated - the justification of decision making. Asking for facte and querying treatments was a fairly easy thing to do and bringing new ideas from the college was something practical wort: teacherg usually welcomed. However the touthy gubject of why unneceseary visite were made or why some patiente 
were even visited at a l. was not broached with the intent of challenging the decieion naking process of the district nurse. This is not to say that patients were not discharged by the student, they were - as a jojnt agreement with the practical work teacher or if the student had admitted the patient onto the caseload. In this case they were then seen as the student'g respongibility " Felationshipe with general practitioners was amother sensitive area particularly with respect to dominance by general prextitioners and to teamworl:

Of course one has to recognise the practicalities of the situation. Decigions about patient care cannot be made to facilitate a learning exercise and quite properly the practicel work teacher has to control the deciaion making process: but there were instances when students did not feel they coutd discuss their jdeas without rigk of offending or causing some distuption to their learning.

\section{Discussion}

Fitting in to both the environment concerned with colleagues and with patients takes time and energy, but is an timportant part of the Iearning process from both the students and the practical work teachers' perspectives. Students quickly recognime what they are expected to do and try to conform in varying degrees to these expectations. 
An obvious and explicit consideration for their feelings and acknowledgement of their expertise, their past experience and their requirements for learning: all add up to good experience for the student. Fractical work teachers al. express a desire to take into account the students" learning needs and discuss the students' ideas "However they only amend the programme, although that may be all that is necessary to give the students a feeling that they are being taken into account" that their self i being valued at was aligned to "not feeling in total control" and also to having "a purpose to the day".

The reeling of increasing confidence i.g linked with increasing pesponsibilities and opportumities as part of the tean. It is talked of as adaptation to community, but this is too simplistic because it applies equally to both those who have community experience and thage who have not. it is certainly the working in a different contexts but related to that is working in a particular role in a different context - the rale of a digtrict nurse. Feeling like a colleague and experiencing what Meliz and Macmillan (1993) idealisticaliy call the "colitegial relationship" able to share ideas, ask: each other's advice and generally assist one another in their work without appealing to rank or length of eervice as a means of bargaining power" (ibid p74) is important in the ritting in process. This relationship is influenced in turn by the relationship or status that the practical work teacher has with the group. 
The patient environment it seen as an important area of learning by the student and acceptance there is equally important. It gives the students game continuity and a feeling of belonging. Although practical work teachers and students refer to the importance of continuty for learning purposes it is equaliy important to the students for purposes of belonging and a feeling of familiarity. General talk about the studentes progress through the course was reassuring. Faibure in patient care was failure indeed because it was Jinked with numsing:

Strategies for fitting in were adopted by a 11 students -some explicitly described them others made implicit reference such as carrying out techniques "how the practical work teacher wants me to".

Strategies for adapting were not only concerned with colleagues but with the overall routines of practice so that they get an overall view of how things work. Therefore the sequence of things taugh is important. Concern for specifics can be imitating when students do not have an overview of how the system worls. The concentration on adaptation of techniques is a very small part of the adaptation requimed to manage practice as a district numse. Al1 students have a broad view of adaptation of which technical competence $i$ s only amall part and which may not be the appropriate starting point. In Eenner's 
(1984) tems the students saw themselves as "experts" in their previous areas of work. The notion of starting as a "novice" is not acceptable and indeed does not appear to be appropriate for those areas of pratice in which students feel confident. It is also clear that students required Eupport from the practicaj. work teacher to regain confidence in this new setting.

The length of time the practical work teacher gpends with the student varies. It appears that the inner city placements give respansibililty earlier than the rural and Lrban, but there is no obvious explanetion for the differences and both express similar difficulties as can be seen from comments across both years of the research.

Climate setting (knowlesige4) could be another terin used to describe the strategy required at this wage in the course. In the terms described by knowles (1984) it again seems to offer the strategy that would help students to fit in to the setting of the community. While not clispgarding physical climate, he considers psychological Elimate even more important. His seven elements such as " mutual respect" which values experience: "collaborativifess" in using the resources of peers: "cimate of mutual trust" with teacherg (ibid p14-17) are all echoed in the students comments about their learning needs in this category. However the achievement of this climate is through the four basic 
components of any educational programme which he describes as follows

- objectives - outcomes stated in performance terms using specipic action verbs

- strategies - activities and res ources to be used as - evidence of accomplishment - measupiment of the objective - criteria and means of validating evidence - the validity and the underlying authority to measure evidence of accomplishment.

Apart from the overlaps in these componenta they do not sit well alongside the elenents for Elimate setting. On the one hamd he affirme his humanistit stance in the elements of climate setting and yet he subcribes to a behaviourai objectives model in his educational programme "This reflects very well the contradictions the students have to face in their plecements and they begin to emerge in the need to fit in and the strategies used to do so.

How well students fit in at the beginning of the course sets the scene for the coming placements. Although studente are resilient to perceived inconsideration and disinterest it takes up their time and energy to establish and maintain an acceptable mole "If students always feel "on the margins" then they may have to postpone some of their" requests for learning. Therefore an effective learning environment is estabished by attention to this fitting in process and is Iinked to the extent to which studente can utidise the 
learning strategies described in the next category. 
CHAPTEF $S I X$

"TFYTNG AND TESTJNG DUT"

Introduction

Duming ach placement the student engages in activi tes which are related to the work routines of district nursing practice. In learning to be district nurses their learning is inextricably linked with what is perceived as district nursing work.

The pervading routine in all placements is a cycie of visiting patients and returning to the base? the health centre, general practice surgery or eidinic "to undertake Various activities such as meeting colleagues, collecting messages: contacting agencies and attending mettingt: The timing and frequency of this eycle of events varies from one placement to another. However it is a pattern that $\mathbf{j} 5$ established early in the first placement and continues. more or less unaltered throughout the course.

Dne of the prevalent activitieg in distmict numing is not unexpectedly: visiting patients. It is this aspect of work where the category of "Trying and Testing out" is most apparent. From the beginning of the first placement the 
student is inducted into the role of the district nurse by observing the specific daily routines of the practical worl: teacher. Learning by doing is crucial in this category. Several students talk of itching to be imvolved and learning more by themeelves. They seek increasing independence from their practical. work teacher to test out their ruture role and to be more self directing in their work and their learning. The students make use of their past experience by way of comparison and by extending their experience. However leaming through self-dipection is dependent on continued access to the practical work teacher otherwise learning can become repetitive and demotivating.

However there are limits to thig sort of activity demongtrated when students want to make change. They are I.mited by tbe fact that they do not have control of the caseload and they cone up aginst attitudes that do not easily accommodate change.

Students are lien to check out their practice with the practical work teacher and indeed it is one of the students. main expectations when they begin the placements. Friorities for learning at this early bage are expresged as knowledge in relation to direct patient care such as nursing techniques or health and social services that can be offered to patients and to their relatives. This is aligned with basic competence and confidence and involves using their 
past experience.

Dependence

In the rimst instance students are dependent upon the practical work teacher for learning about practice. As they become mork confident they become more independent and eventualiy take on more of a management mole in relation to patient care, but within the limits of the caseload of others :-

AM

What do you think you should be getting?

Student A good basic knowledge of what the community is mbout, and how to go about,-becaume I gaid to her I fnow very little about giving petients advice on seeking benefits, who to go to - with what - a particular problem whether it's the health visitor. social worker - who should be contacted rifst. Things like that, which is what I wonted: and ghe's going to ampange for me to go out with the social worker, you get a beter ingight into whet they' re atublaly doing. And realiy my confidence at being able to take on this caseload and cope with it. $=0$ that I reel confident in what I'm doing.

Although in the evening I was in charge and used to delegate the work they were ultimately the day stares problems and you're only in as a backup 
service - and how much social service help you put in. I want more of that, I want to know how much to put in how quickly. I have this fear of swamping people and I clon't think you should do that otherwige you have nothing else to offer them at a 1.ater stage.

$E \times 2,1 \div 1,11$

Again for two gtudents who have had previous experience the checking against the practical work teachers" standarde for basic numsing techniques is important :-

Student I find it ugeful because you metuliy learn the proper way of doing things. When I first started a year ago on the digtrict I was given a bag and an injection bag. There is your bag and that was it. She has sorted a 1.1 that out and it has been quite a joke between us because my bag was in such a mess and she has sorted it out. And I feel better about that now - the fact that is the way things should be done in a professional way.

KU2:1:1, 5

The need for assurance of competence is stated in a different way :-

Student Algo there were so many problems that you face with the patient when I was staff nurge Thing you don't know. I used to feel incompetent even though 
you cover it up all the time, because you never let yourself down. You used to get into the car and think, gosh I don't know how to go about this. You go back into the team and everyone else is busyn everyone else $i$ in answemg the phone and you end up temering your hadr out.

When I was out with the FwT I had time to go to the social services, find out all ebout the benefits. who gets what and the rest of it, which is really good. I've really enjoyed i.t.

$\operatorname{NC} 1,1: 1,4$

For a gtudent who had been not been carrying out practical nursing tast it was a revision of the basic techniques aAM So what do you expect of her what do you expect your FWT can do?

Student I think guiding me along the right limes I'm very out of practice in the basic physical carey which she is seeing me through. Ear syringes which I thought I could just do: but I saw her asking this petient whether he had got perforated ear drums and I thought oh there's loads of things i didn't ask him. That sort of thing I'm very rusty on. The practical part which I have told her I am go we can concentrate on that. Catheterisation and thingsi in the next session. We had a lot of talk about the care plan that we have to do but I couldn't quite 
see who of my caseload last time I could actually do so we have to rethink that one through.

$N Q 2,1: 1,1.4$

For another dimect entry gtudent it was a bit more general but still concerned basic numsing care u-

Student I've got to get used to everything being in the patient's house, not having my own equipment, because in the hospital you lay your trolley for what you want, but you go in you don't really know what's in there. We have a dressing pack in hospital" here you've got to make your own: like that Hampshime Dressing business that's what I've got to get used to. And wearing the same aprom: like you go into a house and the numse has left an apron there. Eut I prefer to wear my own. and a different one for every house. But it don't know how -- as regawds getting equipment and dregsings. that"s a bit hard. So I'11 have to check up on that when I get back I didn't want to say much about more confidence. To me it's just moutine -- I've got to get used to. Difrerent routine after so many years in hospital.

We11. to meet people in their own home and have her taking her dressing off with her dirty fingers. It does take a lot of getting " " " you have to switch ดีค

DC.1. 1.:1.5 
Here the feeling of incompetence is evident but the opportunity to check out is available and used by the student in her own time and has to do with attitude as much ass knowledge.

The routines of practice determine what experience the students get taught and how wejl the gtudents' Iearning needs are met and this has to do with the pace of work, aften commented on as "being busy" "For direct entry students this is an obvious disadvantege for those who have community experience their responses are indxed. Some wish to be busy as part of feeling they are acting like district nurses: others 1.ike the opportunity to take things at a more gentle pace and use the time to do things properly. However for al students there $i$ an optinum level of "busyness" beyond which it is counterproductive to learning.

It would take a resiliant student to withstand the work: directed experience described by the following student in her first placement. n-

All What are the eorts of things you have been doing?

Student This is where I have been a little disappointed because the prartice is very very big. Not the GF practice but the health centre practice is very big. I have been used as a double up all the time. We have gone out every morning and done several 
general cares for everybody else. Not one of them has been oum own so I have been used as a double up m My Fw knowe I teel like this. There is just nothing they can do, so in that way $I$ an a little bit diseppointed with the placement practice because it ig a very busy one and 1 don't thint she (FWT) is able to give me the time. We have been going around al 1 morning and doing complete general cares where there are two nurses needed. I was always with my FWT.

Our programine was lovely. Most afternoons it was going to be teaching with perhaps one or two visits. That never came of because a district numse was gick and $L$ went sick and we were just having to cover for everybody else every day. And even to the last day of filling in my blue book [Fecord of student's progress]. We have to fij. in our report - we had to do that in ten minutes in pencil because we had to go back out again and do another call. for somebody. so in a way I teed that placenents were not considered.

I mean to me --..-... is the wrong place to put a student. It might be a very nice place to put a student for experiences but $x$ don't think it is a place to put a student to learn. especiályy, permaps, direct entry like me. Because all I have peally learned is to do a bedbath at home 
every day without exception, which isn't their faul. Why have a student district nurse there when they can bring another nurge in to meet up. $N I 2: 1: 1.3$

This student: previously a ward sister: did not feel she needed to learn about bedbathe or indeed asepsis - another thing she was taught that she felt was inappropriate. The inain problem here was the work driven practice that directed the opportunites for Iearning. This situation was aj. Jeviated when the student took on responsibility for a smali group of patients in the second placement and it was not untij the practical work teacher was moved to another location due to other staff changes that the situation was resolved. Despite all this the student remained highly motivated "

Fractical work teachems are in many instances unable to control the work situmion. In trying to protect their students from the vagaries of workloads they work extra hours and rush round faster. For gtudents and practical work. teachers alike this causes frustrations and difficulties:-

Aly I know A. ig not in a perfect position as regards people taking work off her" My feeling is and again this is taken from what other PWTs have said -.. is that they shelter the students from heavy wark10ads. They work into the evening just to cope with the student. Have you found that? 
student I think: A. would be inclined to do that and she has been inclined to do that g but on the days when I've known they are going to be busy or she is going to be busy I. ve said to her I can do another couple. And I actually had to convince her that I'm happy to do another couple. And after the first time ghe let me do it.

So yes ghe has been very protectiven but probably being the person $\mathrm{I}$ am $\mathrm{I}$ don't like being protected too much. I've fought against it and I've said to her l.et me do that. (mm)

Like I maid before J've done things and then told her I ve done them. Um. " with regard to things like phoning social services and going to talk to the doctors. If there had been anything that I had thought, this is meally not the way $A$. would have done it then I wouldn't have gone and done it I would have checked with her first. Eecause it still is her" responsibility" KT2. 3 : 4.9 .

This student had a very good relationship with her practical work teacher and felt able to take the initiative in counterating the protectiveness, and in trying to hejp out in situations where workloads are heavy "Thig was in the third placement when students were taking on more responsibidity. Where this sequence of increasing 
mesponsibility falls down and the students needs are not met due to worlolods students experience frustrations and a feeling of rejection and are unsure how to resolve the situation. When this happens in the third placement it means that the newer skilis or management do not get taught presumably with consequences for the student's future practice. Or perhaps it is more subtle than that and the recognition of what can be achieved or what should be posejble in district nursing practice? such as identifying the patients and the commuty's needs and bedng proactive rather than reactive, are not seen as priority,

Students identify specific things they want to jearn in terms of competence and begin to test out their competence as they accompany the practical worls teacher in the first placement. The length of time they spend with the practical work teacher vames and again it geems to be a routine that the practical. work teacher has already established. Firstiy the student works alongside the practical work teacher: gradually being given more respongibility as they take over the regular care of a small number of patients. The variation in time as to how quickly the student is given responsibility for patient care seens to be besed on the practical work teacher"s perception of the level of confidence or ability of the student. 


\section{Independence}

In the early stages students check out thejr jearning as they work alongside the practical work temeher but it is not until they are visiting patients on their own that the full strategy of Trying and Testing Out ig used :-

AlM

$$
\text { How's it feel to be doing the worl yourself? }
$$

Student It was surpriging actually. After ten years nursing experience going and dressing somene's leg licer on my own - I. was so very nervous (were you) Um. " but after the " " it was similar sort of feeling when you were first allowed to do something on your own when you were training - in the besic training. It helped a lot going on my own berause when you re with somecone exe youre not having to think for yourself: but when you first go in on your own you've got to think for yoursedf" You've got to make sure you ve got everything there. check you ve got enough dressings for the next day so that worked out welly yes. It's helped me to see more of the job. To do more of the job real ly, 1672,2 ․ 24

Here the student ic concerned with maintaining care and camping on the established routine as a start to her increasing responsibility " Being alone helps leaming for another direct entry student the decision making was more complex - about referral and amount of care to give a- 
Gtudent well. I thimk you learn new things every day " I think that's inevitable. I don't know that you learn what you think you want to learn, I think it just happens really. I went to see a patient yesterday. which was very interesting. He was adinited apparentiy last night as a potential cardiat infarction. I went to visit for another reason - I thought that was interesting. From what my FWT said he didn't want to go into hompital. He didn't like the iclea. I thought from my hospital experience that when the doctor came he would be admitted and I was very keen to run back and find out.

My FWT I think relt that there wasn't anything that she was necesarily going to do: Therefore the patient was well able to ring up the doctor - I gaid supposing the doctor didn't come. But I think I would have phoned, because I felt that he would be admitted; that I would have phoned him back and found out. It's interesting realiyn looking at it from different viewpoints - we had different ideas. I. Gon th think either was right or wrong but it was interesting.

ÂI So you mull over what you've done? (yes) would you test out your ideas, like just talking now but with your FWT at some stage?

Student we1. I tested them yesterday "It was interesting her view from a district nurse's point of view and a 
hospital point of view, it was different. I think the answer is that one is so tremendously mesponsible when one is in hospital, for patients. and one's just trying to get the balance right as to how much responsibility to take, because one can only do so much. But even in hospital a nurge is responsible for themselves somehow utimetely overall you feel responsible if a patient dieapears off the ward and goes inissing: you teel responsible for them.

$101.2: 2.15$

The use of previous experience here is important and the contrating views give rige to thinking about respomsibility.

Decision making about how inuch responsibility to take in terms of patient assessment is a priorjty for all students and ig seen as the focal point of managing caren In similar fashion to the previous student another direct entry student identifies her priorities for the second placenent n-

Student I think the main thing is assessing when to, how often to visit, and getting other agencies involved really . That was the main problen $I$ had in the first block. $x t=$ easy in the hospital, saying gomeone should be turned two hourly: and you knew: hopefuliy that everything was going to be done. But when someane is in their own home and you know they need the exact type of care: you have to 
compromise, you have to come to terms with the fact that: you can't do that, so you have to bring the neighbours and people into it as well "I think if I can get that established I'm ok.

Fiv1 $, 2: 2.8$

Assessment is not just about use of services or referrals but al wo about direct care. It is seen as ore stage in the confidence building procedure n-

Student I mean if a new patient comes ing the FWT hands it over to us to go and do and it's just by chance that we've not had a chronic sick person. You know they have just been early discharges or wound assessments. Then we've cone back and discussed it with her - I've done a b c - and whether it's right or not:

There was a discharge from hospitals a wound, and I said the treatment that I thought, and I wasn't really happy: I didn't feel all that competent and the mext day my FWT. . " both of LIs went in and went through it with the patient, and I was quite happy. And if I was faced with that same problem again $\mathrm{I}$ would know what to do. I was right anyway but I just wanted her to messure me, to say I was right. ML1.2:2, 7

Fractical work teachers describe the process of trying and testing out as part of the progranme they plan for the 
getudent.

Students talk about checking up: discussing the problems: terying things out, and link this to increasing confidence and movement towards greater responsibility. Self direction in learning is part of adult learning theory (knowles 1980 , Boud et a i 1985)" It is only useful. however when it is purposeful and when the students know what they are to Iearn. For students on this course there were times when self direction was not uesful and it occumped when practical worl: teacherm did not give strong enough guidance to the studente or when they were not accessible enough to talk about some of the experiences that students had undertaken.

While wtudents are looking for a weans of checking their activities, reassurance is not always useful to learning unless it is meaningful to them. However being uncritical can be seen as not taking enough interest or as not teaching: as evidenced by the following experience :-

AM

We were just discussing a minute agon. " you made a comment about how muth writing you had to do while you've been out: to do with your assessment visits. Is this because you wanted experience of assegsments anyway?

Student Yes: I did desperately need experience op assessing patients, here in the community and it is part of our becond block as well. I. cortainly have been 
doing a lot of it. Apart rrom assessing new patients, which I do on my own, $\mathrm{I}$ saw $\mathrm{C}$ my FWT do one assessment and we went through it together atterwards: and since then I ve been doing them on ny own, then coming back and discussing them. I've also been re-assessing old patients. because I'n supposedy taking them over during this two weeks.

AM Are you able to spend more time with your practical work teacher? Last time it was pretty hard going.

Student She hasn't actualy been out with me on visits thig time, but we have discussed thinge afterwards y yes we ve had some time for discussions.

$A M$ Has that been ugeful?

Student Yes it ig useful. Any problems there are or anything you think of that you incur " "oh I can't remember what $I$ was going to say " $A n y$ problems she sorts out and anything you might not have thought of , you know, that you don't know how to arrange or whatever: she helps with that, We havn't had a very structured timeg I'm much more my own boss, but $c$ says to me "You're so good there's nothing mome I can teach you' "I'm sure there's an anful lot more she can teach me, but it's a question of putting your finger on it and lnowing what. 
Student A bit of both really" its difficult to identify when somebody says you're so good d. don't need to teach you anything! yet you ame here to be taught.

Aly So there must be a bit of conflict there.

Student Wel1, i did something the other day, I did this policyg I don't realiy think I'm very good at these asseswing things. I did this nursing care p.lan. She Iooked, she said I've read a book at home: but yours is much better.

I. thought I'm sure that's not true " She's very good though and I think it's good for people to be positive.

VE1.2:2.2 \& 2.7

Trying and Testing out is not just a case of going off alone: there is a measure of judgment required by practical work teachers in order that they can give an opinion about progress. Self direction is only useful. if something is learned and if the student is aware of what has been learned. False reassurance although given with the best of intentions is not helpful.

Students also learn from decisions they have made that have been judged, by their practical work teacher to be wrong. Here the student describes the feeling when the decision made was more to do with giving nursing care rather than 
organising services that would contimue to promote independence for the family $"-$

Gtudent $Q$ has given me a new patient to aseses and monday I. Saw one no problem. Yesterday I gat one I had some problem. I feel I didn't do very well there to be honest. Because the GF wated Us to assess the lady for a pressure sore, wher I got there the pressure sore was healed, which means that the ge most likely never went to see the patienty just passed on the message thmough a message bureau which very orten happens.

She had a stroke way back in Januaryn the real problem is putting her in the bath, not the pressure sore, whith he railed to assess himself. So I feel the lady meeds a bath at least ance a week. Ghe has quite a dense hemiplegia on the left sides she can't get into the bath herself, there is a husband. She is seventy four. the hustand is the same age. There ig a brother in law who ig eighty nine. Between then they do the numbing care. But they reel they are getting too old and need help. I went in for one thing and something else appeaped. I'm arraid I didn't sort it out properjy $y_{n}(\mathrm{~mm})$

You see if you go with one thing in mind, and there is something else I telt distorted if you know what I mean. I couldn't settle it once and 
for al - there and then so I thought I had better find out. (nm)

Next time if t have a gimilar situation happens I. am geared for ity go I will know what to do next time, So I don't think I will have to come back and diacuss it, I will know what to do" I will be able to decide then and there. Then I. would relay to o what I had donen

$5 T 1.2: 2.11$

The practical work teacher is concerned that this student learns "to encourage self care to kepp people in their own homes - getting away from task-orientation " Her discussion with the student has turned what could have been a negative learning experience into something the student regards as Valuable

As students go out on their own they are better able to control the sitution so overcoming some of the difficulties aseociated with the high workloads of practical work tenchers

The following student who found in the first placement that she was very busy and only learning about bedbathing now vimiting patients on her own. Self direction has a purpose :- 
Student Beculse I am now goimg out on iny own. (ame you?) Yes Wednesday I went out to do four patiments on my own and it was tremendous I don't know why but I had time to do it. "And this time we don't seem to be doing everbody s double upg.

AMI

So you've been with your FWT a bit but the actual going in on youm own and having your own patients: apart from feeling they are yours, what else about that has helped you to learn?

student Berauge when I go with my FWT I usually git there and talk to the patient while she does the work. By going in on my own I do the work. I do hands on and although it was only two lots or eye drops: one general care and tablets it was totaliy different that il was able to talk to them and ask how they were w Had they got any probjengy check their catheters: and not stand back and watch, but was able to do things oh it was totaliy different I reality enjoyed it. And $x$ could still discuss things with M.

A|r|

Did it a dso spark off other questions about those patients that might apply to other patiente? You talk about the fact that you came back and talked to your PWT:

student well yes. The first lady was actually my case study and I'd found whe other eye was infected so I 
actually instilled ch loramphenical drops in the other we and give her information about cross infection and gverything like that. And the lady with tablets instead of sitting there and talking to her I was able to see that she hadn't taken her tablets and although you couden't say much ilke is there a problem I could see what tablets she was on which made looking at her different (right). Because the amount she was on: you gtart to think well why is shen It starts to mean things doesn't it) ( 6 ( $y=3)$

And even the lady that $I$ got up she had a fractumed remur and CVA and even putting on the calipers its a bit like a corset - it means different things "You could gee exactly how it should be how she was waking and how independent she wanted to be. ( $\min )$

Because I think when you stand back and watch somebody else do it you don't realiy register you watch them do it but you don't get into it but doing it on your own you really get into them and their problems, and what's going on "I looked at it more deeply.

$N \operatorname{Na}_{2}: 2,4$

The increasing responsibility is related to increasing confidence :- 
Jearning and remembering and what helpe " But its to do with confidence as wel. I think.

Student $x$ think these two weeks have built up my confidemes to go into someone's home and look after them in their home which until I went in on my own it wouldn't matter however much preparation I was given I wouldn't have that confidence tili. I knew I'd done it on my own "I. can spend a year going in with gomeone elee and I sti11. woujdn't be a hundred percent confident. That's just men $K T \div 2: 2: 7$

Working in the learming context helps students to think through things on thejr own, to experience for themseives not only in the cognitive but also in the arfective doinain.

Again increasing independence allows the student to see the importance of working within a patient controlled environment and how decisions in the home are linked to the management of other work. It gterts to provide a broader View :n-

Student $I$ "in very much aware of the difference in the home. the difference in the position that you are in.

AM You as a numse?

Student Yes: that it doesn't matter how strongly I think 
something, I" ve got to be absolutely sume that it's what the person in the home warts: if poseible to get then to make the moves if they something new or something different. "er to say I actually want it. To pick up the phone "One of the patients I went to see this morning had in fact made a decision " He wanted to phone the sister in Day Care while I was there. So we thought about what he actually wanted and then I tried to put in to action.

I asked him to do his exercines this morning but he wasn't very keen on doing... a so he accepted bargaining with the exereisesy and then we just did what he wanted. We didn't do one or two things I wanted becmuse there was only a jimited amount of time.

Its difrement on the timing, you' re thinking all the time, how much time have I got, how much time m I going to use, what am "x going to do next. That's a very strange feeling: I'in still coming to terms with it. How much time to spend on each one, and yet give good quality care.

I've thought of it even more today when I'm with Mrs Dawson that I really wated to know " " " "to be able to test the urine if possible . However when you've got M"s Dawson standing up you can't put the sticks in the thing and you havn't got anyahere for her to sit down, so you wate a lot of time.

I understand how it's much easier to in and out the 
doors guite fasts because you've got this ongoing thing of the next visit that you spend more one visit perhaps with one person and less the next visit. And sometimes you can say, well I've got a lot to do today, would that be alright for a short vimit, you have that possibility: so thats a whole new area

KOL $, 5,3,11$

The importance of the context here is apparent. Trying and testing out in the reality of the patient's home albeit within the given parameters of the caseload controlled by others provides good Iearning pportunites. It demonstrates the patient controlled environment and the autonomy of the district nurse "The coning to know of these complexities of the district nurse's role are seen through the doing. Underlined by the student's rowisation of "a whole new area" A.though the students feel. they do not have control over some of the decigions they can make: within the home they have a great deal of autonomy and this adds to the value that they put on this aspect of the course and to directing their own learning.

If the continuing support from practical work teachers is not forthooming the increasing responsibility is of littie benefit. This student in her third placement was very despondent about the continued support she was receiving a In the main it was a mepetition of what had gone before in the first and second placements when she felt her learning meeds 
had been met and had enjoyed the student role and relt a part of the practice. The expectations for the incmeasing responsibilites were not met :-

AN

I suspect from what $E$ (FWT) was saying this morning that you re short staffed and that you're not able to see her so often. Has that affected your expectations of this placement? Has it been difficult to meet the expectations you had?

Etudent I jugt feel at the moment I'm being used as a pair of hands; Although it's nobody' fault I think there should be - if they're going to train district nurse students there should be people who can be called on if the gtaff are short, so that we can get the cover that we need and the experience that we need and heve the time with the practical work teacher that we need. Which I havent got.

E. has been doing the cinjes and it $x$ " $v$ bad any problems I ve really just had to figure it out myself without being able to ask. If ghe's floating about outside then I've managed to catch her and say. But it'g difficult to keep on intermpting clinics. It stops her trein of thought and its djeruptive to the patiente as well. I don't like having to feel jike this. I can't keep coming back here al. the time, whereas before we perhap met at patient."s and $T$ could chat to her in the car or as we went out. (It must have been very difficult) Yes 


\section{it has}

AM

Have you had anybody else to help out of have you had all the work to do?

Student Yes, we've had other people on duty, but they've been covering other areas and so they ve been covering the work and then going back to their area It been quite busy. I don't feal particularly happy about it this time (mom) \{pause?

A|M

What were you hoping to get out of thie placement? I think you said it would be something to do with management.

Student I. was hoping to have a set of patients that I could go to - a small caseload - that I could go to every day and if some new referralg carne in then I would perlapas have them. If I got too many then I would drop some of the onesis I had been doing before. I would keep the same caseload but include the new assessinents.

Feally I haven't had much time to do that I've had the patients who the other person hasn't had, or she' had some of my patients some days - it's been quite difficult really. I feel quite angry - I know distict nursing isn't meant to be stretching and glamorous. But there are things I ve gone and done "um. I feel I could be using my time better elswhere. Perhaps Mary is a case in point. quing 
in to wash her every day is not quite what I should be doing .

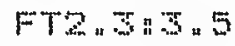

The practical work teacher's views about the student were that the needg were being met although she saw some difticultis a The perceived lack of the student: 5 ability to cope with a caselaod was the reason given by the practical. work teacher for not giving may help she in tact refused help for extra staff: "I thought mo 1 et her get on with it" c clezrly there is a difference between the perceptions of the student and those of the practical work teacher as to what the student's needs aren.

The observations I macle during the half day ispent with the student confined this state of atfairs and the frumbreions of the student relating to jucmeasing rebponsibility for caseload. It was not dealt with by the nursing officer or the college tutor" Both said they thought: chat the student should be mble to sort the problems out " Most. help came from a fellow student in the neighbouring cilinic.

The student continues to be motivated but is looking for Ways in which she can get help. The experience here is in danger of becoming meaningless and routine. Tt is no different to what the student has experiomred before. 
In a gightiy different way another wtudent who had previous community experience found the plecements "boring" and "unstimulating" in this situation the practical work: teacher did not have a caseload with the intention of being able to spend time teaching and drawing from the caseload a variety of patients for the gitudent to care for. However the "busyness" of the practice demanded that the practical wort. teacher had to help out and meglected her teaching duties. In this situation the student is using her past experience to draw on : $:$

Student I don't actually think this health centre is that buty compared to others: sa I'in giad I've had the experience to know that I. won't be able to spend half an hour - three quarters of an hour with each patient, or talk ag long as I. like Q0D $1,3.8$

The student also used her past experience and knowledge of ordering supplies, communicating with generel practitioners and what to do if someone died. She felt the coljege ghould cover thege things for those ljke her who didn't gain such information from practice. This led again into the fact that her practical work teacher was too busy a-

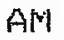
Would you expect to get that (teaching) out heremin practice?

Student Yes" maybe so actually um "yes we should do I suppose. I don't know if they have " "er" I think if 
FWT didn't have a list to do then they would have time to structure themselves to teaching.

Aly You seem to be saying you have loads of time to mpare (Well I do)

Is it because your FWT doesn't have it?

Student Yes. She"s doing a Iist every morning.

A|r| Is that her choite?

Student I think she has to "There"s two people on holiday, I. in not sure what the policy is $001,3 \times 12$

The student goes on to list some of the things she would like to be doing such as teaching and health education and a greater variety of patiente rather than as ghe says:-

student The patients I've had have been long term and you just carry on with the treatment as before. $001,3,322$

The practical work teacher seemed to have a different view of what the student reeded, and felt that she had been with the student too much last time and so " I've tried to leave her alone uniess she wanted help because otherwige if you ve got someone telling you what to do all the time she wouldn't think for herselt" The practical work teacher clearly thinks she is doing the right thing for the student. The fact that making decisions about caseload and delegating are things that have been "rissed out on" because of workloads 
and staff sickness is rationalised by the fact that the student has had previous experience in communty " There is very little contact between this student and her practical work teacher even in the area of patient assessment which is mentioned by al. students a being an important new area for J.earning

The half day I spent with the gtudent involved two of her patients and much of the discussion concermed what ghe wanted to do or saw as the role of the nurse that was not borne out in the experience she was getting. Her decision to leave district mursing for something where she was able to have more abtonomy and get more satisfation may have had something to do with the fact that everything seemed to be concerned with the maintenance of long terin care and elderly. The fieldnote extract from this mtudent s third inner wity placement describes her feelings as she vigite petients:-

Next visit (on foot) to get Mr H up ror the day centre "Second floor flat of a large unkempt building - grafititi on waI 15 and smell of umine on stairs. Well equiped rlat with electricul aids. Mr H hag a whee.t cha ir.

I. Sit in a corner of the room and that when esked, to Mrs H. about the lack of shopping facilities.

When we are walking back to the health centre, $Q$. . says she finds constant visiting to "ehronit patients" quite boring. She asked for "two nurses to $v i s i t$ but nothing forthcoming: No one seems to care" " $Q$ explaing how she 1 eft a note for the nurse at bag up the laundry 
for collection by the incontinence service.

"I knew the home help wouldn't get there

in time". They said (nurses) it wasn"t

their job.

When $Q$ asked her practical work teacher

what to do " she agreed with them"

"I don't know whether she is just trying

to agree with them or whether she would

do it herself anyway" its not clear".

This type of experience has become mepetitive to a state of becoming "miseducakive" Dewey (1958). In thig student it has lead to what Jarvis (1967) regards as a meaningless experience. Learning has stopped and the aim is to get to the end of the course.

Increasing control and being able to become involved with the patients, moves the gtudent on into managerial. aspects of the role and decisions about delegation and referral.

The cycle of learning from experience described as a simple learning model. (kolb 1975) can be discussed in the light of the student's experiences described so far. While a useful starting point for learning its simplicity does not account for all the complexities of learning seen here.

It is clear from some of the situations described here that experience does not always mest in new knowledge in ract for some students they are not looking for new knowledge but for a revision or reassurance of what they 
already know That reasurance however is important in their developing confidence to undertake other experience where they do not have the necessary knowledge otherwise they revert back to routines that are boring " However it is more complex than thigs learning model depicts and clearly one of the important ractors in this process is a person to help facilitate the learning. The reflective process is given little explanation and also one assumes that learning experiences if they are to be meaningrul are chosen for their relevance "However this is clearly not always the case: students do not have the opportunity to chote and their opportunities to bring about any change is limited. Innovation is not possible in their situations. Also students have different purposes for their learning - some are cognitive to meet the college requirements but the Jearning in the community makes use of cognitiven affective and motor skilds "The most complex are the areas that involve decision making. Whare there is less time to try out new thinking. This interactivity ig clearly important as described by various authors (Eoud et al. 1985, Sichon 1987).

Farameters of change

Increasing control and being able to become involved with the patient moves the sudent on to managerial appets of the role and decisions about delegation and referral :-

Student WeII I do, I make up the list every morning and 
delegate the cabeload obviously there's things like with patients coming on once a week, so I do that. then we come back and we discuss the caseload at Iunchtimes: M" used to do it but now $\mathrm{T}$ do it this time .

$A M$

Would you delegate to the lady that we met in the street: the numsing auxiliary? Do you actualiy delegate a caseload to her as well? Do they come in in the morning?

Studert Yes. Everybody has to come in in the morning. because they've got beys whatever. Anyway I think it's much better for everybody to mest in the morning. I know a lot of places don't. They've almeady got their 1.jat and they go gtraight to the patient. But if there has bean any changes or that you discuss them :-

Aly

Changes overnight?

Student It can be - from the twillight. TFid $=$ S

The student ig taking part in the running of the easeload and the routines of the pratice. In this case it involves coominating womk not only of the day staff but aluo the twilight service. Whatever the routine the students get involved as part of developing management skilis. In many instance this was observed during iny visites to the piacements:- 
It was interesting to see you working this morning Are you taking on more responsibility? That's what you seem to be doing.

student Yes. normally there's a treatment nurse on but she's off today so $T$ is doing the treatinent and I'm doing the district numse part.

AM Is that the first time you've done that?

Student Well $\mathrm{x} \cdot \mathrm{m}$ taking over the diary and trying to sort things out. Nornally $T$ has been there and she says its very difficult to not do it when you re 5o used to doing it. It's fine I enjoy it (do you?) yes.

A|M

It eeme to be noving you on. . " "

Student Ves "This particular one (placement) is supposed to begin to take over management side " Next one is do it totally (right)

$A|M|$ Do you feel you are doing manegement side now?

Student Yes eort of orgenising the worle and gort of taking messages and generally running things, (LAUGHTEFi) but keeping $T$ in touch with what $I$ an doing,

$A \mid M$

What about decisiong? How far do you get along that road - say delegating to people?

student Yes." Wejl of course the auxiliary she"s got a set Ioad anyway and if she had any problems she would 
have brought them up now. Um $F$ she's just back from her holidays. And this is what we were working out - who would do what "Because you do have your own rasejoced at this gtage and I ve got my regulars anyway.

AM

And what about discharging people off the books do you do that as we11?

Student I would certainly say to T what about this one. it could be dismarged" And I think that change of treatments leg ulcers and things. I don't do it without saying to her, you knowy I don't think: this is working or can we try. But I think that 5 just ethical readiy more than anything

AMI

But if you had your ideag about treatment would you actually say d don't agree with what's going on here $I$ want to try $x$ (yes). That s acceptable is it? (yes)

KU2. 3. 3.1

With the incmeasing mesponsibilities comes decision making and the decisions that might be made about change some changes are acceptable with agreement by practical work: teachers as mentioned above However changes that are related to more sensitive issues are not so readily addressed by the student. 
Another student identified things that she would try and do such as set up a primary health care team meeting with people who were attached to this very big modern health centre. This was something she would talk to her practical worl teacher about but other things which were also concerning management of the district nursing team were seen as too sensitive:-

AM

$$
\begin{aligned}
& \text { If you were taking aver a practice would you see } \\
& \text { it as important to do sort of a cameload profile } \\
& \text { or a community locality profile similar to what } \\
& \text { you are doing now? }
\end{aligned}
$$

Student I think it would be very interesting but you've got to be very careful when you go into a new area. You've got to see what the set up is before you can do anything.

Although it would be nice to say well you should be doing this until you see how the set-up works.

I. do ferel. there are several things here that could be done. There's a lot of not backbiting but bickering between statt and being an outsider I probably hear both sides whereas they inight not communicate so freely with each other. There's one FEN that: 5 not coping very welly and nobody is peally getting to her and saying let's have a quitet chat.

We're doing a lot of visits that are social more 
than anything else. It's important that somebody visits but I'n not sure it's our role to visit.

Aly

So you would want to control what goes on rather than just let it go on?

Student Yes, that's it.. "Well I feel that I would want to not be in control axactly but know whet's going on morey alud more ware.

$A M$

Yes. Fresumably you'll get chance to do that in superviged preatice.

Student Yes. I think the girl that is coming back heres is on the course with mey um it think she's aware, because we talk abouk these things actually. How do you stand this. And she says well I hope to be able to: you know change it.

AlY

She* 1 have more authority and be expected to make change?

Student That's rightgbut $\mathrm{T}$ have learnt a lot.Its been good. I'm pleased I'm doing it. It's discovering gelf more or 1 ess.

A|M Do you discuss these things with $k$ ?

Student No I just keep to... "I don't like to upset anything It's a bit delicate

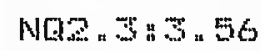

Again the ambivalence about change is apparent. The thange 
is postponed to a time when it can be undertaken perbaps in the supervised practice or later. It can be talked about but not actumly tried out. The experiences that atudents talk about so positively that they encounter in the patient's home are not available in caseload management. Even in the mot trusting relationships theme are some subjects that are too sensitive to engege in.

Even though this learning strategy is very acceptable to the gtudente it is a compromise. While it is possible to try and bring about change in the supervised practice it is clear that students need to practise the unknowns when they are students. As they move into supervised practice they are expected to take on an increasing caselead and act competentiy, so reducing the pportunities for "Trying and Testing Out" and ror asking questions that appear silly"

The sharing of the responsibidity such as described here ig one way in which the practical work teacher can combine support and supervision. One strategy $i s$ a reversal of roles where the student delegates to the practical work teacher as it a distmict nursen In this situation the student is on a more equal basis with the teacher and can take the initiative. It is then up to the practical work teacher to give guidance when appropriate This sort of model is more in line with aclult learming " 
Tncreasing confidence leads to further learning and nore trying and testing out if there is encouragement from the practical work teacher. In its extreme form it becomes learning by trial and error if there is little guidance from the practical. work teacher. This can happen because of heavy workloads of because the practical work teacher does not have a programme to follow and lets the ghudent do things haphazardly. To some extent the practical work teacher must beep some control over the learning otherwige it becomes meaningless and boundaries of developing the managerial appects are restricted by attitudes of others. This becomes most obvious in the third placement "-

Student " " "n " and you ve got new ideass you talk to other people and they've been using different things and they've got a different method of doing something. You come out and try to use it but you come up againgt brick walls by people who think they are more experienced, not really into new fangled ideas. L. is quite energetic and enthusiastic so I appreciate that and ghe's been a good FWT, she's always into new things and discussing things which is nice. But then she doesn't control a caseload so it can be just theoretical really. (yes)

Because she can't say take Mrs Jones and do what you like becalse you ve got to negotiate with this other person whose caseload it happens to be . And I 
mean she doesn't see them when I'm not theme Theres no continution of my experience.

AlY

Seems to be that other people in the team are quite influential in what has been allowed to happen and what hasm t.

Studert You can't change things.

AM

You must find that even more if L doesn't have a caseload?

Student Yes. I do. I think also last time, several patients I. had - dressings and things ... I had to go by their orders when it was supposed to be my caselomd. I was left notes of what should be done and things. But I've been better this time bewase they've been on hol.jiday.

QD 1. 3 3.21

In this example the practical work teacher has little control over what goes on in district nursing practice in this health centre and is acting as a melief to others. The student"s oppomtunities are restmicted by others who do not have the enthusjasm for teaching that the practical work teacher conveys. As a result the student becomes disillusioned and is looking towards finighing the course as soon za possible in order to move on to other areas of numsing. 
A similar wituation prevails with a dipect entry student. Here again the practical work teacher has no caseload of her own but $i g$ a well established and senior member of the district nursing team. Here again the stuclent's regular patients are drawn from varying caseloads and although there are good relationships here the student still feels prevented from making changes other than those of simple nursing techniques. However the student maintains her enthusiasm because degpite the feeling of not being able to make changes there $i$ g general acceptance of students

AlM

D. I just want to talk about one or two of the patients we saw this morning. What do you feel-we talked a little bit about this in the car - what do you feel you get out of going to see all the people on your caseload? I mean, you know: what do you learn about district rumsing by just going out and doing visits like we did this morning?

[FaLISE]" " How LSEfu] is it?

Student Well its a bit like hospital really only it's more satisfying to me. Un in tha hospital you give them al the care like you do in the community. But in their own home they are more relaxed and you know that if you're not doing everything as you should do it they can tell you to get lost or whatever. So I get good deal of satimaction out of it. I ve got my way of doing it and nobody else to come and - Iibe a dressing for instance. I ve my way of 
doing a dreging and I know after a certain length of time I have like goal I know how far they will reach.

Whereas if you ve got someone else doing dressings, inteffer ing with your dressing as such you're not sure where you ame. Community you know exactly where you are because youre the only one communicating and meeting that patient. and doing all the necessary bits of care.

AM

But as we were saying they are not your patientes are they?

Student No er no. I don't want to sound possessive but you are looking after them, ag such it w your came that they're getting and your" care shows if it doesn't show results its a sign that you re not doing what you should don.

AM So you find out whether "in a way" whether what you ret doing is right ( yes that's it). You can check with $U_{3}$ you can come beck and talk to her like you did just now or you can " " or she can visit and see what has been going on. The patient will presumably teli their nurse whether they like you or not. (yes they do) claughter\}"

Uin.." But when you go to do your supervised pratice you re going to have supervised practice 
you're going to have total rewponsibility for ever'ything.

Do you find it difficult not having tatal mesponsibility for these petients or not?

Student At the moment it is a clificulty "they ame on loan. if you like. So you can't organise the days you want to go in. You can't make a dragice change in what you are thinking. Gister has been going along for years and doing the same dressing. Iike Mrs D. "... with her heel. If she were mine I would do her dressing a different way. And you can say wej.l what's matter with coming back and checking with the nurse but on the other hand she might get. offended. 50 I only have her for a month when I' out. But if she were mine I would to it completely differently, her dresgings and the times t. go in. DCL u $3: 3,2$

Discuseion

This category describes how the students develop their understanding of district nurging as they move from dependence to independerce and begin to think about change. This is a process that is clearly described by the students and is used by them as they become involved in the routine of the practice. 
Fat experience as a nurge is uset as a reference point for comparing with current practicen There are contradictions between the two which lead to questions about the present situation. Differences are highlighted which are fairly easily dealt with in relation to task orientated situfions such as dressings proceduresn Either the student carries on in the gane way as before or tries to meet the mequirements of the practical work teacher" It is in the way that care is organised and a knowIedge of ervices that can be offered that are the main areas where trying and testing out is most useful and most complex.

Students want to be seen as competent and to cherk out their competence against the practical. work teacher" In the first instance they une the prectical wort teacher as a way of checking what should be done and what standerds are appropriate, although as they gain confidence in their own ability they gtart to challenge or at least question some of the things that are done or that are not done.

However the district nurse etudent comes to the gituation as a competent practitioner. It is the context that is different and this is demongtrated by the students comparing of past experience. They are adapting to a different context and one which is frequently meferred to by the six direct entry students. The non-odrect entry students a Iso mate reference to it. but in their comparigons it 
appears they are contrasting what they have done before as being an ungualified numse in the community. From their previous experience they make reference to being "thrown in at the deep end" and mot really feeling competent to do the joly or not having the Tul1 roporsibilities of the district nurse. This experience is demonstrated by the newd to 1.err about patient assessments - something they were previous]y not a 110 wed to do. lt appears that previous experience in the community in a different role does not provide any more sujtable a batsground for conridence than experience in hospital. The comparisons still provide Eontrasts and the need to be assured they are competent. There are paral. Iels with the notion of moving from a novice to an expert (Benner 1.984) except that the student has a dirterent starking point -. they are almady qualified กแH

Gompetence is seen in the rirst plence as being associated with the tasks which they all know about as numses dressings for instance. Studerts quickly want to get into the complexities of petient care and decision making abot caseload management. The pace of incmeasing responsibility or movement along this continuun from task to management is variable and sems to be a decision tor the practical wort. teacher acomding to her assessmente of the students

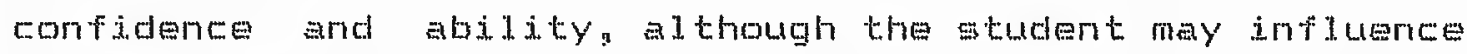
the situmtion by showing signs of being bored with whe more

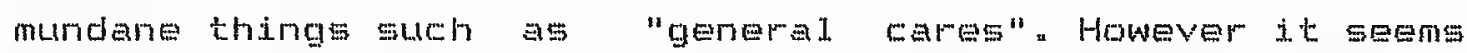


that the complexities of cameload management are usualiy postponed until the second placement and in some cases until the third placement, although some students would Iike the pace to be quicker".

The routines of the practice soon becone faniliar and itudents etart to talk about "getting the work done" and "getting finished on time" "Being busy is a frequent term to denote the number of patients to be geen and is generally aligned to numbers of $v i s i t s$ to be made.

Being busy is a constant part of the practical work teacher's world which is exacerbated by the student's presence. At no time do practicad work teachers say they would rather not have a student: they see teaching district nurse sudents as a major part of thedr role and one the brings rewards such as bejng kept up to date and hearing new ideas and provides a challenge. Fractical work teachers compensate for this extra work by working fagter or longer. However it ig not difficult to see how the "bugyness" syndrome becomes a part of the practice of district nursing.

The inner city gtudents gpente less time with their practical worle teachers than did the urban and rural, it determined by the time in the placements when gtudents started to have responeibility" The important thing for the students seeme 
to be that their perception of what constituted the right pace coincided with what the practical work teachers were prepared to allow. However it was not just a case of giving responsibility but what was learned as a result of this responsibility. If having one's own caseload meant just more of the same and a mepetition of visits then it was not valued and indead was a negative thing for the student. This was concerned with the practical work teachers ability to phan a programme beyond the task orientated procedures and also with the opportunites to try out new idess or at least to discuse them.

As is seen in the text two students one in each year suffered badly from this inability of practical wort: teachers to move along with the students" progress "So athough the gtudent became independent from the practical. work teacher they were not able to thilse their trying and tegting out strategy to its ful potential and the placement became boring. It reinforced the worst of practice and students who were keen to be innovative became disilusioned to the point of wanting to leave district nLพ-

To some extent it seems that the practical work teachers are powerlese to control the learning pportunities that students might take advantage of. They were not able to control high fluctuations in workloade and 
they were mot able to provide an environment in which students might try out change. Trying and testing out was dependent on the routines of the practice. Even practical work teachers who described innovations for district nursing also described how they were ignored or blocked by apathy either from colleague or management. Chance had as much to do with whether the students had opportunities to fulfil all their learning needs as the organisation by the practial work teacher. Although vieits to specialist areas or people were generally planned in advance visits to patients were dependent on what the caseload of fered.

This could be explained by the fact that there are many uncerteinties in the community and therefore students must get used to these fluctuations it certainly is mot $a$ deI iberate ploy on the part of pratideal worl: teacher to give poor experience and indeed for most it was a source of anxiety . All practical work teachers expressed in one form or another a desire to give the sudents the opportunity to be competent practitionersy athough some were more innovative in their thinking than others in how this might be echieved.

However it would seen that the students experience is determined in the main by the easeload as is seen in the comments and observations relating to the variety of 
different patients on the caseload. One useful opportunity to chem this out was when a student and het practical work teacher moved to a new placement. The difference for the student was very striking in that she had a variety in caseload and relationships with other members of the primary health care team including doctors. The pace of wort was at the optimum Jevel to allow learning

Fractical work teachers themselves have ideas about change for their ow practice. All recognise it is a parts of changing face of commuity nursing. Dne acknowledged she was bewildered by it and apprehensive and in fact would prefer to kep the status quo: but all the others had made some avaluation of whet was happeming in their health district. The comnon factor was that athough they were trying to take part in any change or were themsteves innovating ideas they felt frustrated either by the apathy of colleagues or managers or by the workidoad.

It perhaps adds another dimension to the findings of Battle and salter (1985) in that newly gualified district nurseg have not been given the chance to try out their new ideas during placements and therefore are ill prepared to deal. With the present climaten Fisk taking was confined to visiting newly rererred patients which to gome extent is an unknown situation but perhaps there are other "risks" associated with how oftem and who getg vigited that could be 
taken as part of the management ot caseload.

One of the important aspects of this category was being alone to think things through without anyone there of course this thinking didn't wop when the patient had been seen it went on after the student left work as one student. demeribed "T.m not ready to put it awa f. muld things over" " A common experience for us a 11 and one thet can be uged to advantege in this situation. Much of the "Trying and Testing Dut" was a case of checking up on the correct way of doing things. Dr just to get agrement that what had been one was compect. This was a constant reature during my observations both in the patient"s home and in the centres where students were based. It seems there may be opportunities missed here which might allow the student to say - well what woudd happen if I did this - not - well I have done this is it correct?

Fractical work teachers and students dmseribed a simila" strategy of saying what would you do in this circumstance or taking about alternatives but it its the innovativeness of these ideas that is not elder. How far these alternetives deviated from the acepted routine is not obvious and without further evidence it would not be poseible to infer any conclusions using experience is rellated to being motivated. It neede the stimulus of new ideas and new thinking whether adding to or learning new things. 
It would mppear that ensuring competence may ewclude innovation and thet moutine is requimed to prectise the activitieg or competence. The overseding is like learming tewhrical ski.1s where learning ig through demongtration. In relation to clinical stilis it seems the teacher gtudent relationship is beacher-led but teaching the mew skills of management ofters a more equal relationship. 
CHAFTER SEVEN

"FEALTTY OF PFACTICE"

Introduction

The reality of pratice is highly valued as a dearning resoumen Fratice is where the real district numbing todes puace. The student moves between the reality of practice and what in regarded as the ideal of college. In the early placements the differences between the two are cleary demarcated and in some instances seen as separate entities both to be drawn on for learning but for difterent purposes As the students become more critical of medity they take into account the college teaching and start to integrate the two in areas that are of interest to them. The compariang and contradictions give rise to questions

Some wtudente bring theim pratide experience to the coll Bituation in order to debate the relevanes to practice of what is expounded in the claseroom. The college supplies projects with the purpose of helping to bring the wo areas of learing together with varying wuccess. For some it is an integrating and enlightening process but for others it is a burden. The extent to which the college work reaches its ful potential is influenced and largely dependent upon whe vagaries of workdoad in prectice. The available resources in 
the communty for relating college teaching to practice are 1. inited the prectical work teacher being gen as someone who can help with practice based activites such as the nursing process and numsing models. other more acedemic subjects ach as social. policy are interpmeted by the student into wervices and berefits which can be offered to the patimt and as such are within the expertige of the practical work teacher.

The students are critical of both college mo prateice in their respective attempts to portray and teach distriot numsing. However they do not seem dauted by the differences and indeed live with each diftement perspective without obvious difficulty avercoming the differences sems to be more a stumbling biock for the course planners and teachers than for students who see it as fact of itie. A different approach to learning is noted by some atudents and within these individued approaches adopted by whdents the reality and unreality of ench peropective are coped with.

It would be too wimple to say that this category is merely a difference between college and practice. Within whe practice there are differences - on the one hand the studentg diseas of what district nursing should be about, presunably influenced in part by coldege and on the other hand what the practitioners think distritet nupeing is about as demonstrated by their practicent $i$ a two by two spljt. 
The gap in the former, college and pratticen is much telled about in nursing in terme of the theory practice gap but the gap in the latter, within prateice is equally important but I

Farallels of College and Flacement

A student in her second placenent illustrates some of the above points :-

AM

Amother thimg we talked about last time was the nursing theory and pration.

Student I midi think the theory is idealogie, the practice ig realistic. You look at it and you know that by rights you are taugh that go much more should be done, but it can"t be " There are still not the resources to do it. $x$ mean the patient, the general cares she is very Ionedy, needs compary. she is a lovely lady and likes company and one of her c.lubs is closed down. You know it would be an ideal situation if you could get her into a warden controlled flat but it can't be done. But in theory that's what they say to you isn"t it (min) she needs to be somewhere 라 1 sen 


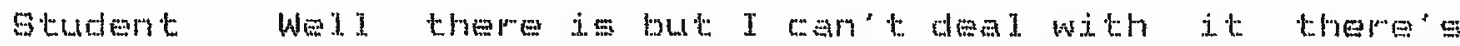
nothing it can don Lumbily her home camers are very good: She has home core geven days a weeks and they are actualiy phoning up for her and trying to push the council to get her into one of those warden controlled places, which is something I wouldn"t. have wome so I 1 ike to hear about. that so other than that theme is mothing I $\operatorname{can}$ do. $\mathrm{It}=\mathrm{sill}$ lesves me with that

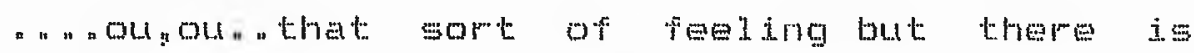

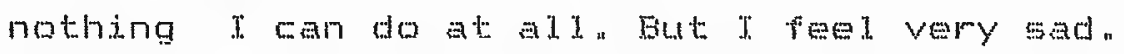

AMI

So are you idstening to the theory when you get back into coldoge and taking note of thity I men you sem to be separating the two things out

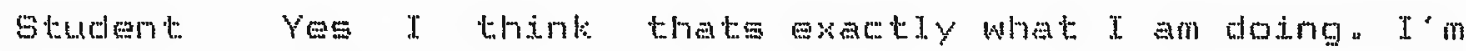
looking at. what they rooldege lectomes are telling me down here thand: descojbe a paths and I'm looking at what $I$ con actudey put into praction down here o Whet themry there is is where and $x$ think to myseita that $\mathrm{t}$ will memermber for the exan situation, this is what can really happen. NT.2. 242,5

The probleme highlighted here $r^{*}$ not just thet moldege

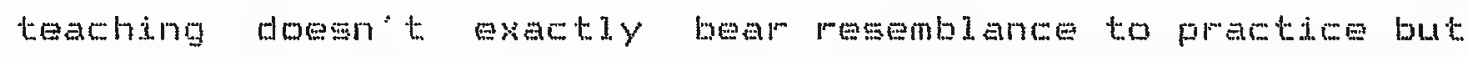
that what the student ses as a desirable achievement for the patint within hem sphere of practede is mot posgibles. 
Other areas within practice such as self care and heath promotion are sesen as the more innovative parts of district nuresng, hut not all existing practitioners agresu fro this wase there is ambivalence about using the new knowlodge in practice

Students were given projects to doy rom evample a teaching

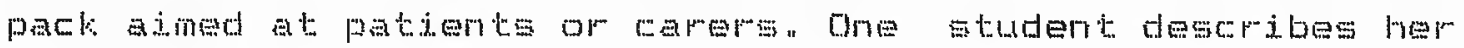
experience :-

$A M$

Does that [ teaching pack.] rit in with what you are doing in the practice at the moment? Dows it complement it in any way?

Student We're doing a lot of teaching. about teaching in the wchools and wollegen but I think is mome aimed at big groups or other mbudents in the ruture, I don't know if you ear adapt it to go into the hone and teach one person i think it makes you think about tomehing and edueteron: which sometimes you might not $\quad$ suppose digtrict numsing has always been a prectical thing and now they are trying to involve prevention in the home situation as well instead of the Health Visitor besing the person who

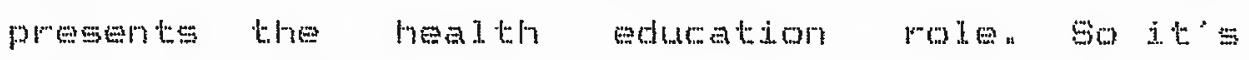
certainly making me think about it but I m not sure how I pould use it.

$A M$ In practice do you mear o " $n$ " " 
Student I suppose the whole system hes to change talking to the older district nurses: $\mathrm{x}$ think they are quite happy with their role at the monent

AM

Do you think they shoutd be? Do you see differences in how you see district numsing ard how they $s$ it?

Student Yes.

Al What are the differmences?

Student well. r think the role should be developed more. Because I don't think we are only practical poople: we've got a lot of knowledge to impart. and also we do a lot of care for elderty mors 50 than health visitors. I suppose you could say district nurses are beter in this area because they are dealing with them every day if you've got the knowledge then I think you should be able to educate other peoplen

Al Have you discussed those ideas with the other district nurgegs

Student No not yeta I don't really klow them very well at a.1.

Al What about your FWT; would you discuse it with her?

Student well i might, she"s a very motivated person.

$00.1,2 n 2,19$ 
The potential. provided by the project is not easy to exploit in this pratude and there is some reluctance to rush in with what might be perceived as new tdeas. This: feeling continued into the thim platement when it was linked ano with the wategory of "Trying and Testing out" The project worle for wone is a burdernome exercige and adds work rather than endightenment :-

Alvi Are there any thinge that you are doing in the college that you are actualy pieking up and practising out in praction or are the two geparate?

Student Honestly we've got a lot of essays to dog projects to do. Fersonally I don't feed it is helping me on the digtrigt - in practice. Fossibly the ENB wants ald. this and this is done in college but it doesn't work out that way in practice. As we wert round [ observation with student] you have most J.jkely noticed thet not everybody $=$ the same you have to adapt yourself accomding to that.

AM And don't you think the college takes account of that?

Student. I don't feel it does so much. Say the project we ve

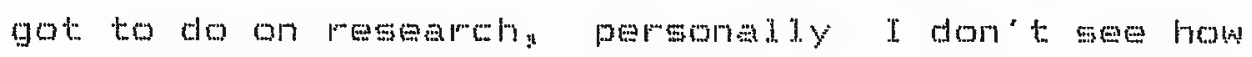
this is going to heip me here. I don't see the connection. I agree I'I I. have to read a lot more but whatever I'm reacing will increase my vocabulapy and my knowledge about the subject which 
might not mecessaridy be related to nursing which means its not: newescarily helping me „

$A M$ Its a pity really isn't it - you are gpending a Iot. of time ".."

Student It $i s$, this is what I mean" I felt ver" I dor $t$ agree its broadening my experiance or my knowledge of policy. But the paychology part we'pe doing " "er." quite a bitwhion is helpoul but its nothing new if you know what I mean. Because I was on the distmite r ve Jearnt mome or leste everything - not everything - but everything they do on the distimt

Maybe I needed a little bit more time than I'm getting here. But maybe $x$ feel that way becalse its harel womk for men lets put it that wayn (inm)" I find it very hamd really: (do you) yes becauge 1 havif done studies rof a long timen $x$ foel iny brain is a bith hay.

AM Wi.1 you be pleased when the course is finished?

Student Definitely" Most of my colleagues were not looking forward to coming back on the disterict but to ne $\mathrm{r}$ Was (Yes) Eecause if feel I ve got more time. I can gtury better from here than at college. college is too tiring. My brain it geturated: when I get home $T$ ean't do my work.

ST1. $3: 3.7$ 
It is clear thig gtudent finds the study dirficult which we diswused while out during my observations Her practical work tencher also finds it difficult to help her in the subject of research. She tinds the placement mome conducive to study than the coljeges previously referring to it in this transeript as "more melaxed" "The recognition that college is hard and by implication less rejevant than prectice Eeeme to make it more diffieut to integrate the who. Now being in her third placement she has been of the same view throughout the tourse and is not one of the gtudents who has come to see the redevarice of college work. However she has admitted previously to a difference in approach to organisation of work.

Integration thmoug comparison and contradituton

While some studente do not see themselves leaming new thing or integrating coldege and prateice work, they ald admit to bome changes in their thinking a seweping in or seming things differently" The coming together is not always tessy for then to identify in concrete ways or specific examplesult de only as the digcusatom goes on that there is a pealigation that some of their chenges in thinking may be a result of influences coming from the interation between college teaching and the pratidge experiences "-

$A|H|$ Do you find that sort of case study [course work. helps you to 3.ink some of the college work to 
practices: the suff youve done in college or doesn't it make any difrerence?

Student I don't think its made any difference what I've done with himgr patienty not really. A lot of it has come from my previous experience on an orthopadic ward. With him being a pamplegit we did quite a lot aith spinal injumes on the ward. A lot of it I can gear

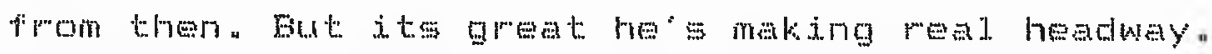
No coldege hasn to paldy apart from the emphasis on teamwork appect and approaching people becase that is geared in because we" re ald working together and he's an excallent patient for that so probably that aspect has but not atutaly from the nursing side of it. The physios helped quite a bits the or' been in there and the doctor and hosplted but without the mumses it would have fallen down beceuse of going in twice a day to do things. expreises and things so that aspect of the college -- yea - but not reatly anything elas.

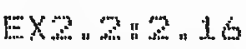

Here the student is drawimg on previous experimen foing on to discuss documentation of the care agin does not provide the student with any redationghips other than those she knew alleady However when we discused thig point again in the thimd placement she had changed her mind :- 
moming? lobservation with students we talked about settling in, you know getting into a new situation and worting on something other than nights you were saying you feel as if things are falling into phace and coming togethem "Can you faplain that a little bit nome like - how are they coming together?

Student I think I ve settled down. I've got my body elock geared to working days rather than nightes

Ancl also what we ve been dojng at college seems to be relating to things we're doing out here. (min) Well for instance I went to the pain relief clinit: went for the day there. And. "rer.. there was whis lady there with a back paing that was having acupunteture - they do acupuncture here - (yes) and when she got up of the bed she was telling me the history of her back pain and whe'd had a laninectomy and epidurals and it was as if she was going througl al. the treatments and now she had to 90 to acupuncture which was one of the last things to try.

When she got of the bed and decided that the acupuncture wasn't doing anything she was going to

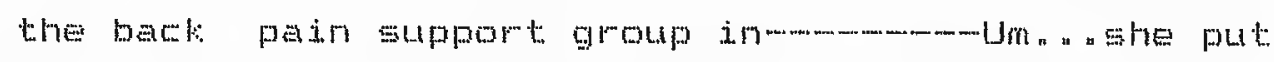
on a quite high heeled paim of shoeg " And her pace wes quikker than mine and $\mathrm{I}$ looked at the sister and sad she's not a true back. Surely ear a reat back pain move that wy othermise your acupuneture 
is marvellous: it meens contrary to what the lady is saying.

I thought that sounds ikke a bjt of college coming out. And we dismbsed how people have physical wymptoma relating to the psychological stress that they have. And $x$ think thats the finst time that $\mathrm{I}$ had consciously thought - that i.s some of collegen Something had finaly related to things that I was going to be weeing in the field. $E X .2,3: 3.2$

Here the student is talking about a sudden realigation that some of the things are relating to acom other "it seme to have cijcked" and "it just seens to be dropoing into place" "The student ig building on previous experience.

Not only is the practical worle teacher a resouree of knowledge but also other visits which are arranged by either the student or the practical work teacher. Not a 1 these visits are seen by the students as helptul buta if well chosen and agreed by the students are wiserul. They make another resoures for learning and for redating one experience to another: experience which may be all drawn from practice. A reference this student makes to "seding the patient as a whole" "

The relating is obvious not just in prectice but also in college. This student goes on to detail how a discustion about the merits of giving patients fiked visiting times 
provoked thinking and contributed to the discussion a-.

student I do relate - even in college last timen sort of the practical placement seems to sepp in more with what we are doing: $\$ 0$ it's working both ways "We al seen to be saying it as a group, on no you can't do that or yes we agree. It seems to be more of a two way thing whereas it was just college and practical. There wasn't the flow of knowledge. $E \times 2,3: 3.8$

The reitating of praction to theory je experienced by others when they start to think about jt in discussion in the thimd placement "...

How do you find the college womk and practice link: up. taking in the car about the fact that you dial your environmental. study and discovered there were no one parent fanilies round here. ere there any other aspets that you reel you would ink ton.....

Student To be quite honest it will does seem to be quite separate: the only thing we have done. " obviously nuwsing models and things like that, and now that I am due for my assessments, I can link that much beter . Social Foldey is hard to get. the inequalities that are there: I can definitoly gee that, particularly round heme -.- Ijving conditions are poor. I can see that I've learnt that but I still reel that college is college and work is 
work, [phacenent] If find it difficute to link up.

$A M$

Do you mange, when you are in collegen link the practice to the college -- the other way round, or don't you think about practice too much?

Student Yes: Yeas it does. I hadr't really thought but it does, especially now that we are Hriting essays. I can do that, but the other way round $I$ find $x$ t cifficulw if that makes sense (yes it does) MCL,

Athough student course work has obviously dratun on prectice the relationships are not clear to the student such as the one parant family -." at least mot ciear mough to say it is relating one to another, but links are there.

Even if there is no straght application of theory to practice the contratictions provoke discussion. The merjective processe and questioning might be utiliseds particularly in the sense that boud et al (1985) descmbes as: returning to experiencen attending to feelings: re-evaluating experience "

The foldowing extract from the tieldnotes written during third inner city placement describes wuch an opportuntey for discussion and jontentes a situation for which there is mo easy application of theory to practesen The problems are those of reality the problems for which there are no premset. answerm (Schon 1983). The student works on a large estate 
whare some of the tower blocks eme notomious for violence and where numses are abvitud to visit in pairs

Driving mound the outer ring road MC describes Q (patient) who is in Mis 30 and mas bi-1 aterea amputation foldowing a motor bike aroident.

We enter a soll ground itoor flat. Sparsely furnished and cold. As we enter ML weys the ] ]etricity mas been cut ofr. Letw in by Gis witte

Mo" gowes into whe gedroom. I follow and wand rimar tro wall.

B is in bed. M says are you getting up todayn No answer from $\mathrm{g}$ who turng his face awy. He is arguejog with his with about wher she shomld go shopping" She is sitting in ei chais at the botton or the wer. Wixe says "he I I

MC " offers to he dp G. to get up No answer" Mo

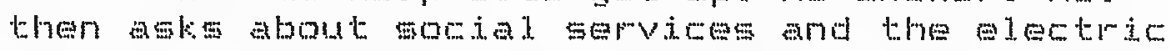
bil. = G. says they have not done anything and Mis says she will comtert them again and tak to N (pwt) about it.

|w "ask "how its your" som" "The wife says he is coming lome from sthool ( residentid special :

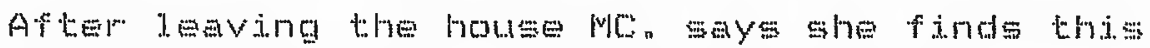

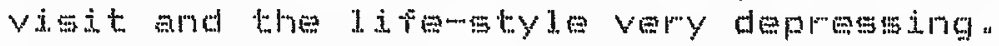
( temprul) , She says she told N" she could

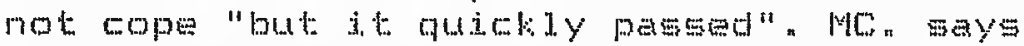
she finds this sort of visjt very trustrating beratime she can" the ho

When we went bets to the wurgery the gtudent discugsed this visit with the practical work teacher who sympetriged with

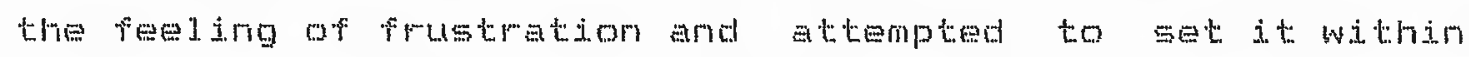
the context of the estate where many suth sacial problems prevaj. "The student was emeduraged to ring social gervices about the electricity 
This example is one such of many instances where meality ean be overwhelming and paintul. Frevious experience has not provided a "stock of knowledge" (Jarvie 1987) to use in this situation and the pratical work teacher is used as a resoumce. However the process of refiection (Boud et 1985) is not obvious, although this is not to say what practical work teachers are not attempting some sort of process. Indeed there was evidence from the observakions that discussion with the students berore and after visiting patients was usust practices

one might expect the "numsing theory" as described by the next student to relate across both the wollege and practice contexts. However it seme that the contradictions betwen the two do provoke questioning Femape this is what is needed to encourage new learning :-

Student The nursing part I sometimes feed they are sighty out of touch. It's ali so much thery. th think oh T*1 just wind on a bit and sit here. (1)ughter'?

Al Have you any examples of that?

Btudent Well perhaps the nursing assesment. cpatient assessment) We had a lady. care study " And we had to do an asessment in a group "Well $x$ suppose we ve done it berope and the next two hours session we had to do the ains and objectives and planning care and then the next one we had to do the evaluating It just semed to go on and on: 
you know In whe end you could have mung Mre T's

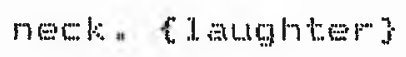

MIV

somebody actally described it as havimg two lines of lampring one tor the collegen and ore tor

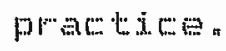

student Yos T

Al|

I ain interested to sen in other students ses it J. i.ke thist.

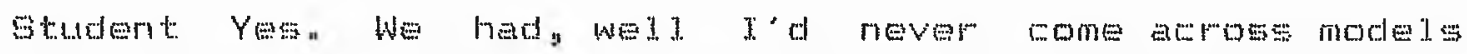

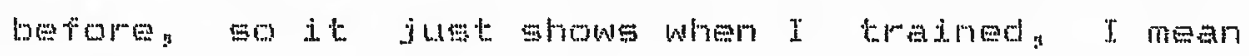
it was years ago (mm) a so when we started on models we had Foper and orem and Henderson and Nesuman arid $\mathrm{I}$ thought: well yes when do you actually use then. I rould ges with the Roper that in artual fact the forms thet we wse here arm basicaldy Foper a basically and $x$ thought

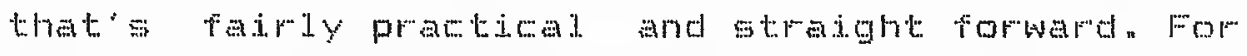
my care study if did Oring becalse I did the

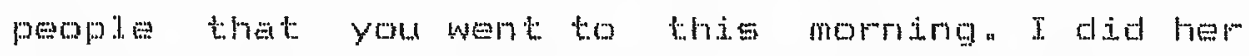
because she was coring for him and ahe'd scalded

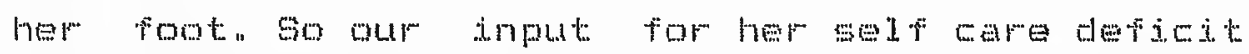

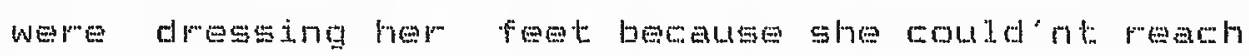
them. And I rebon that was roughly Orem. But Basically if wo all stuck to Foper we'd cover

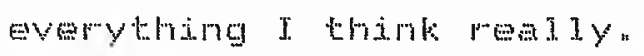

And a lot of time is spent to 1 king through these 
models, it all seems adry taimy that lot does i can't atctuldy see orem working particularly well in the communtey for the majomity of the time. Somethimg like Foper that just deals with the activities of I.ving: a check ligt is far more practical and basic.

$\operatorname{NQ2}, 3: 3,24$

We went on to tall about college teaching in relation to the practice area of primery health care teans. Here again the student can see differences "They do not curbal her I barning but provole some suggestions as to what can be done. Tt engages the student in thinking about the difficulties and 25 guch is very much relating the two areas of learning: but mot in the sense of application of one piece of knowledge to another" The experience of practice provides the impetus for linking the two a-..

$A M$

We were talking about primary health carey whether college teaching met the practice sitution here?

Student It really should do. I don't think it does though. You meet the doctors in the reception area "either when they re going out or signing actipts "There's no formal meeting at a11. And I really feel where should be at least halt an hour a west or once a fortnioht, but there" 9 no formal communication between the sections really"

Won $n$ Ihink there used to be and I think $K$ was going to do sonething about it. but I said to her 


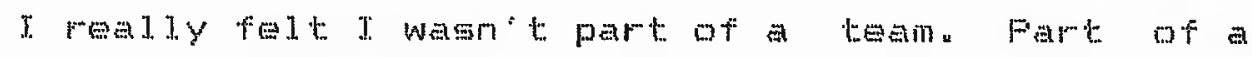
mursing team yes.becalise we ment. here every day but mot part of the primary heath eare team. We get little messages left in the book which is rair enough but I really feel there should be some

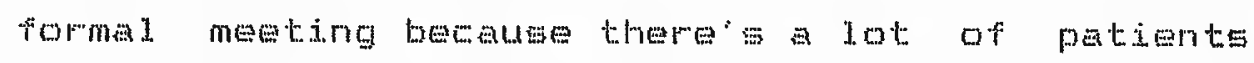
that wa could discus and talk about and Ieam $\operatorname{rim}$

All 50 it ism"t that you aro at odde with what they are teaching in college?

Student No.

$$
\text { NQ2 } 3: 34
$$

Foth these examples are about nursing practiow and not about the more academic subjects such as sociology and psychology that one night expect would be more difficult to relate Students wem to meke thejp own interpretation of knowledge from these subjets. Again they need to mave had some mpperierce as a fremework in which to do this arid therefore wamples come more readily in the second and thimd placeriants $:-$

Aly

Some people have found that the college and

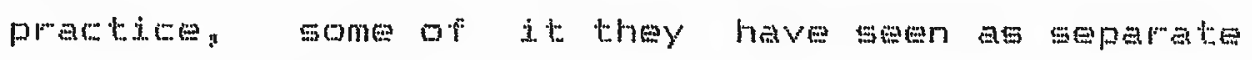
Mre you fournel that?

Student Ahen we fipst stertac in college everything semed 1. it.te parcels and then by about the serond - the second theory and definitwly the thimd themy I 
started to see the links between the different topics. And I think, like the sociology and the poychology ali that we ve done has been melated to meticine and to mursing

AM Has your attitude changed or not?

Student My attitude to numsing or " " " "

AM Yes tow was your practice -.. profesedonaly readiy.

student As regards the -- again live with the social wervices really - in things - like at home - my husband says to me well its wheir rauth that they're in that situation. I'I I speats up on that and say weI] it isn't "Ferbaps its the circumstance they are in. I have tended to see things rrom a wider perspective.

And the attitudes to gocial servites have chenged. Um bewewse its ppened my eyes about what actuldy goes on behind dooms un " we used to live in ore of the ameas thet is a high imigrant populdation. Amd I. think of what our house looked I. ike and whe orein down the road aere 1.16e - could be like with a family in. vou know; i wouldn't have thought it possible a year agow $\mathrm{KT} 2,3,3,30,3,35,3,37$

The resoumes tor learning are guite often saparated with the students using the college for their fasing work and the 
practical wort teacher for the expertise in practicen The two come together in the care study and numsing models athough there is stili. the resing that the interpretation of modeds may be difrerent in pratice to the teaching in the college:

AM Do vou discuss any of the theory that is not dimecty related to services, like peychology and sociology? Last time you were gaying in your head you related things about carers - we discussed Do you actually diseuss psychology and sociology as you hear it in wollegen with your practical work teanher?

Student No, to be truthrul I don't. 1. can't think of any thime I have i mean a littie bit of cociology well they tell you in college you can do so and so here. obviously she feels the same "But there are thing: - one thing we've spoken about is models. One thing thet is very elear in my nind $\dot{x}$ s that we don"tw work to a model. in the community "And to worl: how H [ ]ecturer] ig teaching us is difperent. This is a situation where I muste remenber what $H$ is aying for exmm berauge to do my exan on care study I mut do it. the way we are taught. But it" M patient I have to do it on - a care plan the way M has if done. 50 that the way $T$ split it and thates over the care plan. $N 12,2,2,8$ 
It appears that the student may Lise the pratical work teacher" as an authority on disciplines other than numsing such as social. policy or sociology: but it is infact an interpretation of that aliscipline as seen by the student to be relevants the most common being an interpretetion of social polity as benefits and services "These points are evident in the following discussion when $x$ asked the student if ehe would ast the practical work teacher's opinion about college teaching :

Student Yes because they've got a nodel, bit like Henderson: not Henderson but based on Henderson and I. went to assess an old patient and them I did the care plan and il based it on the Henderson model and we went through it. She"s got a ist of models thet she uses and we went through them to see if they were relevant or not. Yes, we discuse them.

AM

Are those idems about models difteremt to yours? Different to what you are taught?

Student oifferent to what we are taluht in collegen yes. Even working with the model that $x$ had at collegen we ve done twos $\mathrm{x}$ think everyone has thes.j own way of working and you use models difremently" some use them as written: some use them as a check list: you know some only use parts. Anyway my put uses it as a chems list but has her own way of doing things littie bit 
different but we both ended up with the game plan.

AN

What about things that are further awa from practice, Idke wocial. policy or woriology or persolno logy"

student I'm a bit confused about benefits a I have a bookjet about the benefits that my fur gave ine and I. asked her about the beritits . She said she had an idea but she's not sure? about exacty whats going to happen. We didn't realy diswus we went on to something elsen I hope when $x$ go to somid services maybe I'11 understand it $T$ don't think so but I'II try" I've got the bookletso I'I l. look at that before I go: and make a ist and bombard them.

MC1.2:2.15

The student seens to actept the difrerent ways of using numsing models and different perspectives " she agrees they end up at the same point. Here we have the begimnings of questoning about practice rather than just application of theory" Again an example of the varying resoumes that are Lsed for leaming is sean in the example of social policy. and the student's way of making use of then.

\section{A Discovering Fractitioner}

Bringing together the two experiences of learning - college 
and practice - is rejiant on the individual student and atso depends on their previous knowlodgen being prescriptive about rourse work as in escays or care studies, althougl directly related to practice ds not aluay an appropriate venicle for integration as students have pointed out. Father the more ppen approach towards learning as identified by the following student may be a betrer a terative

AM How do you feel about some of the ather theory?

Student What do you mean?

$A|M|$

$$
\begin{aligned}
& \text { We11. sone of the other things you are doing in } \\
& \text { eolitege, are they useful, are they directly }
\end{aligned}
$$

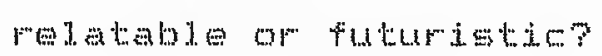

Student r. think futupistic most definitely" i think you go back to the fact. they amost give you the dooriz to open and I suppose ite trying to have it at youm íngertips in owder to apply it practically very basically to situations I think it could be what I make or it. so I could take it. or leave it and I could still get by. It should enthanee both my job satiofaction and patient care.

ANI And so it.s really up to you?

Student I. would say so

Al We talled guite a lot last time about mompetency and the competent practitioner and how you would bnow 
whether you were competent or not.

Student Yes we did (laugher

MIY

Wave you devedoped any more thinking on thate we

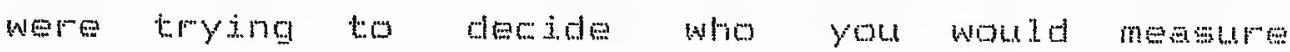

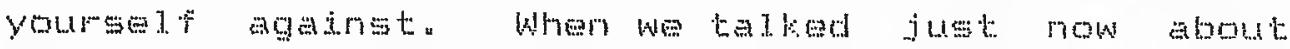

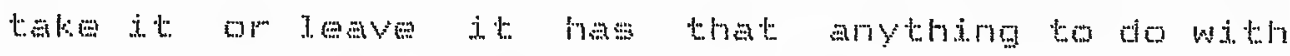

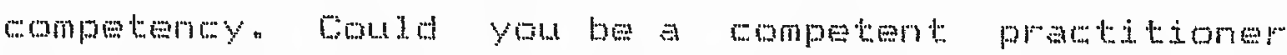
without it. [oheory] in your vi.en?

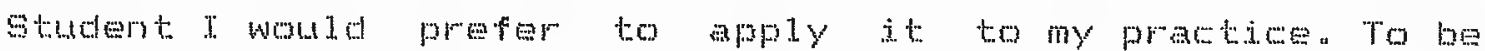
momeste people looking in from outsiden"I don't

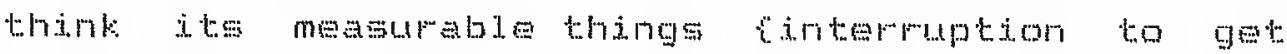

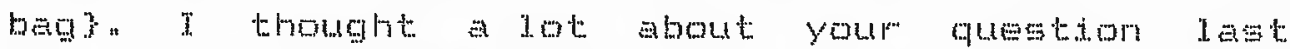
time " How it would decide I was a competemt proctitioner? I really thought about that "And its

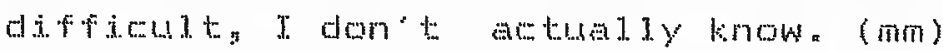

ArI

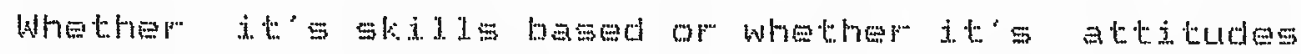
orma

Student $\mathrm{T}$ would prefer both skills and knowletge cohone ringings. I think persomally it would rather mave

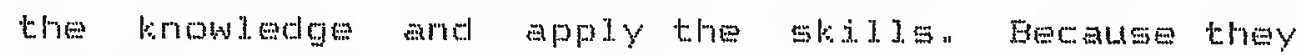

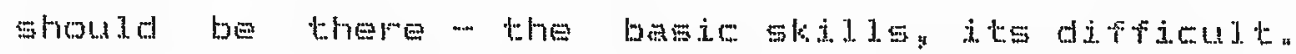

AM It is one of the pople I was interviewing seid they didn't think they nesded to do this courge because whey wore already a competent pratotioner. 50 What is the difference working here or in 
homptals if you ve got prineiples you ean apply them to any siturition.

Gtudent Yes. I think actally district nursing " to develop we nead more input on what we get at coliege, the sociology and the psychology and forward thinting on mursing and models and the nursing procese betrause we" 1.1 just be plodding along doing the same old thing and we won't actually be developing and becoming part of a dynamic team. And perhaps that we meed in the future to become part of a tean with

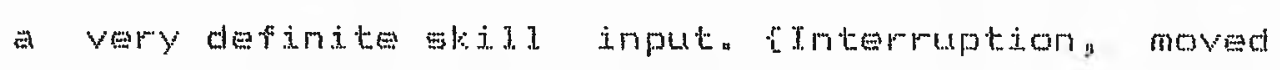
rooms

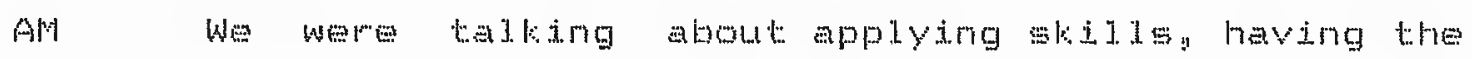
knowlectge to work in a tean and then apolying the stids. You described it list time as a discovering prartitioner.

Studen Did t? - good 10 rd!

AM A self directing learner - I think that was me trying to interpret it. (mim) so you have t changed changed your mind on that. "."

Student And th can t concretise it in any way because $y$ thought about it -.. was quite a challenging

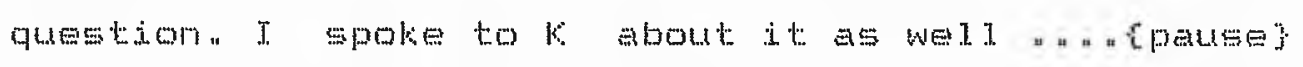
I think its finding a stot in whim to apply the tompetence and skilis rather than waking up one moming and saying that will fit. 
Mabe it's fitting a role and feeling you do that role weil. But then I don't know that there is a concrete roje - the district nume is $x_{n}$ t know We've got one written down: but there again it should be a dynamic one with certain definite characeristics.

AM

Do you peel that the experience you are gaining here is heiping you to achieve it even it you can t. define to what degree?

Student Yes I would say so. My one critidigm so tom is that there"s not enough time for pratical experience to actually settle and relax into the

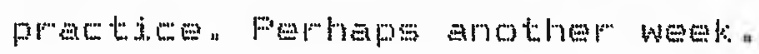

AN His that something to do with the area youre working in or with the patignts?

Student I would say its personel " I jut neat more time. NT2.2:2.6

This student is degcribing whe swhon (1983) describes as artistry and what Eenrer ( 2987 ) terms indution or the intangible things that make up competence or expert judgement. When the practical work teachers weme asted a similar question in terms of whe did they think they shoudd teach or what was importwant they came up with specific things: but agerim found it difficult. 
The student is not advocating application of knowiedge but rather a different way of thinking a - enguitwing questioning. An ided put forward by others but in different words. The college teaching is not separate but can add to the development of the roles a use of the knowledge in the future rather then direct application. It is mot a case of "mot knowing it" having more tine to be able to find out about each thing" as one pratsical. work teacher gates

The student has thought about what she is aining for but is happ to leave it open and to enjoy the new experiences without tight objectives " she develops this in the mext phacement when she has had responsibility for a mall group of patients.

Ir talkimg about her use of the college work to hejp her develop her thinking she decribes it as twking risks and perhaps lowimg maks in the process, but the nature of the course; in comparison with others, allows this leaway again the take it or jeave it approath. This applies to numsing and to the behavioural sciencesi "...

Student So that another new field which is exciting in some ways to explore "And so l'd aim agan to sacrifite sone marks and have a bash but there comes a time when you can't do that anymore [1 augliter) (yes)

AM It's rather like putting yourself in ab chatenging 
position or taking a risk rather than alsays working on safe ground.

Student Yes I was comparing this coumse to midwifery and certainly there"s a lot of scope for not womying about having to learn things. You tan go of at a tangent and somehow gerape through the marks. To me I muth prefer" it. I'm mot too bothered with that sort of learning. perhaps I ought to. I shald have to sort of pin inyself down soon because of the examn it seems to be a more chaldenging coumse: athough I don't think it's as well recognised "which is a shame. NT2 a 3.3 .29

The student is exploiting the flexibility of the course within the boundaries of having to achieve given standarda in the shape of passing examinations. For many atudents this was a real burden and reduced the opportunity to take advantage of their own explorations However all students make reference to sone attempta to dearn new things by using their course work to investigate new knowledge .

Exploring idese mainly from the retererce point of practice 1. eads to new thinking, abejt in small and indeteminate ways. Students find it difficut to give specific examples of new leaming and generally discuss it in terme of how they have come to see things from in a different perspective, or a recognition that they have added to their 
existing nursing knowidedge. Any obvious new learning feens to be more apparent as the student moves towards the final placement and takes on the responsibilitise for managing a sma 11. a ase $1 \mathrm{oad}$

Wuch of the learning is concerned with decision mating in the context of patiente homes ard in the context of working within a group either the district nursing team or the wider primary heath care tem. It is in these contexts that the student is "sorting out problems" which lead to "lowking at things in a different way" "The probjem provides the impdtus for using the mew browledge and integratirig it with other know1edge:

Learning is clescribed as "widening the perpective" or "looking at things in a different way" it ie the context of prateice that provides the stimulus for thinking about the reality of district nurging.

The problems of practice may become very familiar and even boring: particularly in deaing with elderly and problems of increasing dependency on others. Sometimes the student comes across unusuaj situtions at leat for district nurges: which present different problems and start thinking about other aspects of practice that can arm on sociology or psychology taght in tollege. 
In the first instance this eategory seems to be concerned with the differences between college teathing and practice experience. At the beginning these two areas - college and practice meen to be giving different messagegn It is clear that the wtudente think of bringing the two together by the application of college teaching to pratuces in taking this stance the difficulties are obvious - they don't fit.

studente develop strategies for coping with this "gap" and separate the two areas out, Eompartmentalieing the two and working with them in parediel. The students interpret the academic dimeiplines in order to make them usable in the practice gitution. The integration occurs without the students moticing and in fact they are quite surprised when they suddenly realige that the two are jinked. It sems that there has to be some length of time for this process of linking to take place and perhaps it is obvious that studente naed the experience before they can ind the two. However the student already comes with not inconsiderable experience and the contradictions between the previous experience and present and between the college and the practice throw out contradictions which, if used, can be the starting point of greater understanding what is not 50 clear ig how this is dealt with by the practical work teacher, it at aII. It may be that to nake the most of these contradictions they need to be diswused, not to find 
solutions but to think about the questions that these contradictory situations present. It is clear that wtudents begin the process of reflection by talking about what they have seen and what they feel. It appears that these instances are not always exploited by the practical worl: teacher, particularly at time when the student identifies a change in their own perspective.

If students are looking for right answers then they wiIl find this sort of uncertajinty about answers difficult to deal with but if, as one student describes, they fan be seen as "doors to open" and accept that the knowledge and expertise they get on the course can be used in the future then the application model of theory and practice may not be such a stumbing blokk. In any case the integration of college teaching and practice.

For nursing subjects the reintempretation of the college teaching is Jess noticeable. Here the students geen to make straight application and dismise the college teaching as not appropriate or the application is postponed or the teaching i.s amended.

The practical worl: teachers rely on the objectives of the college for their linking and all mention the objectives or the college programme as an important part of relating the college teaching and the practice teaching some temper this with student needs but still the practical work teachers use 
a straight application to theory model and some are at a loss without it as described in the second year when the programmes were not sent out.

What should be taught is not wholly determined by the college and practical work teachers have some things which they think are erucial for alstrict nurses to know before they move on in the courseg and in all cases were described in terms of knowledge to be learned in relation to the activities of district muming. It was quite easy to iclentity the things that they wanted to teach by talking about what they were teaching. Having made assumptions on this basis from the first year analyas i asked a direct question to practical work teachers in the second year about what they thought were the crucial things to teach a student before they went into supervised practice.

In a simple count of the response to this direct question there wat consensus about:-

- recognition of patients rights and values in their home

- attitudes to patiente. carers and colleagues

- communication with patients and primary health care tean including their owr colleagues

- management of caseload, setting prioritiesn and decision making

- teaching: education and encouraging self - caren

Dne person described the crumial apects in terms of open-mindedness about whange and district numsing. recognition of the limite of own competence particulary in terms of caseload management " they should not act like 
martyrs, so many do" None mentioned research in any form except in relation to their own development.

Feality is where the integration and interaction between college and practice takes place and is a dynamic processn The reality of where distict nursing is practised poses problems that do not have text book answers and where the students geek recourse to an expert district nurse in the form of the practical work teacher who can speal: and demnostrate from their experience. However the reality of practice $i=$ not just what happens in patients homes but is also about worting alongside other colleagues and about managing the caseload It is at this stage in the course When students begin to gauge some sort of balance between what is desirable and what is possible and again when they are influenced by the practical work teacher as an expert. However this whole experience occurs within the parametems of caseloads and practices thet are controlled by others and as such the true reality of district nursing practice is not experienced until students are qualified and are then expected to be experts themselves. 
CHAFTEF EITGHT

CONCLUDTNG ANALYSTS

Introduction

This find andys will relate the research findings to the theoretical discussions in chapters one and two. That is to say it will consider the categorieg in the light or adult iearning theory within an experiential framework. The implications for digtrict nurse etheation will then be discussed. The analyais reflects the categories which describe the experiences of students and have emerged more as a process of Jearning than as merely a description of the learning envimonment. It is therefore the focus of the categories that directs the theoretical framework and hence the emphasis upon experience and perlection in this and $1 y=i s$

Experience and Feflection

Experience based learning and with it the process of reflection is regarded by adult learning theorists mas eruciad to the process of learning from experiencen (Nezirow 1981, Kolb 1984, Eoud et al 1985" Jamvis 1987, Gchon 1987)" The experiential learning model (Kolb 19g4) is a simple but useful. starting point from which to explore the process of 
learning: but it does not make explicit the process of experimee and reflection. Boud (1985) and his colleagues attempt to memedy this deficit by examining the components of reflection as part of experience. Reflection in the context of practice has also been examined by schon (1987). An attempt to look at experience, taking into account the social contexts has been undertaken by Jarvis (1997). Their combined work based on the practices of adut education has contributed to a greater understanding of the complex nature of learning from experience n

Summary of the categories as an experience of learning

The three categories have arisen from the analysis of the experiences of sturents as they learn to becone district nurses: The categories demonstrate the complex process of learning from experience which has emerged a a staged process. Each category can be regarded as covering broadly a stage in the gtudents' Jearning. Firstly the gtudents are adepting and fitting in to a new situation and preparing themselves to gain from experiences secondly students engage in the activity using certain learning wrategies that are determined by the routines of practicen finelly atudents incorporate their new learning into the reality of practice With varying degrees of suceess"

The stages may be summarised m followg- 
1. Students enter the learning situation with some anxiety and a heed to rind their way around and to fit into a strange envimonment. Fitting in $i=$ concerned not jugt with physical things such as uniformy equipment and becoming familiar with the geographical area, but also with melationships and the accepted practices of the oroup in their placement. Fast experiences of nursing are used to make sense of the situation and to orientate thenselves in new learning situations "Experiences are used for comparison and as the foundation on which to build further Jearning. Students come with expectations of how and what they should be taugh, and all develop strategies as to how they ran best fit into this new situation.

2. As they become more familiar with the placement they begin to develop ways of leaming which accord with the worl routines of the practice. They find it tiring working in the new sitution and keeping up with college work" Frustration with the pace of development and, in some tases the lack of development is evictent as they become independent and reel restricted in testing and trying out their ideas to the full. Fositive feelings al $=0$ prevaid. with increasing confidence and responsibility. Fractice and college are used as refuges to air their perceived successes and failures. The experience in placement begins to raise questions about the links between college teaching and practice experiencen and strategies are developed to cope with the 
differences.

S. The increasing independence and the move towards taking on more responsibijity provide a greater understandimg of the practice of distriet nursing and students begin to talk about having a different perspective - a broader viewn It is difficult for students to identify new knowledgen They tend to describe it as a new way of looking at thingen The drawing together or integration of college teaching and the reality of practical experience is beginning but there is no conclusion to this process and it is seen as something that may happen in the future other aspects of development are postponed because of the limitations for innovation and change. The experience is therefore a continuing one.

The categories then: demonstrate the students use of experience and also certain characteristics in each learning environment that either promote or hinder the students' learning. It is also clear thet the routines of practice and the barriers to change are influential across ali learning contexts. It is appropriate therefore to analyse fimsty this individual learning experience and gecondly the context of the leaming environment.

Experience as an individual activity

Throughout these stages experience is used differentiy 
determined by the biography of the stuclent: their past experience of learning and 1 ife events (Boud et 11 1985). Biography melates to learning needs not merely at a competency level (knowles 1984 ) but at a level of self confidence and in coping with new situations.

The ume of hospital experience by the direct entry students and community experience by the non-direct entry leads to 1.earning by comparison of the two experiences, initiated by a conscious realisation of the differences that can be equated with "loss of confidence" or "disillusionment" (Eoud 1985 p.19), or "inner discomfort" (Boyd and Fales $198 \mathrm{~s}$ p.106), or "timjurcture" (Jarvig 1987 p.9), or "disorientating dilemma" (Mezirow 1981 p.7) " This conseious realitsation of the differences between past and present experience leads to the prompting of reflection and questioning what are the differences between taking into account the patients desires in their own home and in the hospital? This leads to thinking how these desires may be incorporated into the care planning and about the approach to the patients. These incidents are taken up only if the learner sees them as appropriate to themselves or to what they need to leamn.

The work of Jarvig (1987) provides posmible explanation for some of the situations experienced by the studenta "He describes the concept of meaningful and meaningless learning 
in terme of responses to experience not al of which mesult in learning: The response he calls habitualisation arises when people undertate activities with which they are familiam. It is "a taken-for-granted response to a situation" (ibid p.78), where individuals" self confidence is mantained becaume they have "a stock of knowledge"(ibid P.78) and experience on which to drawa The extreme of this response is evident in some professional practitionera where the need to change is apparent to otherg but not to the practitioner. The habitualisation process has led to apathy Indeed some of the gudents describe this situation when they themselves are wanting to talk about change but see nurses around them who carry out practice as an extreme habitualised mesponse. As the students progress through the course they themselves come to work in an habitualised way, gaining in confidence and drawing from a developing stock of knowledge and experience.

The district nurge students are in new gituations. They are comparing their past experience which to greater or lesser degree is used in the new situation in which they find themselves. They are in whe Jarvis (1997) describes as a sitution of "disjuncture" (ibidp.79) where previous experifences are similar but require some adaptetion or adjustment to provide a basis for action. This adjustment is a potential for learning and indeed is described by students as increasing confidence as they adapt to the new situations. It is a situation experienced by all students 
and the support they get from their practical work thachers helps to maintain their self confidence "This digjuncture a 150 results in cognitiven affective and skilis learning. It depends upon taking advantage of the "teathable monent" (Jarvis 1987) to make the most of the learning potential in this gituation. For this to happen both swuent and teacher must be aware of the need to jearn" Digjuncture is a potential for learning but must be taken advartage of for learning to occur and it then will become again habitualisation.

Two further responses are described by jarvis (1987) as meaningless learning. One occurs when the taken-formgranted experience becomes mepetitive and boring and has no meaning. This was well described by a student whose experience had gone beyond the bounds of habitualisation. The second occums when the students find themselves in a situation where they are unable to log their past experience because it bears no resemblance to the present. In this situation students require direct teaching for them to be able to relate this to present experience. There are no obvious parallels here except that students do find themselves in Gitutions for which they have Iimited previous experience particularly as they begin to learn about managing the caseload. Although the student who described her lack of contact with her practical work teacher was probably experiencing this situation, she did not have the answers to enable her to make decisions about patient caren 
This analysiw of meandingful and meandngless shows not only the differmt points where meflection may be best used but also the $1 \mathrm{imitations}$ and the potential of reflection. The optimum time for reflective learning ig when "there is a Iimited disjuncture between the biography amd the experience" (ibid p.84). How the learner makes use of the experience then $i s$ determined by the value of the experience to the learner and the opportunities for learning that are avaijable to the wudent in the learning provironment. The process of reflection becomes an important part of 1. earning *

Utilising the process of experience and reflection.

Feflection is described as a dynamic procese - "a kind of spiral - a back and forth" (Boyd and Fales 19ge p.106), a cycle (Kolb 1984, Boud et al 1985. Jarvis 1987). The process of reflection as a part of the total process of experience leads to a change in perspective for the leamer. During the many experiences of the students on the district nurse course there are clearly times when they have been able to reflect on what they heve been doing and they descmibe changes in perspective about professional practice and about themselves. This has been evidenced during the interviews and the oberervations and through the comments of the practical work teachers about the studenta throughout al1 the categories. The timing varies. It may occur in one incident: in one placement or over the whole course. The 
strategy for learning which the student sets up in "Testing and Trying Dut" offers good opportunity for reflecting on experience. While thig strategy may be to a certain extent imposed by the routines of practice it is utilized by the student:

The stages of the reflective process -... meturning to experignceg attending to feelings, re-evaluating experience (Boud et a 1. $1985, p .37$ ) - provite a useful framework for looking across all the categories in order to analyse the exterte to which meflecting on expewience ig used by the student or by the practical work teacher in factidtating 1 earning.

It is important to remember that Boud has defined the meflective process as one of "intentional learning" - that which has a goal or outcomen The difficulty with this definition lies in the different levelg of generality "In fact the definition of intentional Jearning in the context of Eoud's work seens irrelevant and raiss unnecessary questions. For instance all students on this course have the goal of being a district nurse - at a more specific Ievel they may have the goel of learning about social service provision and even more specifically about a dreasing technique. The discrimination in generality is not obvious from Boud's work, but it will be assumed that ald the students on this course are intentional learners. 
- peturning to experience: the objective description of what has happened.

This is something that the practical work teacher undertakes with the student throughout the placements and relates to difrerent situations It can of coumse take place immediately after the event ag. following a patient visitg or later when the student meets with the practical work teacher" It car also be undertaken by the student without anyone else being involved $e . g$. on the way home in the car where it is "mulled over" or "thought through" "

Feturning to experience is therefore something the students can initiate when they relate their experience to the practical. work teachers about their activities with patients with the intention of learning. The learning here is ganing gpecific information - finding out how to do something or checking whether or mot what they have done is correct. The practical work teacher ask how the student has "got on" with patients and this initiates some discussion. The opportunities for returning to experience are cilearly available but the extent to which they are followed by the mext part of the process is not go clear.

- attending to feeling: awareness and understanding of feelings which may be barriers to learning "

During the interviews the students talk about their feelings 
of fitting into the gloup as sometming that has to be reckoned with before they wan go on to learn fully about district numsing At the very last it wases up time and encry" A1 I students talk about it and for gome it is a major topic in their interviews n fractical work teachers are aware of some of the difficulties " one initiated distusson to include the courge tutor "but in the context of teli.ing the student "how she ghould behave" it was made quite cher to her that alme was now a student and we more or less apelt it out to her" now she hal to arcept the fact that she was a student, she had already made a decision to Jeave the other place." $"$ a different som of awareness Faising other practical wort: teachers mad a more gympathetic tone and this was reflected in the responses of the students

In their expewiences with patients the students melate instances of having become aware of their feelings which may affect their learning for instance: the way in which they are expected to be accepting of ath home circumstances or ways of life - dirty homesn. different ethnic cututom " Good feelings can also be radsed and are in evidence in the many insturness when gtudents identify increased confidence There are instances when students are involved with sensitive situations in the home and indeed with coldeagues: Where they are abe to idmotify how they feel and then osempibe how they wid. talk about it to their practical work teacher" n 
Feflacting on experience is maindy conemoned with the

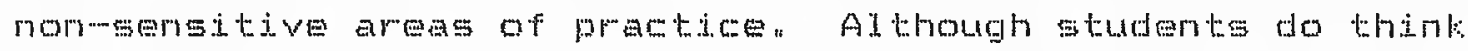
about situatoms suth as making bhonges. the assistance with

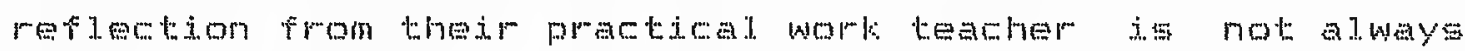

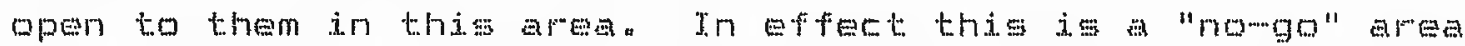
and therefore reflectiong although individumlly indulged in, does not result in an outcome in Boud"g terme ing " a new

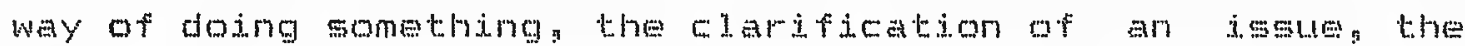
development of a whilg or the resolution ot a problem" (ibid p.ss). The outcone of this merlection is a decision to do nothing or a postoomement of a decision or a negative response that results in a decision to gat out of

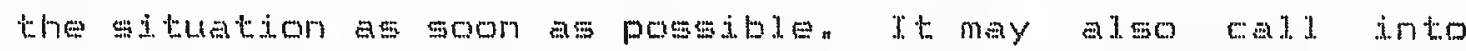
question the dmoividualistic focus of this reflective approach (Eoud 1985 ) where the political and socian montext is largely igmored and therefore studentes are not able to oxaming mangen Not least because practical work teachers are aso partor this oforial and political context.

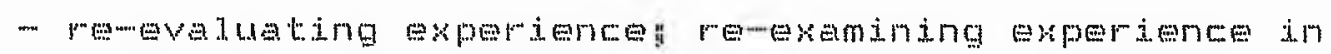
the 1 ight of the learner's intent. associating new knowlecge with that whith is already possesseds and integrating this new krowledge into the learner's

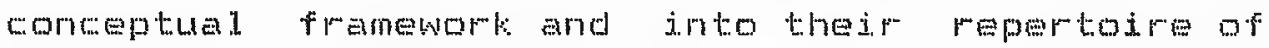
behaviourm

knowledge con be developed by adding new ideas and information or through the adaptation of what was al eady 
known to new situationg. The students am very lemen to have their previous knowledge recogised and the post megistraton status of the compe means bhat students do not Expecte to have to relearn things they already know. The

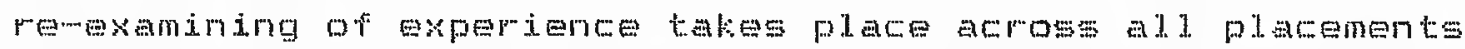
and particularly in the third placement, when students are trying to fit their new bnowledge into the reality of district mursing as they approach the time when they will no longer be able to fall back on their gudent atatug at also involves looking back on what they lonow. For exampleg ona student had experifnce in orthopedics in a hospital Etustion ancl drew or whis knowledge in the home. rnteglating new learning into their "stock of knowledge" is something the studente talk about in making links betwesm the college and prietimen Here the students are demonstrating that aspect of rewaveluating experience that Goud et al (1985) calis validation ".."a meality test" (ibid P.?. (3)

Fe-.evaluation will have verying results for individual hemproma It may result in the diswading of an experience as providing no informationg surin as that described of a visit. to a sperialist hospital department other experiences need to be teased out to discover what might be userul and

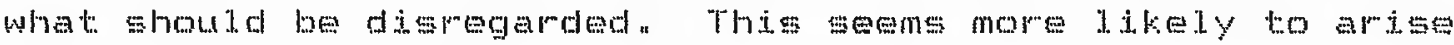
from visits to patients where therg rare complex problems to unravel and whe student is left with a mix of feesings and attitudes that neef to be discussed, in this situaton 
remevaluation might be open-wnded where the test for reality has to be left until the student has qualified as a district mumse the influence of context it important here (kemmis 1985, Jarvis 1987), Whilst rewevalution and indeed reflection are directed by the intentions of the individual, they are also part of the gocial context. The ability to bring about change or even to test out reality may be inhibited by the sorial or political context and in

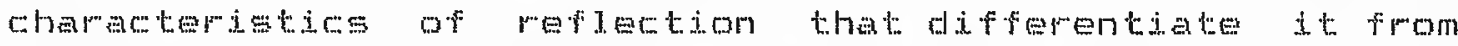
idle speculation or day dreaming "What da clear from this study is that the context: that is the learning envimonment. is not easily controlled by the practical worle teacher.

As Boud and Griffin (1967) state the stages of reflection are not as clear cut as diagrammedcally shown. They do not follow "a simple linear sequence and they are not independent of each other" pass As with al modele it is only useful to aid our thinking about the process or in case of difficulties in meflection "to think about the stages we have described and examine whether amy of them have been omited" "In this mesect it may help praction work teachers to facilitate the process it they have the skilig to do so. The elements of weflection are clearly evident in the categories and the opportunities for utilising the process of reflection as part of experience are also identified what is not elear is the depth into which reflection is engaged. However Fowell (1987, 1989), using an adatation of Mexirow's (198x) leveds of retiectiona showed 
that meflection at the higher levels that lead to learning and a change in pergpective were demongtrated more by communtity nursess than by hospital nurses. The greater autonomy and bak of institutional regimes were the reasons given. This is a useful comparison with enother post-registration group of numes albeit smalla that indicates the potential of the learning environment for promoting reflection-inmaction. However it its olear from the distrite nume students in this study that the community leaming environment has its ourn restritcions to learning and that a technical-rationality model is generally supported by the practical work teachers.

Again it is not clear as to the level of the ability of practical work teachers to undertake meflection as a teaching strategy. An assumption from the evidence would be that some pratcical work teachers are not providing the students with opportunitiec fo reflect on practice evem when students clearly want some help. others give help in the form of a sympthetic approach to the difficulties of being a student. They initiate reflection by recollecting what has gone before and an understanding awareness of the students feelings in the learning process all are concerned to apply theory to practice as stated in the p. Tacement objectives 
The Context of Feflecting on Experience - The Learning

Environment

The learning environment is very infuential on the gtudents ability to learn from theip pretice A A a I the categories show there are bermers to the students learning not least the practice regimes that direct and in some instances, restrict the students opportunities ror reti lection"

The influence of environment on retlection in practice is a concept taken up by schon (1985) "He describes reflection as thinking and adding to knowledge while in practice epitomined in his well used phrase "retlection-in-action" (ibid pos)" Fom Schon the context is ald important where learning by doing, in protessional moucation takes on special meaning "It is not just the sitting by" Nelly" or technical. mationality model of learning but the combination of learning by doing with reflection. It is a refuction that includes dialogue with the teacher or" in schon's terminology "the comeh". The main activities of the coach in "demonstrating: advising, questioning, and criticising" (Schon 1987 p.se) are carried out in the practicum - a seting designed for the task of learning a practicen Here students laarn by dojng " alhough their doing "falls short of real world work" "It "mpproximates" a practice morldy and reflection in the practicum takes place in a protected: sare envimonment. However the practitum, or practice setting, for district nurse students, is where they 
experience directiy the pressures and stresses of the uncertain womd of district numbing 1 is in this enviromment of metuing meal every day problems that reflection takes phace in the "mampy lowlands" (solnom 1.997 a.2) of indeterminate problams.

The difference betwen the reflection-in-action clescribed by sohon end that of other writers is his emphesis on the reflcetion within and while undertaking practed a som of thinking on your feet familiar to many professionals and a feature of professional practice. The observations atw students gave examples of this type of thinting in stuations where they were not certain of the action to be taken. However for the students this presents a difriculty as the ation they may consider aporopriate may be different to that favoured by the district murge who has responsibility for the coseload. The eare taken to ensure that they work within the estabished pretice of others $\mathrm{is}$ mentioned by all students and is apparent in all the categories. The ailemme is well. stated by one studenta.-. "you have to know which sister is looking after the patient as to what they would do" "This does not mean that sturents do not have their own ideas but they develop ways of putting romard those ideas in an acceptable way there is no obvious theory of practice to be drawn on as practical work tachers and district nurses have their own ways of worting The very alitonomy which Pwwel1 (1987) refers to as promoting

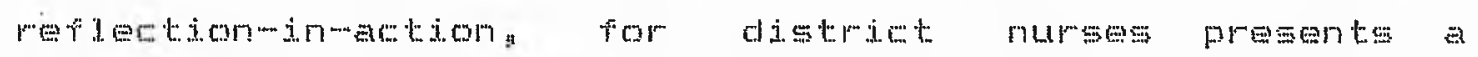


somewhat complex sitution for the student.

This is not to sey that there is no shared view of practice: andeed as stated previously there is a consensus of opinion from the practicall work teachers about: what should be taught to studentis and this generally meflects the objectives of practice put formard by the collegen The studente do not always share this view but are not able to discuss the different perspetives freely. This is similar to the findings of Twim (1989) im her study of heath vistors and fieldwork teachers who adopt respectively a non-directive and dimective mporoach to cidents she describes these diferent perspetives on practice as "contlicting paradigms of practice" (ibid p.274), These findings then question the feasibility of developing the intuitive judgment of fonting-in-practice (Schom 1983), where knowledge is generated from pratrice and Where the artistry of practice is obervablen the reality of practice can be very contradietory,

The practicum then" provides the student with the opportunity to observe the artistry of the profeseion and to develop the abijity to rewrame problems which cannot be addressed by application of actepted theory. The important point for schon (1983"1987) if that while practitionems may use theim dntuitive knowimg to solve familiar problums: not unike "labitualisation" (Jarvis 1987), they may also 
come arosos many problems where there are no prewset answers as noted in this study "In these cases the practitomer reeds to be able to reflect in-mation by meframing the problem and having the contidence to act in uncemtainty hempring to merlect-in-action is therefore an important skill for students to acoulde and can ondy be learnt in pratice settings (Schom 1985). Whether or not the practice setting should resemble the sefe and protected environment described by Schon is in question" Indeed the "practicun" is a mather contradictory concept in the light of his emphosis on working with indeterminate and real dife problems "There $i$. a danger that a protected "practicum" wil resut in the simulation of real dife problems which may then be rarried out in an institutional setting, megating the whole idea of refilection-in-atation

The concept of reflewtion-in-wetion his added another dimension to the process of meflecting on experience: at though the procese is not fundamentadidy different from that deseribed by other autmors "However in descoribing reflection as a part of protessiond pratice he presents an appea 1 ing and understandable argument for the pase ob practical browledge as a legitimate and central type of

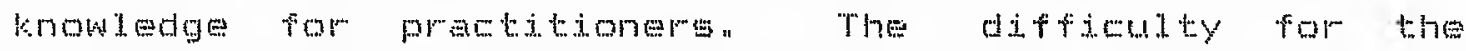
distoret mume students is that there is no obvious stoct of practical knowledge for them to apoly. Therefore it they are working individualy to a technical rationadity model of application to practice: even in the practice area they 
Wil find conflict between the practice of one practitionem end mothers despite the consensus of espoused theory of practice put forward by the practical work teachers "This contradiction in practice is again simsim to that for health visiting students (Twinn 1989).

A more reflective moded y whith one student testribed as the discovering practitioner and one practical woms teanem descmibed as malytical and enquiring practicen mould of mome opportunities to utilise fully the pratice sutting as a learning enviromment. This type of model would meet the demands or unertainty and umpredictability which charatreise the practice getting by equating with the two main assumptions underlying sehon's arguments (1905,1907) Mamely $n-$

1. Wany of the problems that practitioners meet are complox "messy problems" for whith there are no prewset: armwers to be applied by those who do not actually comprehemd them and who are outside the practice setting

2. The knowledge to solve these problems comes from practice. This knowledge is only accessible by the observation of expert practitioners who pass on their knowledge by the demonstration of professional artistrys the intuitive judgment of knowing and the Ekili of reflection in-action, which together are the charateristics of a reflective practitioner (schon $1993,1987)$ 
This argument is not new (Fyle 1949, Polanyi 19b7) but has been related to the profesising by schon's work with professional groups His ideas have been taken up by others in nursing (Fowell. 1987), in health visiting (Twim 1989) anc in teacher education (Fish 19g9)" The parallats with intermittent experience in teacher education are userul nere "The contribution of observation to learning is described at four levels, which wan well be related to the observation of prateice by disticte nurse studentga They are desceribed by fwish (1989) as

- It can help shape in the students mind what con and what should (and should not) be done.

- It can help her to begin to consider whether and for how she can personally operate within a cilassmoom.

-.. T. can begin the vital process of associating atsion

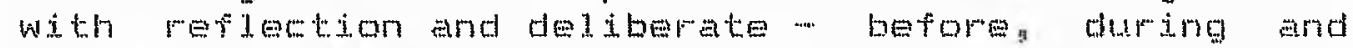
arter action - which can help the student to develop her own persomal theory"

- Properly mbedod in other sohool experience activitien "n it can help the student to see how a aide variety of practicel experichen together with a ranges of theoretical. perspectives can contribute to personal theory"

$(p, 105)$

This descuption brings some of Schon's (1.98s) ideas into a British context. The district numse students are undertaking blocks of experience in the reality of prectice. The levels of observation detailed above are clome to the experiences described by the district nurse students indeed there is evidence across the categories to demonstrate the progress in learning postulated by Fish (1989). The main point however is that the aim of observetion is not to mimic what 
is happening: but to "merine ones"s own thinking and Ultimately one" 5 own actions" (ibid palos). A further important point is that without the knowledge to observe. think critically, reflect on and andyse whet has been observed and experiencedy refinement wil not oceur" it is also important for district nurses to be able to devejop personal theories that may subequently guide their practice in the context of the praction setting of district numsing The sturlents therefore need not only the individual abili.ty to gain from the observational experitences but a jso the guidance and help from the practical work teacher in order to set the observations within the context of prefticen In the light of my study therefore there has to be some questioning about the concept of a "practicun" in Schon"s (1987) terms - "time of pressumes distrations and risksn" " $"(p, g y)$ - which may wed insulate the student too mus from the rean world of the prectice getting.

Droe district numbe students began to take on aspects of manging practice as described in the category "Feality of Fractice" they were concemed with taking rieks because they were working in situtions which were unknown - visiting mes patients for the first time or working alone perhaps when

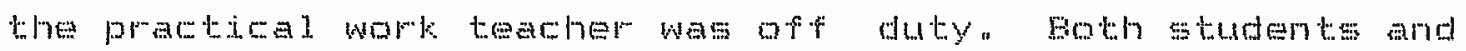
practical work teachere were able to descibe such gitutions. Athough gtudents ad not perceive that they were at the tire being dejiberately put in situations of risk, this was clearly more than "appmoximating the real 
world" (Schon 1987) and was a mecessary experiemce for students. How these experiencex prepared studente for the next stage of their course - that of supervised practice -.. is not very ciear. Femponses were mixed as to whether or not these experiences had prepared thein "However all stubents agreed that increasing respongibijty and with it the element of risk entailed in unknown situations: was impartant in learning how to become a district nursen,

Jmplications for digtrict nurse education

The analyeis has raised issues about the experiences of students in the practice setting which pertain to way in which the opportunities for learning are made available to the students and the ways in which the students are able to utiliag the potential for leming. The opportumities for learning arising from the practice of district nursing and the utidisation of learning are to a great extent dependent on the learning environment that prevals in the practice. This environment is much more about the practitionersg their was of working and their attitudes to the students and to learning, than about physical characteristics such as heatth contres, teaching rooms ofrices and primary heath fere teams identified as suitable placement roiteria by the English National Boamd (1987) (See Appendix 7). Learning from experience in practice is about the fecilitation of learnimg about controling some of the experiences end about being able to identify and formulate a theory from 
practice. The application of theory to practick model mases difficuties for students within prattice where there are contradictions between practitioners and between college and pratice - where the curriculum does not portray the reality of distriet numsing prateice The skilds modej of practice presented by the objectives curricusum for djutidet nursing (ENB 1987 ) is contradictory to the mumamistic model of adult leaming taught to practical wort: teachers (ENB 1987), Fumbrmore the individualistic approach to practice espoused by the practical work teachers $i=$ at odds with the task orientated and work driven practere experdenced by the students:

The powerlessness of the practical work teacher to influence the prevailing practice in the learning environment ig obvious , The seteing up or any somt of praticum a a sefe movironment to try out ideas would present ditriculties ror one thing the practical work teachers seem to work to a competency based model and for another their personal theories of district nursing - their essumpions values and

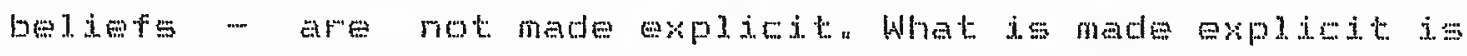
that of task orientated reactive prackice " This means not that they do not hold personal theomes of practices but rather that they do not discuss these theomes to any purpose with the students "Fractical work teachers express their own frustrations at not being able to give students what they reel is a good deal. There is confict between their atiss ror learning and whet is achievabie at is not 
thet they are ingensitive to the problems of students or that whey are unawe of the shortcomings of practice at is rather that their own aspiratons for teaching cannot be achieved.

However the provision for learning through practice is something that pracicical work teachers hold dear and that district mume students value The opportunities to experience many aspects of practice are clearly available However the pportunities to readiae the learning potential of practioe and to conceptualise it as the focus for developing district numing practice raje issues that district numse eduction needs to consider. These are issues about the featumes of the learning environment that influmee the leaming processes and learning experiences of the students "thet have implications ror the students the practical. work temehers and the epistenologieat stance of the practice and the college.

\section{Students}

Firsty the sudents have some intluence on their own lewarng and are motivated to make the best use of their experience in prectice. They are able to adept to the uncertainty of the communty and to develop, to some exterts ways of trying and testing out thedr experiences and of riting into new situations 
self directed with the help of their prectical work teachers and are eager to make use of resources available. However as part of self direction they reguire guidance on what to learn. This is echoed in the evaluation of the English National Board pilot studies (Leonard and Jowett 1990 ) whor pre-regiatration students were not sure what they needed to know. Although district nurse students have some ideag about their own meeds: for learning to continue to be meaningful and to be utidinged they require access to the practical work teachers" This access may be spasmodis and to a certain extent resisted by the students as their confidence grows. Indeed the increasing mesponsibility gtudents value is measured by the increasing independence from their practical work teachers.

Linked to the identification of learning nesed is the importante of acknowledging what studentes alleady know from their previous experience in learning. Although students are able to identify instances of having to repeat experience and to demonstrate competencies they already have. particularly prackical techniquess it seens this prior learning is not related to present learning need: Crediting students with prior learning in the practice area is clearly important to then. The assessment of prior learning in the area of prectice is one that needs to be addressed. The work of winter (1909) in assessing prior learning for entry to masters progranmes could be a useful starting point as it inoludes nurse entrants. However this 


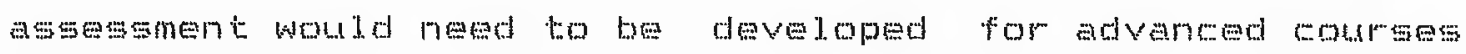
that inelude edinical prateice such as district musing.

For students to be able to integrate wollege teaching with practice they need the ability to think in abstract toms and to synthesse material with other disciplines "The application of knowigdge bo pratical situatong in the haphasard way axperieneed by students is ikely to negate the worthwhideness of browledoe (Feters 1981) that arises from both the behavioural and biologital seiences, because it is neither understood as a seience nor sem as relevant to practice. The process of integration 15 sem by the students as their responsibility and could be enhanced by the reflective process which they have already developed in an ad hoc rashion.

The reflective process also requires analytical skills to enable students to integrate rew knowledge into their conceptual framework. It is ciear from the students comments and from the observations that sudents are anedysing current practice and trying to set their own values and beliefs into the realdty of the pretice setting The postponement of this amalysis in some of the more sensitive areas of change diminishes the potential of reflection in developing their own values and beliefs towards a personal. theory about digtrict nursing practicen 
Fractical work teachers

Secondy the practical work teachers are of great importance to the students. Iearning process: not only in helping the fitting in process. but ajso in aiding the students understanding through peflection. The potential inrluence the practideal work teachers maly have in controliding the Learning envimonent to allow optimum learning is limited by the attitudes of colleagues the lack of control over workigads and the inabihity to change routines of practice where mecessary" However thejr individual redationships with the students are also very influential and can help the student to overcome some of the frustations that actur " the Gevelopment of a "practicum" providing a balance between real and protected practice. where the stucht can experiment and learn from mistakes would be appropriately within the domein of the practical work teachers " However this sort at development requires more control over the routines of practice and programes of leaming that woud allow the students to indiate chenge and to talk apenly about their ideas.

Fratcical work teachers are expected to be not ondy experts in district nursing practice but also teachers of practice. As such they transfer both the personal or tacit trowledge of district muming practice and the knowledge of pratical techmiques, by working with and alongside the students. Atrimson"s (1981) study of the clinical experience of 
medical students leads him to put forwara in the context of medicine, ar argument similar to that put forwerd here. The professionel womk concerned with technicality is made explicit in rules; procedures and tewhiques at but the personal. or tarit bnowledge, concerned with the internediate worl: of a profession. $i s$ not made explicit and cannot be formulated into procedures and tempiques "Both types af knowledge were used by medical students in thedrefforts to become doctors and used by doctors to team in the eI ineal setting. Atrinson's (1981) concisions are that the two are "intertwined" "He gtates the point thus"-

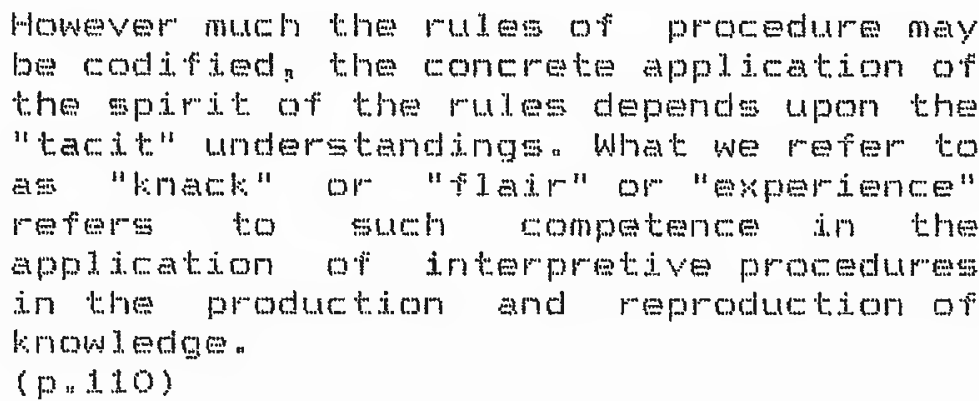

Eoth types of knowledge are transmitted by the practical work teechers - on the one land by denonstrative and explicit description of techniques and on the other by giving intreasing responsibilitity for patient and caseload management to students and implitity fostering texta intubive practical knowledge. It ig importent that sueh major changes as nurse education is now undergoing do not mean that the best of the old system of apprenticeship "what of being chose to an expert in action" (Jacka and Lewin $1997, p 32$ is 1.05 t: 
In an erfort to integrate theory and practice practical work teacherew work closely to the placement objectives set out by the rollege. In teaching the prectice of district rumsing they are ajso concerned to ensure competence. Both these ractors lead to an objectives based and a wkils based model. or teaching. A move towards a more reflective approach to teaching would sem more appropriete and has implications for the teaching of adut learning theory in practical work temcher courstes.

The findings here are similar to those of Mags (19g9) in lris evaluation of the preparation of practical work teachers in England. of relevance to this study are his recommendationg that there should be resources to support practical. work teachers! continuing education to maintain and develop their teaching stilts and knowledge! manegerial and professional support to make effective use of the prectical work temcherg' skilla

The experiences of students in the "Fitting In" eategory suggest wht stuents would benefit from not having to move to another location for supervieg practice as is the case now. The pratical work teachers role coud then be extended to rover students experience in supervised practicen 
Epistemology of College and Practice

Thimdly the epistemological gtance of the college influenceg the approach of practical work teachers to students learning through its guidelines or objectives for practice which are described in terms of objectives for competencen The college also seems to requime the students and the practical. work teachers to integrate the college teaching and the practice experience by application of college worl: to practice. Clearly the college is comerned to encourage the integration of theory and practice. A more explicit framework with acknowledged college regponsibility in this process may draw the two environments of learning closer together. The work on courses in teacher education has much to offer cumpiculum planners in working with models that concentrate on the question of theory and practice (Webb and Wikingon 1980). Their individualistic modela-

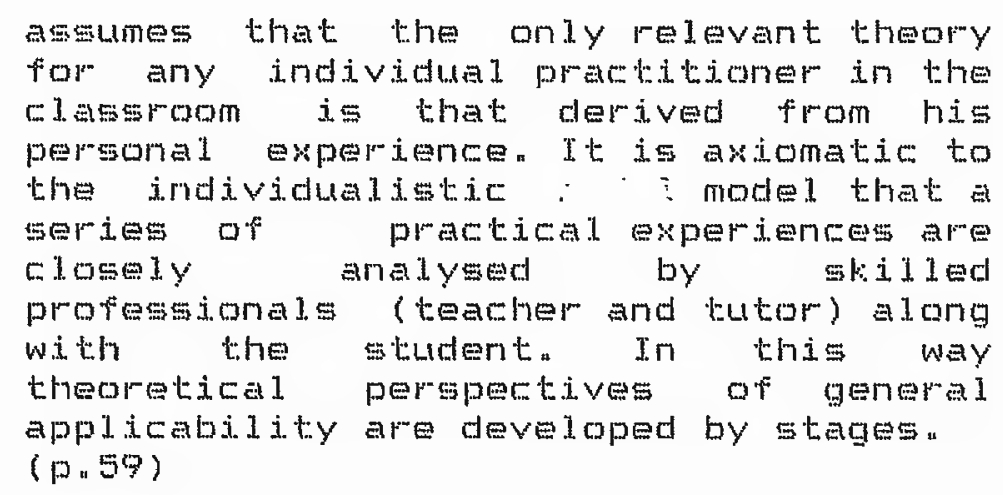

This type of model draws on prineiples of edusation in this case learning in practice - not as in so many numsing courses where a competency model is adopted or where a model 
of nursing which originated for a totally different purpose to that of providing a frameworl for curriculum is adapted.

The knowledge taught to sustain the practire of district nupsing does not appear to be clearly identified in the curricujum. Spicer (1985), on the assumption that district nursing knowledge is embodied in what course documents describe as Frinciples of District Numbing found great variabijty of content under this heading across fourty eight centres ofrering district nurses courses in the UK. The content ranged acmoss the biological and behavioural sciences and spicer concluded from her content analysis that district numsing knowldge has borrowed knowledge from other diecjplines and the uniqueness of distwict numsing with its complex applitation in the home is "unseen" "The similarities in these findinge with those of Twinn (1969) and of my study indicate that the knowledge used in practice is largely unddentified and unacknowledged and therefore the technical. rationality model of knowledge epplication is at best confusing and at worst irrelevant.

Development of personal theory indicated by Fish (1.989) and Twinn (1999) as an important aspewt of practice based Jearning is described by the students in terme of what is important to them in district nursing for intance a- 
- giving time to patients

- treating patients as individuals within their homes

- manging resources to maintain patients at home

- setting goals to meet expressed patient needs within the Iimitations of patient and career resources.

- working as a nursing team.

However theme personal beliefs and values,the beginnings of personal theory, stand in contradiction to the apparent pmevaling beliefs and values that are evident in the routines of "busyness" and visiting and the seeming inability to control worldoads and practice (Mackintosh 1975. Foulton 1981. Badger et a 1989). It appears from my mesearch that these contradictions result in compromise rather than the testing out of what they mean to students and are therefore ineffective as learning experiences. Students have clear ideas about what they would Iile to achieve in their role as district numses and about what they would bike to change to achieve these aspirations.

It is clear then that experience with the indeterminate problems in the patients homes is where district nursing is carried out and where the students gain most of their experience. This is the experience that is highly valued by the students, the care of the patjents at home " It is where the "arkistry" of district nursing is learnt: where the core of district murging is observed and where practical. 
of district nursing is observed and where practical knowledge is trangferred. The certainty of this experience is highly prized and constitutes the reality of aistrict nursing.

Conclusion and Tmplingtions for Future Research

The changes in nurse education as a result of Froject 2000 will provide students with the initial experience and knowledge of nursing in the community. This in turn will result in further changes to programmes that prepare the proposed advanced pratetitoners (UKCC 1990) who will be practising as district nurses.

This atudy examines the learning experiences of distritt nurses from the perspective of the students " In so doing it has gone some way to gaining an understanding of how studentg learn in practice and what helps or hinders their learning. Attention has been drawn to the difficulties experienced by students in fitting into new settings and trying out change, to the detrimental effect on learning of rigid practice routines and to the powerdessmess of the practical work teacher to influence the learning environment. Issues have been paised about learning in the practice setwing which have implications for further research and for tourriculum planning. 
The development of a packege to mondtor and evaluate the pratice getting as an mavironnent that provides optimum learning would be an appmopriate project for turther mesearch. lit is important that oriteria for assessing and monitoring enviromints should refiect the range of issues imvolved in leamimg in practeice and should be useful to those working in the setting for self evaluation and monitoring "The criteria might appropriately raise questions about:

- the almount and level of influence of the practical. womk teachers on the opportunities for Jearring in the practice setting

- the awereness of gteft within the setting about the learning needs of distmict nurse who will be probising as advareed practitionars (UKC) 1990$)$

- the attitudes of practical work teachems and other nurging staft to inmovation and change

- the 1 evel and amount of contwol by the practical work teacher over workloats.

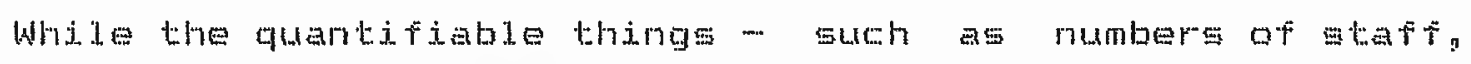

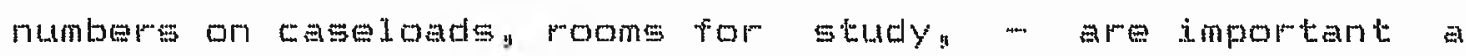
more comprehensive package of evaluation i.s required.

Fed ated to evaluation of the learning environment is the 
Epecific development of practical work teachers" teaching skills. Students establimh a strategy of "Trying and Testing Dut" which provides opportunities to reflect on their experiences. Action research, involving both practical work teachers and whdents "to develop teaching istategies based on experiente and reflection would be a further way forward. ciosely linked to the above is the development of a "practicum" where students can analyee the realities of practice in the light of knowledge taught at college and where knowledge developed in practice can be identified. Again action research could provide opportunities for researoher and practical work teachers to work together to enhance both amects of the practical work teachers role. that of teacher and practitioner.

The new programmes for advanced practitioners will oblige educational institutions to develop new curriculan At this point curriculum planners will need to take account of the contradictory ains of an objectives "skills based curmiculum, end the humanistic philosophies underlying adult learning theory "This research has raised issues about such contradictions, the results of which are evidenced in difficulties in integrating college teaching and the reality of practice. This is also related to the issue of competencen it seems here that if competence is identified as an end point by objectives that emphasige behaviourist philosophy there will be a danger that students will continualy have to repeat their learning. The changes in 
Froject 2000 will provide a foundation and a levej of competence from which professional practice can be developed - an ongoing process " If this approach is to be succescful there will need to be different starting points according to individuals previous learning . For instance, in this study the practical work teachers without exception had the same otarting point and used the same routine of moving from cinical tasks to mangement of caseload as noted in the "Fitting In" category. In this respect the assessment of prior learning needs to be addressed in CumricuJum planning.

The findings from thig study are comparable with findings from studies of other practitioners who learn in practice settings (Atkinson 1981. Figh 1989. Twinn 1.989) "The issues raised make a contmibution to the planming of learning from experience for nurses undertaking post-registration programmes and for practitioners in other professions. 
CHAFTEF NINE

ETHNOGFAFHTE AFFENDIX - A pOStgCript

Discussion and comment about the research method has been incorporated into chapters three and four. This reflexive account will analyse ethnography as it has bee. n used in this research and provide a starting point for others in nursing research who may chose this methodology.

At the outset it became quite ciear that compromises would have to be made due to the practicalities of collecting and anajysing data over the short time available in the taught practice of each coures and to the limitations of a single handed part time researcher. Despite the rather despondent renaples from fayne et al (1981) that ethnography is only possible for full time researchers, it seemed to me to be the most appropriate method for this reseameh. However the appositeness of such remarks becane obvious as the research progressed. It is a complex method and the involvement of the researcher as an instrument of data woll dection and of analysis sometimes makes for introspection and sejt doubt " It a 150 requires a great deal of sensitivity in interacting with gatekeepers and informants. The researcher hes to draw on personal mesources or resiliance and welf confidence to maintain fieldwork and analyeis over periods of time This combined with the 
inteliectual requipements to be inaginitive and to develop conceptual categories: were all things for which T. was unprepared when I embarked on this research.

I have drawn extensivejey on the work of Hammersley and Atkingon. In particuler their approach has provided a framework for fieldworls and analysis.

Fiteldwork.

Fiejdmates improved as $x$ became nore adept at focussing on themes that began to emerge. In the first year i ejther tried to record everything in the setting which resulted in a great deal of inconseguential information, or I recorded very littles as many things that happerned appeared at figst sight to be of no significance. As Atkineon (198ג) points out, it becomes easier to gedect key issues as the research progresses and as substantive themes emerge to guide the data collection. Selectivity in making fieldnotes is not Gasy to achieve at the beginning of the data collection. when the researcher is deliberately trying to be open to the perspertives of others for me thigi was something $\mathrm{f}$ was constantiy trying to achieve - a distance from the setting and from the people in the setting. Making judgenents about settings with which you are familiar is very easy to do. The decision to choose settings where I had no previous astociations with the staff helped me to metain my 
"gtrangenes" " I realised that my preconceived ideas about what went on in the practice setting had to be changed and this fart in itself was an indication that I had entered the setting with expectations of what I would find.

The fieldnotes in the first year would have been inproved if a more comprehensive version had been written up at the end of eacly day. Although the iturature advises the researcher to make fuld witten recomds that can be read and comprehended at a later time: it is ondy when you test this out by trying to make sense of something three months later that you mealige how sensible this advice is.

The research diary was a most userul tool. It gave landmarks and structure to the date collection and provided a context agalnst which to check the validity of the inferences fField and Morse 1985). As a reflexive account of the process of the research." . it provided an ppportunity to express feelings on paper and in this way to kepp the social and intellectual distance necessary for the analytical work of ethnography " Linked to this notion is that of personal intuitive theories (Hammerseley and Attingon 1983) "The diary raised awareness about such theories that inight affect andysis - for instance my concern about the standards of mumsing practice in the context of changes bhat require distriet numbes to develop their rolen student experience was a guide and reference point that detemined date 
collection. Adult learning theory set this within an educational framework al though the activities of astrict nursing practice could have been of equal interest and raised diterent issues. In making explicit the theoretical gtance it enables others to draw their own conclusions from the remearch. A ugeful. example is Melied (1981) study about student nurses in which she useg the term "fitting in". However the interpretation within the framework of occupational socialisation has different implications to those that arise from an interpretation within a framework of adult Ieaming.

Analysis

As J. stated in Chapter foury transcribing my own fieldnotes was the beginning of analysis. Transcribing spartect of ideas that led to anaytic notes (Hammersley and Atkinson 1983). It was not until the second year that 1 fully realised the potential of such notes. Although they had their beginninge in the theoretical notes (Schatzmem and Strauss 1973) Used to order the data they soon became an important part of the analysis as progressive focussing developed. The construction of analytic notes "constitutes precisely the internal dialogue, or chinking aloudy that is the essence of replexive ethnography" (Hammergley and Atkinson 1983 ). In fact the development of topics or themes that quide progressive focussing arise rrom transcriptions and riejdnotes and subsequent analytic 
notes. In any future research if would file these memoes in a more Eystematic way, in order that they might be retrieved more quickly. Indeed much of what I have learnt from undertaking ethnography has been about the recording and filing of data for future retrieval and comparison.

While student transeripts provided the starting point for analysis and category development: practical work toacher transcripts and observations were used to provide a different perspective and to check out meaning. In abstract terms the use of different perspectives seemed a rather nebulous concept, but it came alive in the analysis " Sone comments by stuclents would not have been as meaningful Without the practical work teacher comments or the observations " For ingtance it was clear in at least one gituation that the student was not having as mush interaction with the practical work teacher as she would like. When it became clear that thig was a deliberate stategy on the part of the practical work teacher: it charified the differences in explanation of heavy workioads made by sudent and practical work teacher. This instance was easier to explaing through understanding that there was a discrepency between the student's and the practical womk teacher's priorities for Ieaming. The practical work teachem explanation also provided further evidence that the student was being left alone. The observations too provided a stronger basis for gemeralisation within setwings - for instance: noting how studente acted or felt within the 
patient's home in comparison to when $x$ saw them in the health contre. One of the difficulties of having to negotiate all the terme of the research in advance with the health districts, due to my own time constraints. was that I could not change djpection easily" It was clear that negotiation within the setting could have taken place and that further vigiting or theoretical sampling could have have been undertaken. Thig dis useful to know and would give confidence in future for larger scale research. In this study one extension of my observations could have been to observe and pecord interactions between student and practical. work teacher" had this option been available.

It was this whole area of having to make compromises over theoretical sampling that caused me the most concern. Ferhape it was my eagerness to make use of the grounded theory model. within ethnography that caused some of my concern and confusion. The nature of grounded theory (Glaser and Strauss 1967) as a process, with its systematic ateps of progressiony is not to be confused with the broader approach to ethnography which uses other models such as analytic induction. The differences became apparent as the research moved into analysis and theoretical sampling as a form of constant comparison. At this stage of my mesearch I was anxious to ensure that my analysis was as rigo rous as possible. Ferhaps this anxigty came from a wish to defend qualitative research rather than from the demands of ethography. 
The process of grounded theory begins with the intention to develop theory as conceived by blaser (1978):-

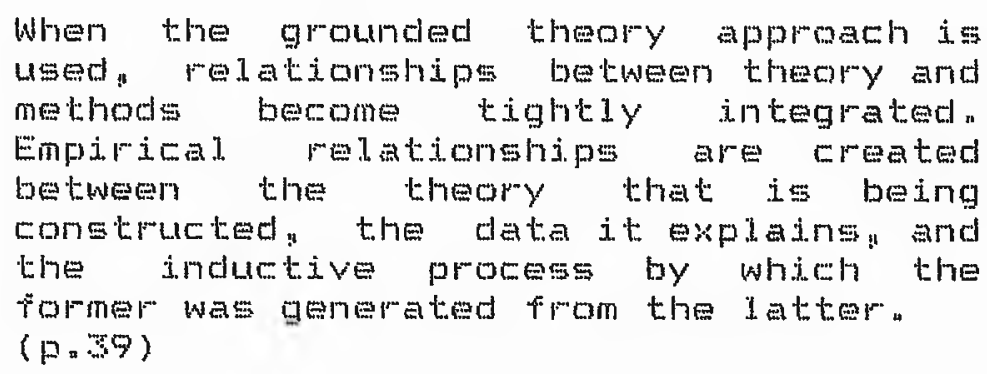

Within the definition the purpose of theoretical sampling is to develop theory " Within ethnography the purpose of theoreticat sampling is to discover and develop categories that seen most 1 ilely to develop theory " of coumsen as previously stated, there are various stages where the research may be concluded before the point of theory developinemt. However it may be that ethographers are intent on testing theory.

Common to both is the attention to detailed documentation and referencing in order that ideas may be retrieved and their source in the data identified to illutrate evidence and linke made with other concepts. A useful point in the grounded theory i.terature is the reninder that category development ig Garied out at a conceptual level of analysis so that the relationships between concepts wan be mapped in the data. The temptation to get bogged down in the date is thus avoided wurther pratcical information on sedf pacing whith I identify withy in described by Glaser (1978). He suggesth that analysing data should be restricted to between 
two and four hours and that ideas should be written down rather than takked through. His terminology of the "clrugless trip" was very reassuring at the stage of feeling "blocked" and not able to write His advice $i=$ to write down anything you think is analysis with a liktle reading to stimulate the writing. Then "through this tributory generated ideas find their release by associations and flow like coraz" and following this Eureka effect "energy is lost. "xextitement changes to stultification " "closure leads to gatisfaction"(ibid p.24). In other words the important thing is that the ddeas are recorded, so that they can be returned to Iater"

The assumptions of ethography (Hilton 1987) 1isted in chapter three have to some extent been tested during this research. Studying culture "as it is" can be tempered with replexivity - the recognition that the researcher will influence the setting. The fact that you are included in the conversation or asked advice is an indication of acceptance by the informants (Field and Morse 1985), but it also indicates that you cannot somehow become "invigible" "In this research werlexivity has become important on two counte. Firetiy it is clear that reflection has much to contribute to the leaming process in the practice setting of the communtys in relation to both gtudentg and practical. work teachers. Secondly it is as Hammers ley and Atkinson (1983) state. "the key to development of both theory and methodology in social science generaly and in ethographic worl: in particular" $(\beta \times 236)$. 
REFEFENCE:

ALLAM" F, and DOLLEY, M. (1987)" The Curmiculum in Nurging Education "London "Croom Helm.

ALEXANDEF, M.F. (198S), Learning to Nurse antegrating Theory Fractice. Edinburgh : Churchilu Livingstone.

AREYFIS, C. (1982). Feasoning" Leaming and fition. San Frameiseo : Jossey-Bass.

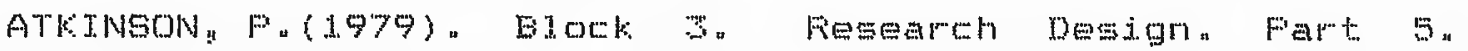
Fesearch Design in Ethography DEso4. Research Methods in Educetion and the Social sciences. Midton keynes "Open University Fress"

ATKINSON, F.(1981). The Clinical Experience "The construction and reconstruction of medical reality "England "Gower.

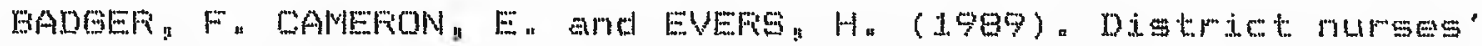
patients - issues of caseload mangement. Journal of Advaned Numeding " 1.4, $518-527$.

BALL; Gu. (1984) " Beachside Feconsidered " Feflections on a Methodotogica. Apprenticeship. In Burgess $F \quad G$ (ed) The Fescarch Frocess in Educational Settings "Ten Case Stuties.

BALL, S. S. (1981), Beachside Comprehemsiven a casemstudy of secondary schooling "Cambridge "Cambridge University Fresess.

BALL, 5.J. (1983) " Case Study Fegearch in Euctution "Some

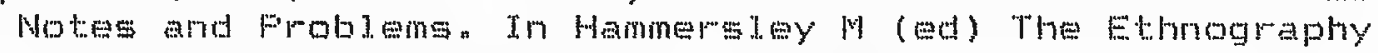
of Schooling " Wethoclological Issues:

Driftield: Nafferton.

BALL" SuJ "(1986)" Gociology in Focus. Education. Essex" Longman.

BATTLE, S. SALTEF, B. (1985). The Distritet Nurse's Changimg Fole. Guildford : University of Surrey.

BATTLE, 5 (1989). A study of Curriculum Innovation in District Nurse Education and Training. University of Surrey " Unpublished Thesis:

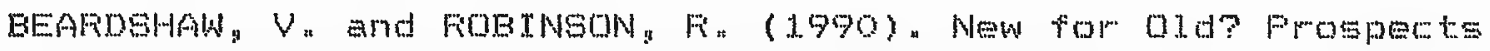
for Nursing in the 1990 s "Fesearch Feport 8 . London " King': Fund Tnstitute.

BEATTIE, A. (1987). Making a Curriculum Work. In Allan"F and Jolley,M. The Curmiculum in Nursing Education. London " croom Helm. 


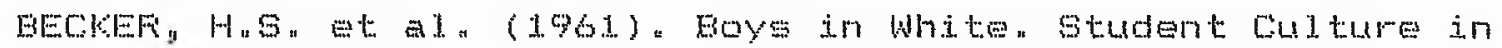
Medical. School " Chicago " University of thicago Fressa.

BECKEF, H,S and BEER, B. (1992) "Farticipant Dbservation:

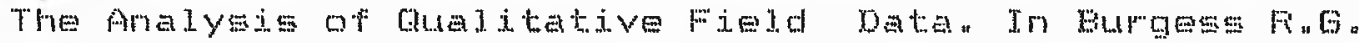
(Ed) Field Fiesearehn A Soureebook and Field Manual. London. Deorge Allen and Unwin.

BELL, c (1969). 'A note on participant observation' Sordology:, 3 , pp $417-1$ -

BENNEF, $F_{n}(1994)$ From Novice to Expert. Excellence and

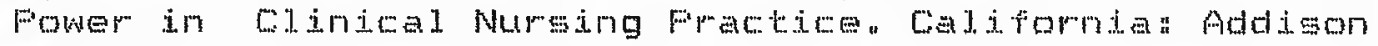
- Wegley Fublishing Company.

BENNEF, F' (1987) How Expert Nurges Use intution. American Journat of Nursing 1 " $25-31$.

Bouo, 0. (Ed.) (1989). 2nd Ed. Developing Student Autonomy in Learning . London "Kogan Fige "

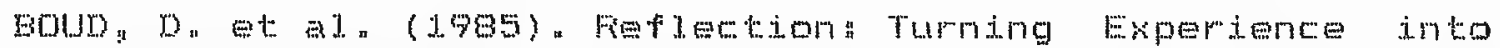
L..earning " Londom "Kogan Fage.

BOUD, $D_{n}$ and GRTFFN, $V_{n}$ (Eds) (1987) "Appretiating Adults" Learning "From the Learner" Perspertive"

Londom "Kogan Fage "

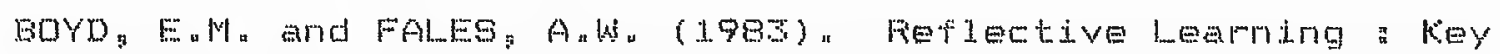
to Learning from Experiencen Journal of fidvanced Learning $14,824-8 \mathrm{~g}$.

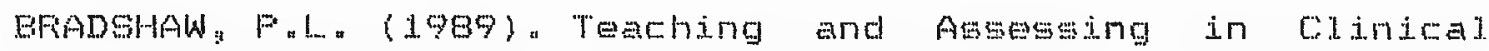
Nurging Fractice" London "Frentice Haji.

BFitGH, B.F' (1989). Theory and Fractice in the study of Adult Education. The Epjotemological Debate. London " Foutledge.

BFoOKFIELD, S. D. (1987). Developing Critical Thinkers" Challenging Adults to Explore Altemative Way of Thinking and Acting " open University Fress"

BFOWNHILL. R. J" (1987), Objestivity and Aesthetic Education

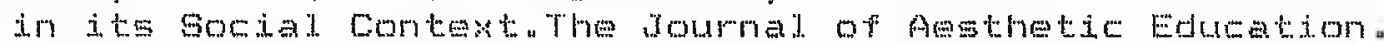
Vol. "21. No. $3.29-44$ "

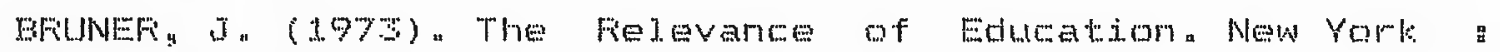
W. W. Narton.

BFUNEFy I" (1977). The Process of Educetion "Cambridge Mass. " Harvard University Pross.

BFYMAN" A. (1988) " Quantity and Ruality in Goeial hesearch. London " Unwin Hyman. 
BURGESG, F. G. (Ed, (1982). Field Fesearoh "a Sourcebook and Find Manuel. London " Beorge Alden and Lnwin.

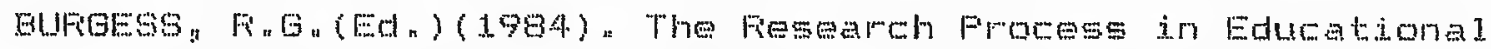
Gettings : Ten Case studies. Lemes " Falmer Frass"

BUFGES . F. G. (Ed. ) (1905). Strategies of Educational Fesearoh Qualitative Methods . Lewes " Falmer Fress.

BUFOES9, F. G.(1985), Fheld Methods in the Study of Eduretion. L.welues: Falmer Press:

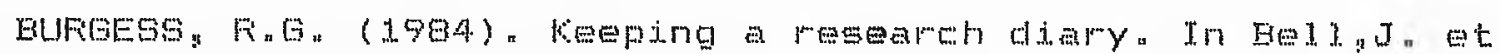

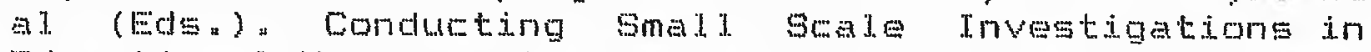
Educational Management. London "Harper" "

CANDY,F" (1987) "Evolution,Fevolution or Devolution" Inereasing Learmer control in the Jnstructional setting. In Boud: D and Griffin, "(Eds) Appreciating Adults Learming "From the Learmers Ferspective . London " Kogan Fage.

CARTWFTGHT, A. HOCKEY, L.., and ANDEFSON, J "(1973) " Lite Before Death. London "Foutledge and Kegan Faul.

CHALNES: A. F" (1982) "2nd" Edition. What is this Thing Calied Science. London "Open University Freses.

COMEN" L. and MANTON, L. (1989). Brd Ed. Fesearoh Methods in Eduction. London "Foutdedge.

COFNEF, if L (1990). The Newly Fegistered Numse and the Cancer Fatient. FhD. Thesis Unpublished "university of Landon:

CFOSS - DUFFANT, A. (1987). John Dewey and Lifelong Edumation" in Jarvisn F" (Ed.) Twentigth Century Thinkers in Adult Education "London "Croom Hejm.

DENZTN, NKe (1978). Znd, Fuition. The Fesearch Act. New York New York: "MeGraw Hilln

DEWEY, J $(1916)$. Democracy and Education n An Tntroduction to the Fhilasophy of Education "Now Yorl: "The Free Fress.

DEWEY, I. (1938). Experience and Education. London " Collter Macmillan Fublimbers.

DINGWALL: R. (1977) The Somial Drganisation of Health Vigitor Training a London "Croom Helin.

DINGWALt F" (1980)" Ethics and Ethography "Sociological. neview. 28, 87.-41.

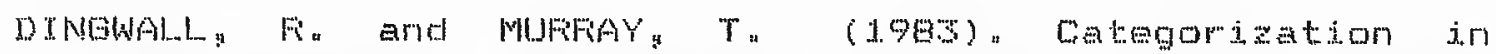
accident departments" "good" patients "bad" patientsand "children" "Sociology of Headth and xilness g, $127-128$ " 
DHSS "1979, The Numsen, Midwives and Heath Visitom Act. London " HMSO

DoH, 1989. Caring rom Feople "Communty Care in the Next.

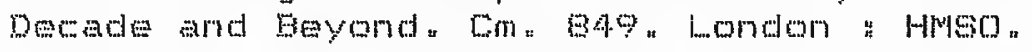

DoOo: A.Fn (1974), Towards an Understanding of MLrsing. Unpublished Fho. Thesis "University of London.

DUFFY, ME. (1987), Methodological. Triangulation :A Vehicle For Merging Qualitative and Quantitative Fesearch

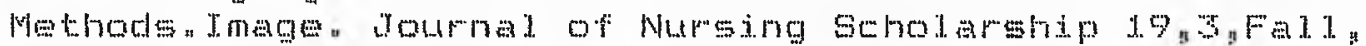
$1 . \pm-135$

EISNEF, E.W. (1985), 2nd " Edition. The Edutational Tinagination New Yort: "Macmithan Fublishing Company.

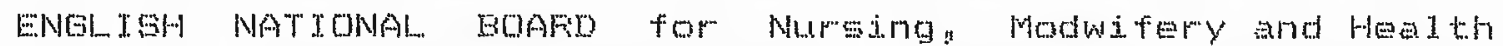
Visiting (1983) Curriculum in oistrict Nurbing for Fegistered Genered Nurses "London" National Boards for Nursing. Midwifery and Heath Visitimg

ENOLISH NATIONAL BOAFO for Nuraing Midwifary and Health Visiting (1987 mevised). Fegulations and Guidelines for Distrit. Nursing Education and Training and Felated Matters" London "English Mational Board"

ENGI ISH NATIONAL EOAFO for Nursing Midwirery and Health Visiting (1990). Guidelines for the Community Fratice Teacher Course" Circular $1990 / 26 / A F S / M B$ London: English National Board.

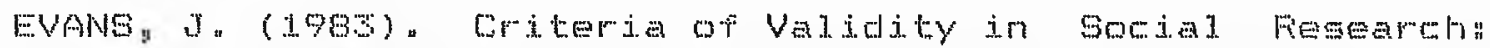
Exploring whe Felationship between Ethographic and Quantitative fpproaches "In Hammeley M. (Ed,) The Ethography of Schooling "Methodological Issues. Driffield: Natfertonn

FE. "U. (1981)" Experience "Reflection L Learning "London " Departinent of Education and Godencen Further Education Crurritulum and Development Unit.

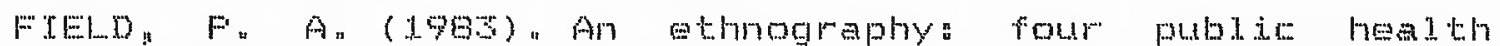
nurses' perspectives of nursing. Journal of Advanced Nurming $8,3-12$.

FIELD, Fa, and MOFSE, J.M. (1985), Nursing Fesearchn The Application of Duditative Approaches " Kent" Croom Helm.

FIELD, F" A. (I990) "Vadidity and Feliabidity jn Ethnography" Unpublished seminer peper given at pepertinent of Mursing Studies " London "King' = Col1ege "

FISH, 0. (1989), Leaming Through Practice in rnitial Teareher Training London: Kogan Fage. 
FRETRE: $F$ " (1972), Fedagogy of the Oppressed. Harmondsworth: England " Fenguin .

FFETWELL, J "E. (1982) "Ward Teaching and Learning " London " Foyal College of Nursing.

GANS " H. J" (1982) "The Farticipant Dbserver as a Human Being: observations an the Fermond Aspects of Fieldwort. In Burgess $F{ }^{\prime}$. (Ed) Fiedd Fesearchn a Sourcebook and Field Manue1. London "Beorge Allen and Unwin.

GIBSoN. S. (1980). A Critique of the objectives Model of Curriculum Design Applied to the Education and Training of District Nurses. Journal of Advanted Nursing. $80,5,161-67 n$

BLASEF, B.G. and STFAUSS, A.L. (1965) "Awareness or Dying. London " Weidentield and Nicolson.

GLASEF, B.G. and STFAUSS, A.L. (1967) "The Discovery of Grounded Theory" London "Weidentield and Nicholson.

GLASEF, B. Q “ (1978) "Theoretical Sensitivity" Califorma: The sociology Press.

GOLBY" M" et al. (Ed.) (1975) " Curmiculum Design. London" Croom Helo jon association with Oxford University Fress.

GOLD, Fi" (1958) "Foles in sociological Field Observation" Social Formes vol, 36,170 , $217-22 \%$

BOODLAD, S. (Ed") (1984)" Education for the Fofessions. Guildrord " SFHE and NFEF-NeIson.

GFIFFIN, C. (1967). Adult Education "As Social Folicy" England "Croom Helm.

GRIFFIN, Co (1.98\%), Curriculum Theory in Adult and Lifelong Education. England " Croom Helm.

HABEFMAS, In (1971), knowledge and Human Interests. Bostom: Beacon Fress.

MAMIMERSLEY: M. (1979), Block o. Making Sense of Datan Fart 1. Analysing Ethnographic Data. Milton Keynes "Dpen University Fress:

HAMIMEFSLEY: M. (1983) " (Ed.) The Ethnography of schooling: Methodological. Issues a Driffield "Naferton.

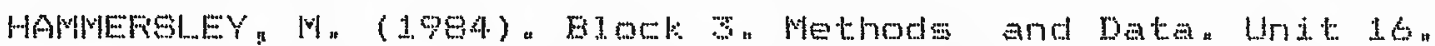
Ethnography "DESO4. Fesearch Methods in Edutation and the Social Sciences. Milton Keynes "Open University Freses

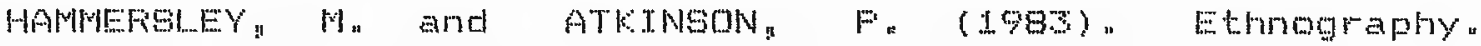
Frinciples in Fractice. London "Tavistock Fublishers. 
HAFGNEAVES, D. H. (1967). Social Felations in a Secondary Sehool "London "Foutiedge, Kegan and Fabl.

HAFTFEE, A. (1984). Malcolm knowles: Theory of Androgogy "A Critique . International Joumal of Lifelong Education. Vol $:$ No 2, 20S-210.

HILTON" A" (1987), The Ethoglmphic Ferspective. Module 7. Fesearch Awareness. Lombon "Distance Learning Centre! South Eank: Folytechnic..

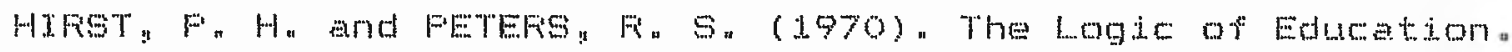
Lomdon " Foutledga and kegan Faul.

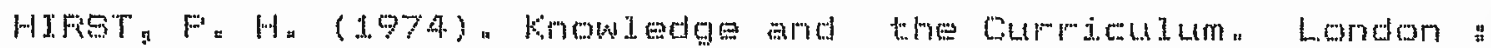
Foutledge and Kegan Paul.

MOSTLEF, I. (1982) "The Aims of Adute Education. Monoglmph 17. University of Manchester " Department of Education.

JACKA, K. and LENIN" D. (1987). The olinical Leaming of Student Nurses. Nurse Education Feserach Unit. Report: No.6. University of London "King"s College.

JAMEs, $V$ " (1986) "Care and Work in Nursing the Dying:

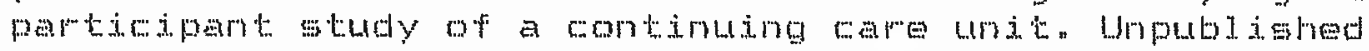
Fh. D. Aberdeen "University of Aberdern.

JAFUIS, Fin (1985). The Somiology of Adult Continuing Edutation " London "Croom Helm"

JAFVIS.F" (1987), Adult Leaning dn the Soedal context. Londan : Croom He1m.

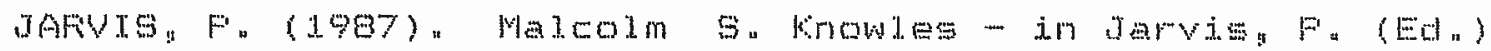
Twentieth century Thinkers. Engdand " Croom Helm.

JEFFEFY, Fi, (1979). Normad rubbish " devimnt patients in casuality departments. Socjology of Healtin and Illness 1. $3: 90-107$,

KEMMS. 9" (1985). Action Fegeam and Folitics of Action. In Bud, $D$. et a " Reflewtion "Turning Experience into L..earning London "kogan Fage.

KENWOFTHY, $N$ and NICKIN, $F$ a 1989 . Twaching and Assessing in Nursing Frateice. An Experiential. Approath. Hondonn scutari presson

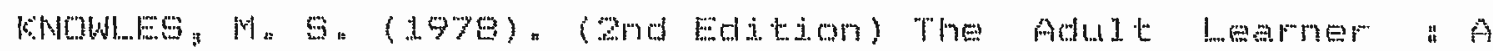
Neglected Species, Howton " Gudf Fublishing Dompany.

Kowles. M. S" (1980), (2nd Edition) The Modern Fractice of Edumation. From Fedagogy to Andragogy . Association Press. 
KNOWLES, M. S. (1989). The Making of an Adult Educator". An Autobiographical Journey. London a Jossey Base Lton.

KNOWLES, M. S. et. a . (1984). Androgogy in Action "Applying Modern Frinciples of Aclut Edumaton. San Frantigeo: Jomsey Eass.

KOL, D. An and FFY, R. (1975) "Towards an mpalied theory of experiential learning " Jn Cooper, C.L. (Ed, Theories of Gromp processese Lomion "John Wiley. (ppnsw-58).

KoLe, D. An (1984), Experiential Learning. Experience as the Soure of Learring and Development. Frentice-Had l lne.

KRATz $C$. F. (1975). Participant observation in dyadic and tryadice situations. International. Journal of Nursing Studify " $12,169-174$,

KFATz, C. Fin (1978), Care of the Long-Term sick in the Communtsy Edinburgh "Churehili Livingstome.

LACEY, C. (1970)" Hightown Brammar" Manchester University Fress:

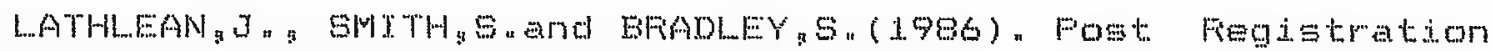
Development Echemes Evaluation. Nursing Erlucation Fesearch Unit. "Feport No 4 "

University of Londor a King's Colltege.

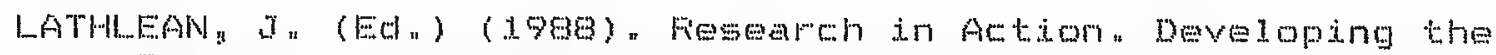
Fole of the Ward Sister "London "King" Fund Centre.

LAWTON, D. (1973). Social Change "Educational Theory and Curriculum Flanning "London "Hodder ard Stoughton"

LEONAFD, An AMd JOWETT 5 . 1990. Charting the CoLimen A study of the $b$ ENE Filot Schemes in Prempoistration Murse Eduration. Blough. National Foundation for Edutational Fesearoh dn England and Was 1 as

LINDEMAN, E. O (1926)"The Meaning of Adult Education. New Yowk "New Republi." "

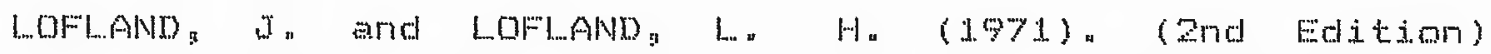
Analyzing Social Setting "A Buide to Gaditative observation and Anady is

California "Wadsworth Fublishing Company.

LOVELL.. "Fin. (1980) "Adut Learning "London "Croom Helm.

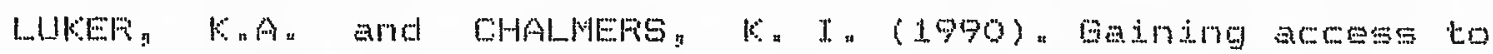
chients "the case of health visiting. Journal of Advanced Nureing 15,74 men

LUKEF: KaAn (1978). Goal Attainmert: a possible model for assasting the role of the hed th visitor "Nursing Times" Or.c.aniona 1. Fapers. $74,1257-1259$ 
MACKENZIE, A. E. (1989). The District Nurse within the community context. Key xeses in District Nurging. Faper One "London " District Mursing Association.

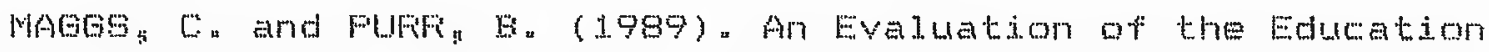
and Preparation of Fieldwork and Fimetion lork Teachers in England. Oxford

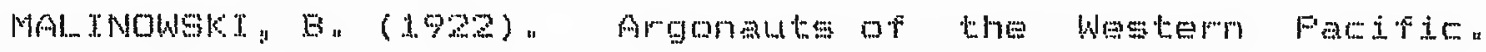
London " FoutJedge and Kegan Fal.

MALINOWGKI, B. (1982)" The Diary of an Anthropologist. Extract from Wajinowskin. B. $(1967)$ " A Diary in the Striet gerse of the Term. Londom. In Eurgess Fu. (Ed) Field Research : a Sourcebook and Field Mantial. London : Foutiedge kegan Faul.

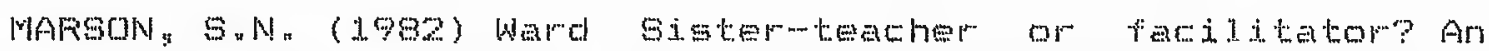
investiqation into the behavioural characteristics of effective ward teachers " Journal of Advanced Nursing 7 " $347-367$

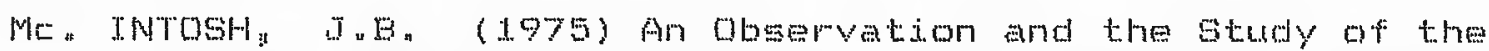
Work of Domicildiery Nurseg. Unpubidshed Pho D. Thesis. University of Aberdeen.

MELLA, K. M. (1981) " Student Nurges Accounts of thedr Work and Training "A Qualitative Analysis" Unpublished Ph.D Thesis: University of Edinbugh.

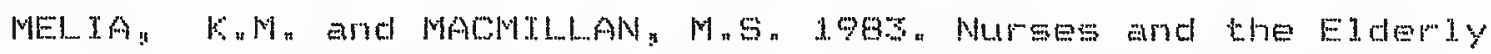
in Hospital and the Community" A Study of Communication. Edinburgh "Nursing Fesearch Unit. University of Ediriburghn

MEZIFOW, I. (1981), A Critical Theory of Adult Learning and

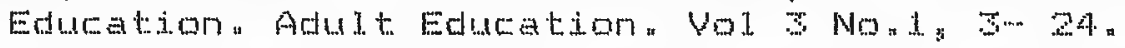

MEZIFOW" J (1985). A ciritical theory of selfowirected

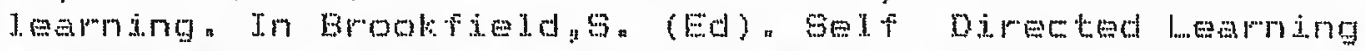
"From Theory to Fratice. New Directions for Continuing Education. No 25, 17-30. Ean Francisco "Jossey Bass.

MEZTFow: I "(1988) "Transwormation Theory" Faper aiven and avaliable at the South East Conference of Adult Educators. Nov 1989. Eastbourne.

MeTCHELL: E.s. (1986), Multiple Triangulation "A Methodology for numeing seience. Advances in Nursing seience $8(3)$, $15-26$.

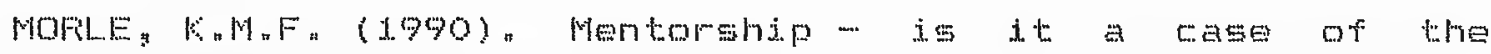
Emperor's new elothes or a rome by any other namen Nurse Education Today 10,1,66-69. 


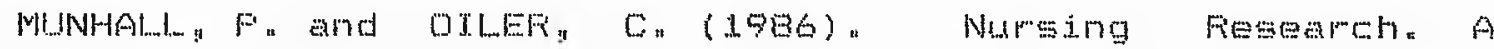
Qualitetive Fer"spectiven Nomalk "Appleton-Century croptes

N.H.S. (1990), Community Care Act. Chapter 19. London:

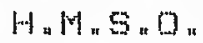

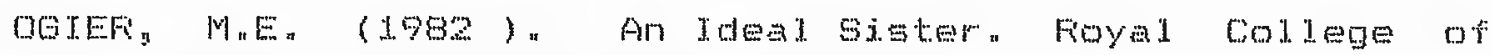
London : Foyal College of Mursing.

OLDFOYD, D. (1.986) "The Arch of knowledge "London "Methuen.

DFTON, H. D.(1981). Ward Learming Gidmate a London : Royal College of Nursing

FANEL OF ASSESSOFS for Digtwitt Numse Taining (1976) Feport of the Working Party of The Fanel or Assessors on the Education and Training of the District Numse London : DHSS.

FANEL OF ASSESSOFS for District Nurse Training (1979): cumpiculum in Distriet Nursing for Fegistomed Nursess and Fiegistered General Nurses. London "DHSS.

FANEI OF ASSESSORS for District Nurse Training. (1982). Elide to the Curricudum in District Nursing SFN/Fion and Fules on the conduct of Coumses and Examinations "London: DHSS.

FAFry, A. (1990). Freparation of Mentorship. Unpublished Esc Dissertation "London "Kings Coll tege.

FATEFGON, Fulk $(1979)$, Valugs "Education and the Adult. London : Fowtledge and Kegan Faul.

FAYNE: 6. et al. (1981). Sociology and bocial Fiesearch. London: Foutledge and kegian Full.

FEMGFEY, 5. E. (1980) "The Hard Sister - key to Nureing. London "Foyed College of Nursing.

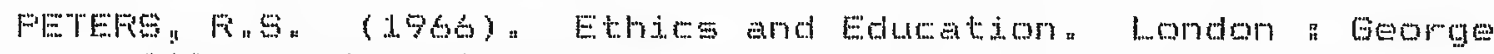
Alyen and Jinkin Ltd.

FEFEF, Fis. (1981) " Essays on Educators. Unwin Education Eooks:

FOLANYI, Ma (1967), "The Tacit wimension. New York " Doubleday"

FOLANYI M" (1958). Fergomel knowledge " London " Foutiedge and Kegan Faul.

POPE, $M$, and DENICFo, F. (1986). Intuitive Theories - a Fesearchem "a Dilema some practical methodological implications. Britigh Educational Fesearch Joumal. Vol. $12, N 02,158-166$. 


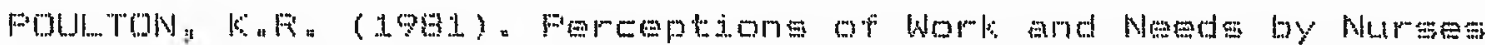
and their Fatientse unpubished Fho whesis "university of surrey.

FOWELL, J "H" (1987) " A Study of the Existence and Extant of Feflection-in-Action in Feldion to Fratising Fegistered Nurses. Unpubdished Mate Dissertation " University or Burrey"

FOWELL, J "H. (1989)"A reflective practitioner in mureing. Journa of Advanced Learning $24,824-932$.

FFING, Fu(1976) , Knowledge and Schooling "Englandnaper Books.

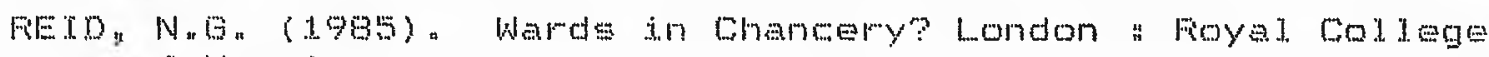
of Nurging "

FETD. WA" (1978) "Thinking About The Cumpiculum "The neture and treatment of curriculum problems "London "Foutledge and Regan Faul,

FEVAVS, Fin. (1964) Standame for Morale" Cause and Erfects. London "Nuffield Frovinedal Hospitals Trust. Deford University Trust.

FOGERS, C.Fin (1969). Freedom to Learn. OHio " Charleg and Merriti.

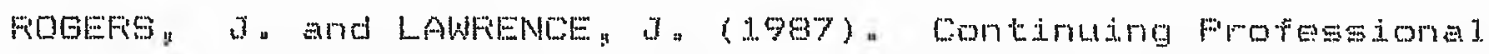
Education for qualified nurges midwives and heat vistiors. London "Ashdale Fress and Austen Cornish Fublishers Lton.

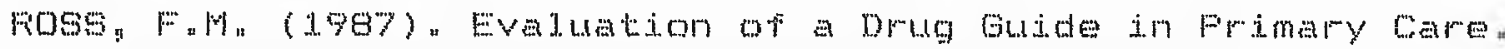
Lnpublished Flo. Thesis "University of fondon.

Foss "F." (1990) "New Horizong in Community ware " policy perspectives for distriet numsing key Jesues im District Nursing. Faper Two. London "Digtrict Nursing Aswociation.

FUNCTMAN, Fu H. (1985) Ward sister at Work" Edinburgh" Chuehil 1. Livingstone.

FYl. 6 " (1949) "The Concept of Mind London "Hutehinson.

SOHATZMAN, L. and STFALSS" A. (197S)" Field Fesearch" Strategies for a Natural Sociology. Englewood Cilitis: Frentice Hail. .

SCHON, D.A (198\%), The Feflettive Fratitioner. How Frow fessionals Think in Action. New York "Bascic Books Tne"n

SCHON, D.A. (1987) "Educting the Feflective Fractioner. San Francisco "Jossey Bass Fublishers" 
SCHFOCK, FinA (1991), Fhi Josophital IsEues, In Fecent Advances in Nursing. I "Hockey" L. (Ed:). Edinburgh : Churchill. Livingstone.

SCHUTz, A. (1964) " Collected Fapers 11. Studies in 5ocial Theory "The Hague "Martinus Nijhoft"

SKEET" M. (3974), 4th Ed, Home from Hospital" London" Maconil I an Journals"

SFICEF: J (198s). An Investigation to Tsolate District Nursing knowledge from Curmiculum content in order to Identify The Frinciples and Fretcice of Digtrict Nurging " Unpublished MSe, Dissertation "University of Surmerm,

BFFADLEY, I.F (1979), The Ethnographic Interview. New York: Holt Finehart and Wington.

STRAUSS "A. L. (1987)" Dualitative Analysig for Social Geientists " Cambmidge "Cambridge University Press.

STENHOUSE, L. (1981), An Introduction to Corriculum Fesearch and Development. London : Heinemann.

STOFEY, M. (1985). Developmet of a new staturom structure for Nursing, Midwifery and Health Visiting in the United kingdom: Journal of Advanced Nursing 10,79-81"

TOUdH, A. (1979) " 2nd Ed, The Adult's Leaning Frojects " fresh approach to theory and practice in adult learning. Toronto ontarido y Institute for Studies in Education.

TOWELL, D. (1975) " Understanding Feychiatric Nursing " London: Foyal. College of Nursing.

TWTNN, 5 "F" (1989)" Change and conflict in Health Visiting Practice o dilemmas in assessing the professional competence of student health visitom . Unpublished FhD Thesis " University of London: Institute of Education.

U.K.C.C. (United Kingdom Central Couneil for Numeng Widwifery and Weath Visiting) " (1986) "Froject 2000" A New Freparation ror Frateticen

W "KCu (1990) "The Report of the Fost-Fegistretion Eduaturon and Fractice Froject."

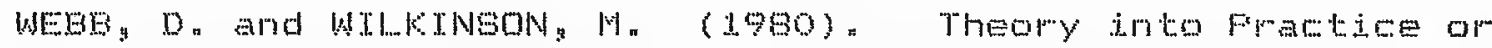
Fractice into Theory "In Alexander Fu and whittaker I. (EWs.) Developments in Fig. Society for Research into Higher Education.

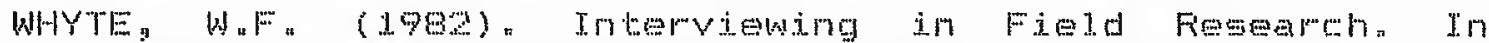
Burgess: $F \cdot B_{\text {. }}$ (Ed) Field Fesearch a a Sourcebook and Fied Manugl " London : Beorge Allen and Unwim. 


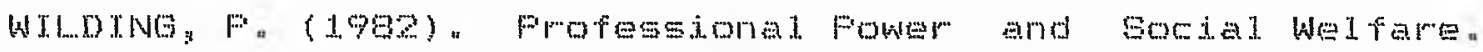
London "Foutledge and Kegan Faul.

WHTER, $R=$ (1989), Leaming From Experience "Lewes: The Falmer Fress。

WISEMAN, J "Fn (1979). The Fesearch Web, In Eynner" I. Stribley, KuM social Research " primeiples and procedure " London "Longman/Open University Fress:

Woode. F. (1986) "Inside Schools " Ethography in Educational Fesearch. London : Fout]edge and kegan Faut.

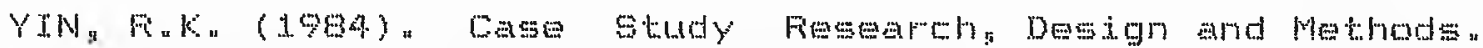
Beverley Hills "Sage Fublications. 
DISTRICT NURSE COURSE

AIM OF THE COURSE

1.1 The aim of the course is to prepare a district nurse to be competent to commence nursing duties in the community and to be able to accept individual responsibility for the professional standards of her own performance. To satisfy this aim the curriculum has been designed to emphasise the use of a problemsolving approach to district nursing and reference is made throughout to' the 'nursing process'.

NB. Although the female gender is used in these guidelines all comments apply equaliy to the male student.

\section{COURSE OBJECTIVES}

1.2 Four main objectives are incorporated in the out line curriculum. The principles should be applied throughout the course of study and not limited to specific units of learning:-

Objective 1 To assess and meet the nursing needs of patients in the community.

Objective 2 To apply skills and knowledge and to impart them effectively to patients, relatives, other carers and the general public.

Objective 3 To be skilled in communications, establishing and maintaining good relationships and able to coordinate appropriate services for the patient, his family and others involved with delivery of care.

Objective 4 To have an understanding of management and organisation principles within the multidisciplinary team and a positive approach to future developments to meet health care needs.

1.3 The outline curriculum will be found at Appendix 1 a.

\section{LENGTH OF COURSE}

1.4 The course must be of at least 38 weeks exclusive of study leave. The first 26 weeks must be planned on the basis of two thirds theory to one third practice and this must be followed by a period of supervised practice. 
1.5 The curriculum allows flexibility in course planning but requires that theory and practice will be inter-related throughout the course and that there should be some concontration of study at the beginning and near the end of the course.

TAUGHT PRACT'XCE

1.6 Onenthind of the first 26 weeks (ref 1.4) must be allocated to taught practice. The student must be placed with a practical work teacher who will assume responsibility for planning the student's practical work programme, allocating a controlled caseload, and teaching the skills of district nursing within a primary health care team. It is the responsibility of the course lader to ensure that the student is placed in a suitable learning environment. A note on the recommended criteria for practical placements will be found at Appendix 2.

PRACTICAL HORK TEACHERS

1..7 Practical work teachers must have completed an approved course and hold a qualification approved by the Board.

1.8 The practical work teacher/student ratio must be one to one furing the period of taught practice. The practical work teacher must not have allocated to her any other student during the pertod in which she exercises her responsibility towards the district nurse student.

1.9 A practical work teacher shall have a reduced but well balanced work load whilst training students. Ref. Whitley Council advance letter (NM) 3/81, paragraph 6 and ENB Circular $1986 / 1.9 / 3 M R$ (see Appendix 3)

SUPERVISED PRACTICE

1.10 The required length of supervised practice is 12 weeks. For this period the student must be placed with a supervisor who has undertaken an approved course (ref 4.3); and who is currently practising as a district nurse or, if a nurse manager, has imnediate responsibility for district nursing services.

For further cletails of supervised practice, see Appendix 4.

ASSOCIATED EDUCATION AND TRAINING

1.11 Opportunities for shared education and training should be developed with other students being prepared to work in primary health care. 


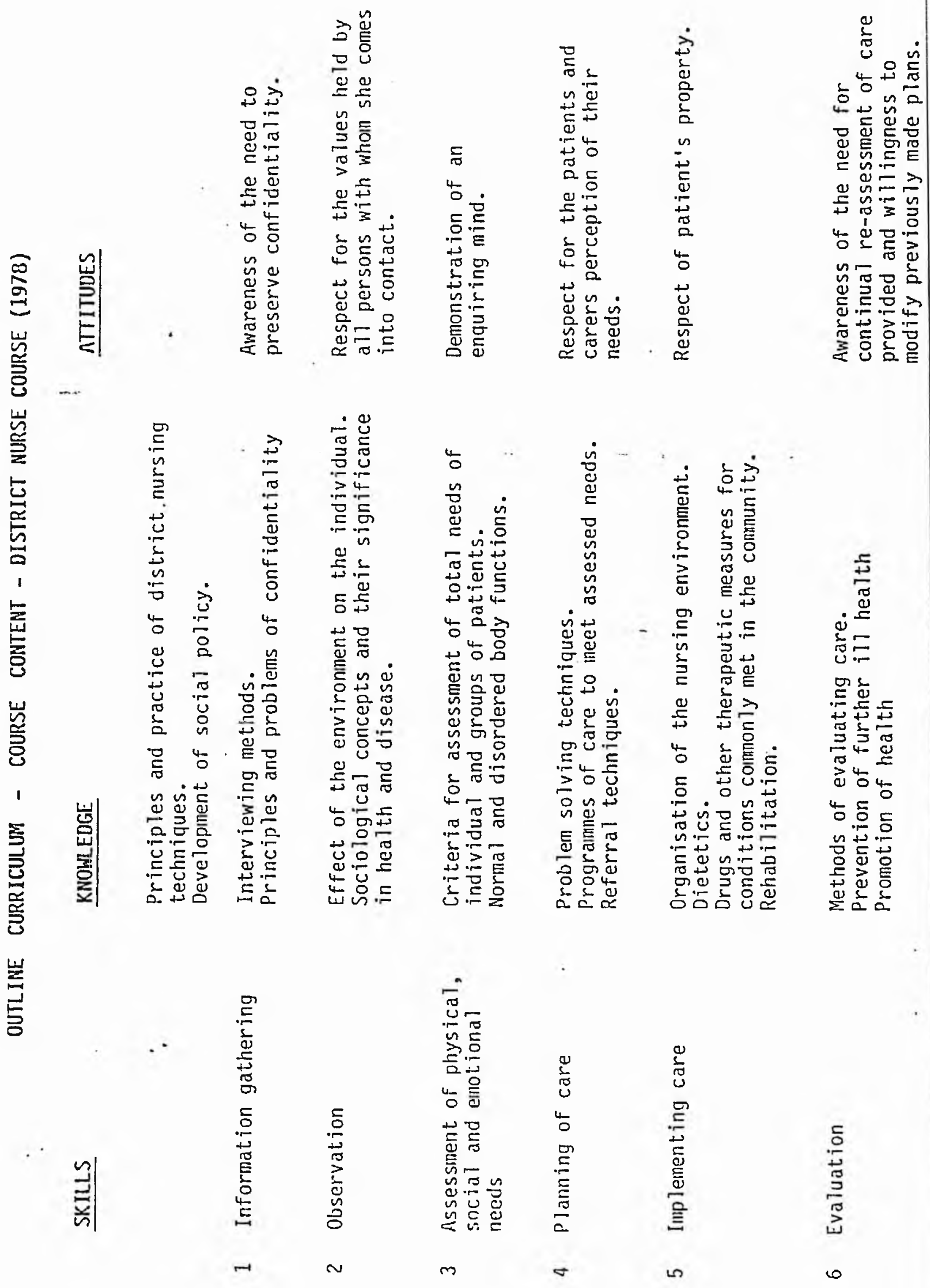



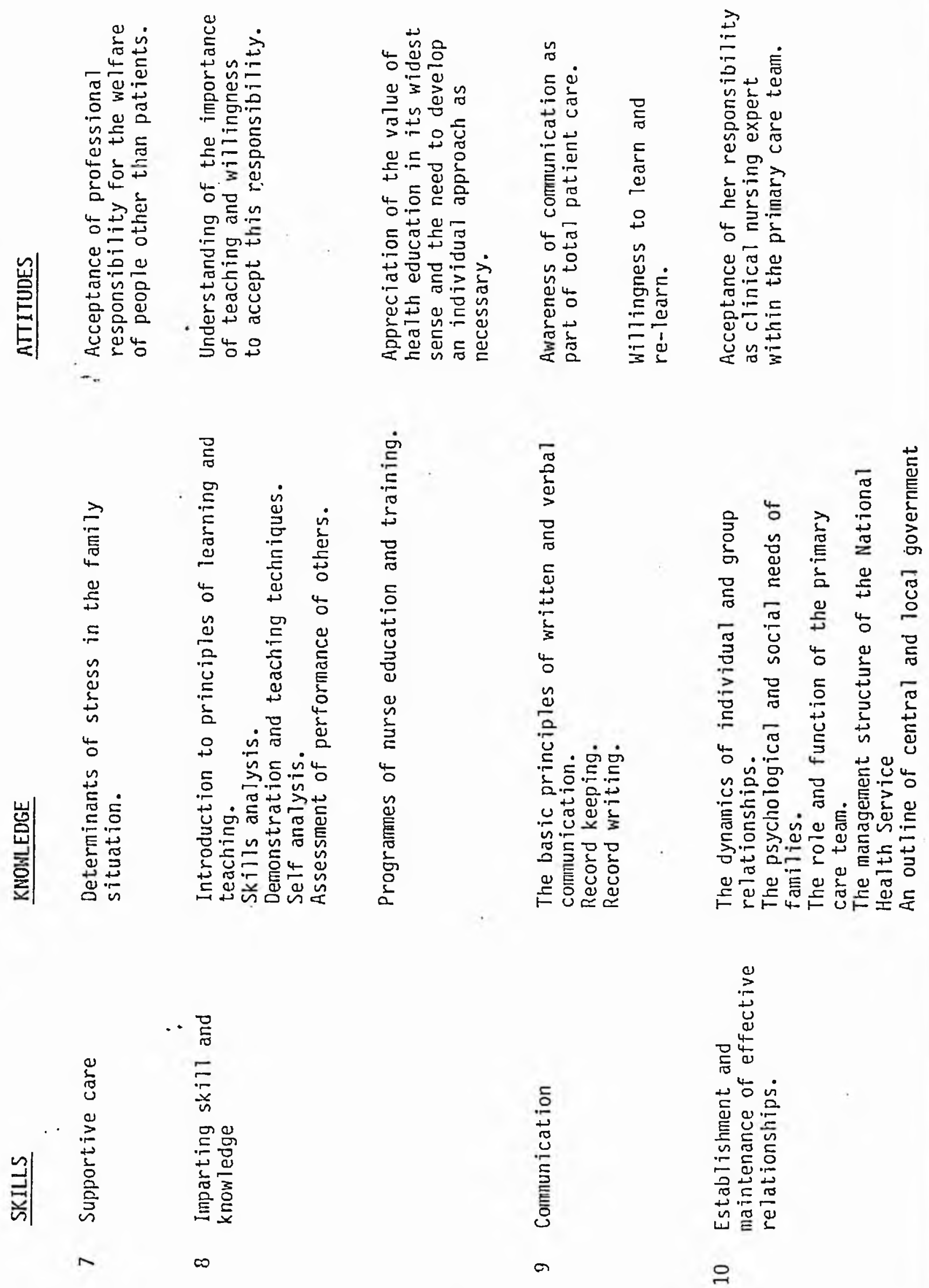

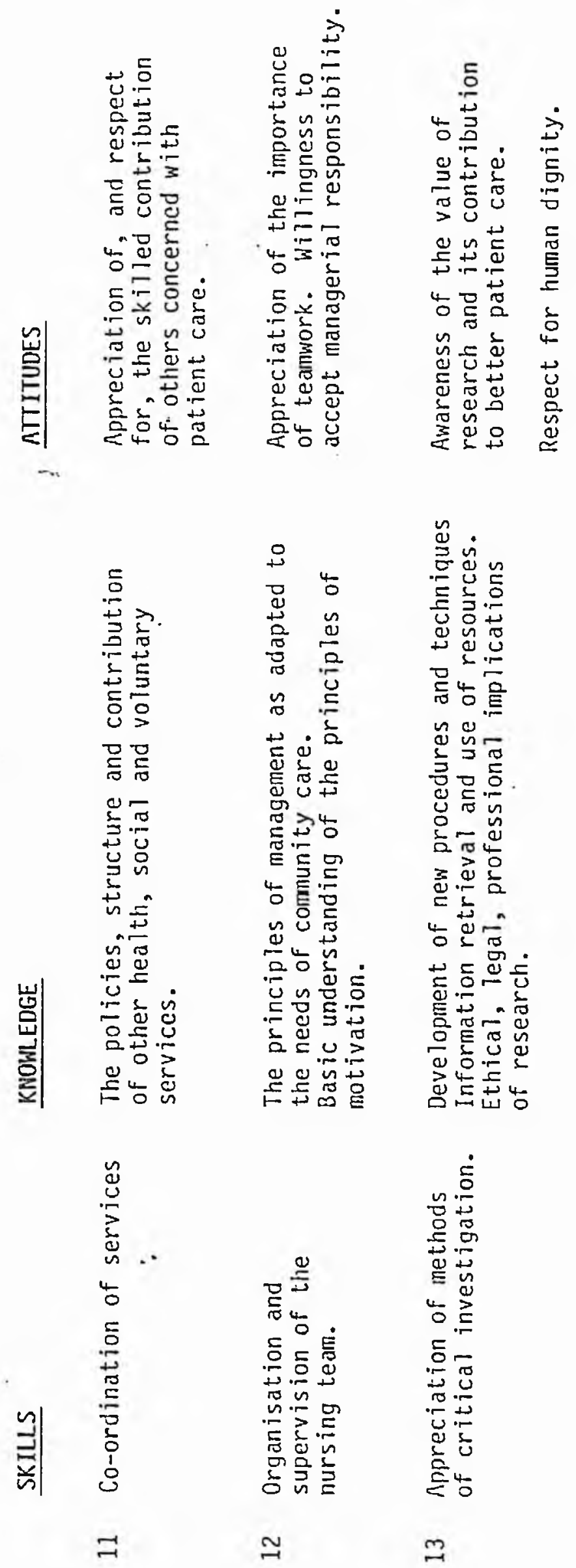
APPENDIX 2

BIOGRAPHICAL DETAILS - STUMENTS

\begin{tabular}{|c|c|c|c|}
\hline STUDENT & $\begin{array}{l}\text { PRBFESSIONAL } \\
\text { QUALIFICATIONS }\end{array}$ & $\begin{array}{l}\text { LENGTH OF } \\
\text { COMNUNITY } \\
\text { EXPERIENCE }\end{array}$ & $\begin{array}{l}\text { CAPACITY IN AHICH } \\
\text { EMPLOYED } 2 \text { YRS. } \\
\text { BEFORE COURSE }\end{array}$ \\
\hline t.yr. & & & \\
\hline S.T. & R.6.N. '66 & 15 mths. & $\begin{array}{l}\text { Charge Nurse - Hospita } \\
\text { Staff Nurse - Comunit }\end{array}$ \\
\hline Q.D. & R.G.N.' 83 & 10 attis. & $\begin{array}{l}\text { Staff Nurse - Rospital } \\
\text { Staff Nurse - Comaunity }\end{array}$ \\
\hline F.H. & $\begin{array}{l}\text { R.G.N.'74 } \\
\text { R.S.C.N.'77 }\end{array}$ & 2 Heeks & $\begin{array}{l}\text { Ward Sister - Elderly } \\
\text { Acute Medical }\end{array}$ \\
\hline U.E. & R.B.N. 'B3 & 1 year & $\begin{array}{l}\text { Staff Nurse - Community } \\
\text { Staff Nurse - Agency }\end{array}$ \\
\hline K.O. & $\begin{array}{l}\text { R.G.N. }{ }^{\prime} 68 \\
\text { R.H. } 70\end{array}$ & $\begin{array}{l}\text { I day } \\
\text { (vol.) }\end{array}$ & Nard Sister - Medical \\
\hline T.R. & R.G.N.'B1 & 1 year & Tuilight Service \\
\hline H.C. & R.G.N. 'BO & 1 year & $\begin{array}{l}\text { Staff Nurse - Hospital } \\
\text { Staff Nurse - Community }\end{array}$ \\
\hline D.C. & R.6.N. '74 & None & $\begin{array}{l}\text { Ward Sister - Elderly } \\
\text { Hedical }\end{array}$ \\
\hline
\end{tabular}

NON-BUAL. COURSES ATTENDED
AGE RANGE

Brit. Tuberculosis Ass, '67 Ophalnic Nursing Dip. '68 1stline Han 'ment Course' 76 Cert. Oncological Nursing' 86

Care of the elderly Promotion of continence Patients cone first 2 day course ' 87 Diplona in Counselling 1 year part time '86-' 87 None

$41-50$

None

$22-30$

$31-40$

$22-30$

1

$41-50$

$22-30$

$22-30$

None

2nd.yr.

\begin{tabular}{|c|c|c|c|}
\hline N.T. & $\begin{array}{l}\text { R.G.N. '78 } \\
\text { S.C.H.'B5 }\end{array}$ & $10 \mathrm{mths}$. & $\begin{array}{l}\text { Staff Miduife } \\
\text { Staff Murse - Community }\end{array}$ \\
\hline F.T. & $\begin{array}{l}\text { N.N.E.B.' } 80 \\
\text { R.G.N. '85 }\end{array}$ & 12 aths. & $\begin{array}{l}\text { Staff Nurse - Hospice } \\
\text { Staff Nurse - Comeunity }\end{array}$ \\
\hline N.Q. & R.G.N. '64 & $\begin{array}{c}5 \text { yrs. } \\
\text { (pt.tine) }\end{array}$ & $\begin{array}{l}\text { Hone Care Sister - } \\
\text { based at Hospice }\end{array}$ \\
\hline R.U. & R.G.N. '71 & $1 \mathrm{yr}$ & Staff Nurse - Hospital \\
\hline E.X. & R.G.N.'78 & 4 yrs. & $\begin{array}{c}\text { Staff Nurse - Community } \\
\text { Eyening Service }\end{array}$ \\
\hline Q.D. & R.G.N.' 76 & 3 yrs. & Staff Nurse - Community \\
\hline N.1. & $\begin{array}{l}\text { R.G.N.'74 } \\
\text { S.C.H.'78 }\end{array}$ & None & $\begin{array}{c}\text { Night Bister (relief) } \\
\text { - Hospital }\end{array}$ \\
\hline R.T. & R.G.N. 'B1 & None & Ward Sister - Medical \\
\hline
\end{tabular}

Sťudy Days - Terminal Care

Pain Control Symposium 'B7 Assertiveness Course 'BB E.N.B. 931 '87

None

I.V.Therapy ' 86

Study Days

Hanagenent ' 86

Diabetes ' 85 , Hanagement ' 86 , E.N.B.Assessors 'B5, Aids '86.
$22-30$

$22-30$

$51-60$

$41-50$

$31-40$

$31-40$

$31-40$

$22-30$ 


\section{RESEARCH PROTOCOL}

\section{Title of the Proiect}

The Community Learning Environment - An ethnographic study of students and their practical work teachers in district nursing.

Aims.

To describe and gain an understanding of the learning environments of district nurses in the practice setting of the community. To suggest indicators for good learning environments in the community.

\section{STUDY DESIGN.}

The study is based on the grounded theory form of the ethnographic approach. The qualitative nature of this research does not allow the testing of research hypothesis or measurement against strict criteria. The aims are deliberately broad and non-specific. In keeping with the methodology more precise objectives will emerge in the course of the study.

\section{TIMETABLE.}

Pilot Study

Main Study

Estimated date of completion

Written report
October 1986 - August 1987

October 1987 - ongoing

October 1989

July 1990

\section{SAMPLE.}

District nurse students and their practical work teachers will be drawn from institutions that can provide examples of community learning environments in different geographical areas.

\section{A) ACCESS.}

Gaining of access will take account of the following factors:

1. Gain p̀ermission to enter Institute from where the student sample is to be drawn.

2. Discuss research proposal with Institute staff and students.

3. Initial identification of student sample and corresponding health authorities.

4. Gain permission to enter health authority by:

a). Telephone contact with official correspondent, nursing officer and practical work teacher who have responsibility for the student while they are undertaking the district nurse course. 
b). Written confirmation of agreement to participate in the study and outline of participants involvement in the study.

5. Confirmation of health authority permission with students.

6. Awareness of need to ensure continued agreement with participants throughout the study.

7. Careful scrutiny of research proposal, including ethical considerations will be carried out by the supervisor of this project.

B. DATA COLLECTION AND ANALYSIS - Main Studv.

Data will be collected by interview and observation.

1. Initial unstructured interview conducted at the institution with each student after the first and before the second practice placement.

2. One unstructured interview with each student and practical work teacher conducted separately during the second practice placement.

3. Observation of each student for one period of their normal routine while in the third practice placement, followed by a further unstructured interview with student and practical work teacher separately.

4. Unstructured interviews with students at the institution following their third practice placement.

5. Data will be recorded by audio tape at interview and written fieldnotes following observations.

6. Data analysis will be an ongoing process. As categories emerge from the interviews and observations they will be developed, refined, modified and in some case disproved. The finding will be analysed in the context of existing theory relating to learning environments, adult learning and learning from experience in the work area.

7. Preparation of written report.

C. USE OF FINDING.

1. A report of the findings will be made available to all the participants. Wider dissemination of findings will be achieved through publication in professional journals, presentation at conferences, talks to research groups and teaching to district nurses, practical work teachers and nurse manager.

2. It is anticipated that this preliminary research will raise questions for research.

Confidentiality.

All information will be treated as confidential and only used for purposes of this research. Names of informants, health authorities or institutions will not be revealed.

\section{A.E.Mackenzie,}


Interview with -..-.-... - 3rd placement. Feb 17th 1989.

3.1 I just want to pick up from last time when we were talking, one of the things you said was that you were getting slower and I wondered whether you still think you are getting slower or have things changed?

3.2 No, (laughs) I have speeded up this time, I've had a heavy case load. I've been working on my own most of the time because of this situation so I've had to cope. Really, that's perhaps to the patients detriment, maybe I've missed things, I've probably missed things that I would have picked up on if I'd been taking my time. There just hasn't been the time in the last two weeks to do that.

3.3 So you're not worried about that now (no that - laughs - resolved itself, yes)

3.4. I suspect from what ----- was saying this morning that you're short staffed and that your not able to see her so often has that affected your expectations of this placement has it been difficult to meet the expectations you had?

3.5. No they haven't been meet. (Why is that).

3.6. I just feel at the moment I'm being used as a pair of hands. Although its nobodies fault, I think there should be, if they're going to train district nurses, there should be people who can be called in if the staff are short, so that we can get the cover that we need and experience that we need and have the time with the practical work teachers that we need.

3.7. Which I haven't got. --..- has been doing the clinics and if I have had problems, I've just really had to figure it out myself without being able to ask. If she's floating about outside then I've managed to catch her and say, but its difficult to keep on interrupting clinics. It stops her train of thought and its disruptive to the patients as well.

3.8. I don't like having to feel like this. I cant keep coming back here all the time whereas before we perhaps met at a patients and I could chat to her in the car or as we went out. (It must have been difficult) yes it has.

3.9. Have you had anybody else to help out or have you had all the work to do?

3.10. Yes we've had other people on duty, but they've been covering other areas and so they've been covering the work and then going back to their area. Its been quite busy. I don't feel particularly happy about it this time (hmm). 
3.11. What were you hoping to get out of this placement, I think you said it would be something to do with management?

3.12. I was hoping to have a set of patients that I would go to - a small case load - that I would go to every day and if some new referrals came in, then I would perhaps have them. If I got too many then I would drop some of the ones that I had been doing before. I would keep the same caseload but including the new assessments. Really I haven't had much time to do that, I've had the patients who the other person hasn't had or she had some of my patients some days - its been quite difficult really. I feel quite angry - I know district nursing isn't meant to be stretching and glamorous but there are things that I have gone and done. I feel I could be using my time better elsewhere. Perhaps ----- is a case in point, going in to wash her everyday is not quite what I should be doing.

3.13. You would make changes there would you ?

3.14. Yes - its difficult I don't know whether to say or not (yes). Perhaps if ----- had been available, I would be able to just say is it really necessary, could we organise it a different way and then if it doesn't work - fair enough, (hmm) rather than just going in there every day without saying anything.

3.15. Are there other instances where you feel that if there had been your patients you might have done it differently (yes) any other examples that come to mind?

3.16. Hmm... the terminal patient that I went to last week, he just died last week-end, hmm I felt there wasn't enough input there perhaps its because I've had so much experience in terminal care. I tend to think they're my baby, but not possessively, but I think... she was being visited once a week when I got there last week. I started going every day, getting the Marie Curie in, I think they'd been in before but I got the evening service in. The daughter was really at the end of her tether and I think that was a shame because she'd worked so hard, our input could have gone in earlier, and relieved some of the tension she was feeling. By Thursday she was pretty up tight, pretty cross and her mother actually died on Sunday and I think she now feels guilty. Perhaps saying a couple of things to me that she didn't really mean. I saw her this week and took everything out of the house and I said that I'd got and see her next Friday to give her time and the children will have gone back to school then. So I felt there that our input could have been better.

3.17. Did you discuss that?

3.18. No, I haven't really said very much at all. I haven't had the chance, because ---- goes home at lunch times. I find that quite difficult. I obviously can't go home so I sit about and do my forms and things, I find that... I don't really like that.

3.19. No... so you haven't had any formal teachings either ? (no). Have you asked for any teaching (no not really). 
3.20. Did you say this morning that there was another person on the course, are they based here? (No at -..-- ).

3.21. Do you ever get together with that person?

3.22. Yes, I do, I rang her last night (laughs) because I was feeling a bit grumpy. She is quite good she just listens and says what she thinks. We are quite close like that we can say to each other. I don't think you should say something to -----. (hmm).

It's very difficult I don't want to... I know she's very easily upset and I don't want to upset her, and a lot of it isn't any fault of hers but I think she could put a bit more effort in. ( $\mathrm{hmm}$ ).

3.23. It's an awkward position, you have to continue working...

3.24. Yes, whatever I say I've got to carry on and if I'm working in this area when I'm qualified it could become quite difficult. I don't want to upset her and say anything.

3.25. Have you discussed it with -..-- (yes) and what was his advice?

3.26 He wasn't very helpful. I didn't find him helpful. He said that when he came to visit he would discuss it but when he came -..-was doing the baby clinic that afternoon so I took him out and we just talked about the patients. I said have you had a word with --..and he said no, and I said well you know this is fairly typical of her being in a clinic in the afternoons, while I'm out. It's not how I envisaged a PWT being ( $\mathrm{hmm}$, that's right). I don't need to be protected from all sorts of things but I just like to know that there's somebody there who's going to be helpful and say $\mathrm{OK}$.

3.27. Because you seen to be relying on what you have already learnt before (yes).

3.28. Would it be fair to say then, that you haven't really learnt much new. (No, I haven't). But has it changed your ideas or changed your attitude?

3.29. But I'm still finding things difficult... just like last year, that I don't know how to handle, like what do I use after the Aserbine. I'm, still at that stage whereas now I think I should now have a series of things that I can pick and use it, whereas I'm still wondering well has that helped. Well over halfway through the course I should be feeling more confident and have some basic teaching about things like that and what has ben used by my PWT to advantage or not. It comes back to this thing of it's mine and I don't want to share it. (hmm).

3.30. It's very difficult for you I can see that [pause, to look through notes]. Yes, another point I wanted to pick up was links with theory and practice. I'm just trying to find out whether you make the links yourself by actually just thinking about what you have done in college or are there any specific ways in which links are 

seemed to be one way to make links, are there any others?

3.31. Hmm, well... the only thing...hmm, well, I haven't really done much linking this time. The only thing I'm very aware of at the moment, I'm doing another assignment this time on communication and I'm very aware at the moment of how people are using their non-verbal signs. I'm storing it all away to use as examples (hmm). (Is that the psychology assignment ?) yes. (And that going to be used as an assessment ?) yes. And I'm finding it very difficult, because its.... all the reading that I'm doing its only really people from the ... and theories, none of it you can say is concrete, that where somebody does a certain gesture it means this. So it's all supposition and I find it difficult to write about things that other people have thought. I haven't got anything on paper yet and it's got to be in at the end of March.

3.32 Did you choose that because of your background? Anyway you must know quite a lot about non-verbal communication.

3.33. I choose that because it leapt at me none of the others seemed to stimulate my thoughts. But I've read quite a bit, but I can't seem to get anything on paper, there seems to be so much to put in without quoting things that I've seen.

3.34. Is that required then... are you expected to draw on your own experience?

3.35. Yes, you are to a certain extent but they also want to know the background and they want to know the theory and things and that's the bit I'm finding hard, whereas thirty percent of the marks are on how you relate it to district nursing.

3.36. So it's psychology you have to draw on not nursing research like Macleod-Clark's stuff on communication, (no) it's the psychology.

3.37. The other thing that has struck me while I have been doing the research is the sort of protective environment that students are in because they are not taking full responsibility for the caseload which is normal practice - so one question that arises in my mind is how do you actually find out when you're in a risk situation, you've go to take a risk or in stressful situation, whether you can cope. Do you ever get put into those situations?

3.38. What do you term stressful situation?

3.39. I'm particularly thinking about patient care if you went into a situation and you didn't know how to cope, have you had chance to test yourself in that like going into the unknown and find a catastrophe has occurred?

3.40. I have been in situations like that before (on this placement ?) not on this placement. I mean, I had to go in yesterday and take somebody stitches out and I thought: $O h$ it will be fine and then 
when I got there and got the dressing off, it was all weepy and bloody, so I didn't take the stitches out and I keep thinking I should ${ }_{313}$ have taken them out really. Anyway, I'm going back on Tuesday and I think I'll take them out then... I mean they won't hurt to be in but it worried me that I had said to the patient before I'd really thought, Oh, I'll leave then in. If I had not said it, I would probably have taken them out today. And that's... that put me in a spot. Well it's not putting the patient in danger so I could take them out Tuesday and I don't think the stitches were doing much good anyway. I'll probably have to dress the arm for a week or two anyway.

3.41. And yesterday, I went to a terminal patient who's uptight, he said he didn't want to know anything about his illness. They told him he had got carcinoma of the lung and that's what he knows and now he's been told he's got congestive cardiac failure as well and the prognosis is very poor. And I said to him, which made me feel stressed, do you want to know any more about what's going to happen, have you changed from when you said you don't want to know? And that's because I was feeling comfortable in the situation and after I said that I felt uncomfortable, but he gave me an answer which is good because I wasn't clear whether he had changed his mind or not, and he said no, he hadn't changed his mind and didn't want to know any more. An yet, you wouldn't think I would find that stressful because I have been in situations like that before but I lull myself into security and then all of a sudden, it grips you. But his wife said to me she was very glad that I asked that because nobody had really asked him again. And I was just worried I've nursed people who've said they don't want to know and right near the end have wanted to know and said why didn't you tell me and I didn't want that to happen, because I think his wife is doing a grand job and I didn't want him to go against in the end if she'd stopped everybody telling him more about it. So we cleared that up and we can now carry on.

3.42. So as you go in, you come across these situations (and does that give you a feeling of what it's like ?) yes.

3.43. And perhaps the next time I wouldn't say I'm not going to take those sutures out, I'll think a bit more before speaking out.

3.44. Have you discussed that with -..-- ?

3.45. No, I haven't seen her since. (Would you expect to do that ?) yes I probably will to test out what she thinks.

3.46. It seems you are drawing on a lot of background experience you have had before...

3.47. But, I don't know whether it's right or not, I've never been told whether what I am doing is correct... because I've always worked on my own. I was relief for people on holiday. They always told me about the good things that I did but I don't think sometimes they told me if I'd done things wrong, I think they were quite protective 
(And are you finding that out here ?) No, I want somebody to say : God! that's terrible, why on earth did you do that and I would say ${ }^{3.14}$ well that is what I thought but can you tell me what to do the next time it comes up, (hmm).

3.48. Last time we discussed a situation where you had been to a patient and you'd done some counselling and I think ----- had been with you, clearly that hasn't happened again this time, so that recognising your skill, your experience hasn't happened this time because of the lack of contact (yes).

3.49. This was the same terminal patient that I was counselling with -...last time.

3.50. Except that the experience with the GP was negative, (yes I find that very frustrating) yes.

3.51. I find that quite insulting really that people shouldn't recognise the skill that I have got just to wave it away as if it's an extended role and it's not for you. Whereas I'm willing to do it I would have thought that was a good resource, having nurses that were not specialists and stuck away but nurses that have specialist skills and can teach others they are in contact with.

3.52. Just one more thing. You said you were talking to your colleague who is on the course with you, do you find the group supportive as a whole.

3.53. Yes... hmm... the group's too big, definitely too big. We've sort of gone into smaller groups now around various tables and we tend to stick to those and the people in those groups are very supportive,which is quite good and as a whole the group sticks together. There was an episode over counselling last term, hmm, with -----who you are going to see as well. She and I decided to opt out of counselling because we felt we weren't getting anything out of it and obviously we took something away from the group. We were disruptive and we opted out and whilst we were out of the group that day, the counsellor actually discussed us with the group and the group, as a whole, was very supportive because they didn't like the way we were discussed. And, we've actually decided now that we wont go to that because we didn't find it was beneficial. I found that I've had experience, I mean, I haven't had so much that I don't need anymore, but $I$ found that it wasn't doing me any good. I found that talking to people who had been in it, in the group, they were concentrating on all sorts of things and getting away from the actual patient who they were talking to, they were looking for all sorts of signs and signals and I didn't want to get this into my brain and loose what skills of counselling I'd already had. But I talked to ----- about it and he said that's fine, there the group pulled together and I was surprised.

3.54. That is good, you need support somewhere.

3.55. I did talk to ---- but I don't think he's any help, he just said yes and 
no and I think, he thinks I'm quite strong enough to say things on my own but I don't want to upset anybody and I think I will do if $\$ 15$ say anything. The slightest thing will upset somebody.

3.56. Unfortunately it does happen.

3.57. Does it, do you think something should be said because, the girl that I'm at college with, she said it's for everybody else good if I say something. People who came out the next time will not have had the experience and she says, well what if I'd been in ----- and she'd been here with no experience to call on, how would she have coped.

Tape turned off - see fieldnotes.

Footnote

An extract from this transcript is found on page 183 coded as FT2.3: 3.5 


\section{Glossary of Punctuations used in the transcripts}

Glossary of punctuations used in the transcripts

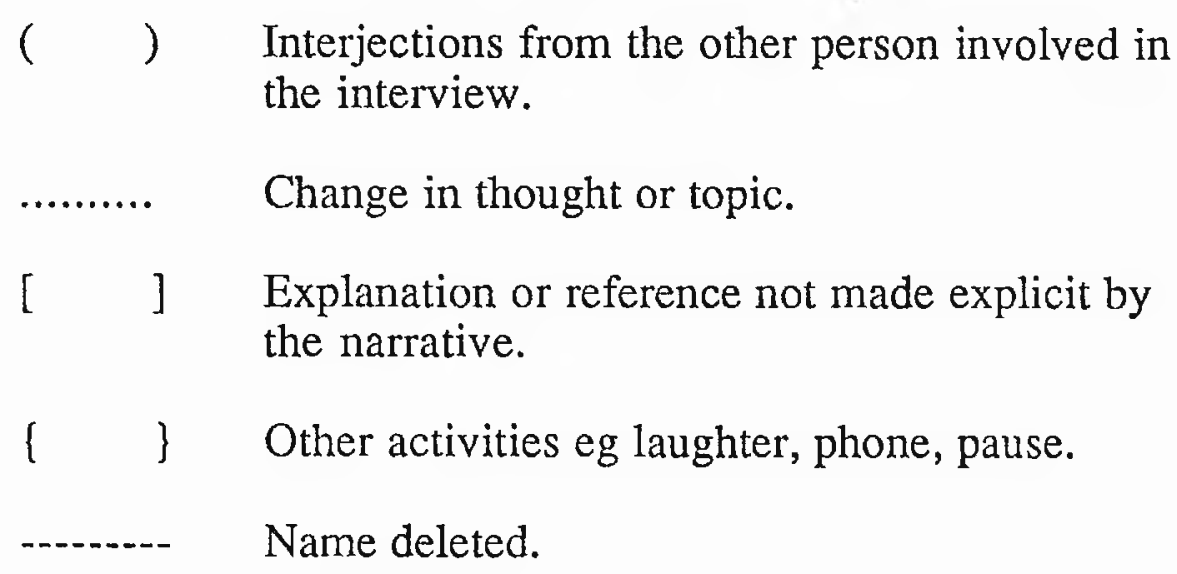

Coding system used in the transcripts:

Initials - Student identification eg KO

1st fig. - Year of study eg 1

2nd fig. - Placement eg 3

3rd fig. - Paragraph eg 3.28

Example KO.1.3:3.28.

Student KO in the first year of the study, in her third placement found in paragraph 3.28 in the transcript.

This system makes it possible for the reader to locate the student in the year of study and in the placement within that year.

The female gender is used throughout in referring to respondents. Although one respondent was male identification would compromise confidentiality. 
AFFENDIX 6

Extract from Fesearch biam i Fictitious names used throughout).

Year 1 - November 1.tth.

To interview ko in placement. Found $\mathrm{I}$ had not contacted the gatekeeper (Director of Nursing Services); although it contacted the officiat correspondent - Iane Smith. When I telephoned Jame Smith she was only too pleased y chatey and sad not to bother going to the Director. Things change so quickly - need to be sure and to "over ask" "

F "W "T" very concerned about using tape recomder" Time spent beform the interview talling about my research and answering questions. Thic obviously needs doing to allow pespondents to become familiar with the research. Eventually persuaded to use tape - reinforced confidentidityn

Interview with ko. Told ko I had tried to imagine how she mut have felt coming to a new place. [strangeness in an unfamiliar landsoape - important to student -- ladn't realised how stmange it feels - hostile even.l

Asked ko to get closer to the tape - soft voicen said again - after tape of -- not sure whet I wanted seems very anxious .... which she says ghe is about the whole placement. Fielaxed discussion when tape its of . This also applied to F."W.T. ko says Will. I pass information to F"W.T. "because if so she would plrase it not to be hurtrul".

[Methodological note - giving informetion to informants stress contidentiality. use of tape. Access and gatekeeper. Protocolis.

[There teems to be a great leap from hospital experience to communty, Things like knowing wheme to go ine.clinic door locked couldn't find way in " Has this affected her" learning? Time short - does it allow for this . Has different approach to eare from $F_{\text {"Wn }} T$ " ? important! I

Year 2 - February zand.

Further tranecriptions olearly it seems importent to have people who wan think things through - conceptualise $v{ }{ }^{\prime} v_{n}$ conrete thinking - shown in difference between NT3 and KUS.

r.mplications -- need to look at theory and pratice are we separating them out too much i. "e. college/practice and therefore creating a void that is not already there? is it just applying in practice? Can you think about practice and postpone the application? students have to in some casses.] 
AFFENOTX 6 cont:

Each time I transcribe another door opens up. It is therefore importat to transcribe ow tapes, although boring "Hearing the voies takes you back to replayl reflewtion. An important point for taping interviews - a role blay. Fe-creating the semen.

Certainly has arfected my thinking about district numsing. often thinking about standards and the poor gtudents who

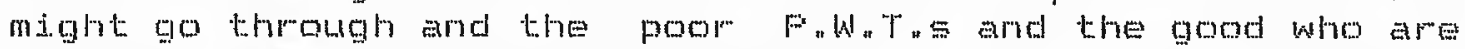
rrustrated - also the mismatch between student and $F_{\text {" }} W_{\text {" }} T$ *

[M.N. I have to make sure does not affect my "digtancing" it could intimoduce bias

Sone transcripte are boring and uningpiring some are very stimulating " Feel you want to work with those people and follow them up Ferhaps in future evaluate practical. placements or courses. Ferhaps there needs to be some sort of criteria for HaAns and colleges - both - to evaluate placemerts

[Not just theory and practice - its vision and reatity so how close $i$ w the HAx"s notion of district numsing to the college's notion if we work to a premset curriculum we are restricting the ability to educate for meality. Academic fredom $v$ " $v$ " vocational preparation n But no - it's not that - - its using the actademic development in thinking inted lectul development - to help develop the protessional mole not move it further away rrom pratotera

CMn, Interviews need to reflect interest and level of ability of articulation of students. Is a skill in helping people to articulate their thoughts "1 
RECOMMENDED CRITERIA OF SUITABLE PRACTICE FOR THE PURPOSE OF PRACTICAL EXPERIENCE FOR DISTRICT NURSE STUDENTS.

The following guidelines are issued to assist in the selection of suitable practical placements.

\section{1. $\quad \underline{\text { Siting }}$}

a. A group practice or health centre. Where possible a teaching practice.

b. A room available for practical work teachers to conduct clinical demonstrations, discussions and counselling interviews.

c. Facilities areas for private study and work completion should be available to the student.

d. Quiet area for private study and work completion should be available to the student.

2. Primary Care Practice

a. Primary care team concept upheld by members.

b. Maintenance of Age/Sex Registers and other methods of identification of 'at risk' groups would be an advantage.

c. Health assessment projects, e.g. cytology Clinics, Screening Clinics for the Elderly.

d. Practice lists should ideally include a cross-section of:

Age groups;

Social class;

Ethnic groups.

e. Where these facilities are not available, consideration may need to be given to the provision of some contrast experience, e.g. rural or inner city areas.

f. Teams of all nursing grades to provide managerial experience.

\section{Learning Environment}

a. The learning situation should be under the management and control of a qualified practical work teacher.

b. Placement monitored and facilitated by a nursing officer (district nursing).

c. Practical teaching and the delegation of a controlled caseload must be undertaken by a qualified practical work teacher.

d. Continuity of instruction is an important factor and consideration should be given to holiday arrangements and a relief qualified practical work teacher for unplanned absences. 
AFFFNDT $X$

TEFIMTNOLOOY

The roliowing tems have been used in this study and are defined as 70110 was

Distritut NurE

A Fegistered Generad Nums who has undertakn post-registration qualification, recordable with the Lnited Kingdom Gentral. Gouncil for Numsing lidwiferr and Health Yis iting

Fractical. Work Teacher

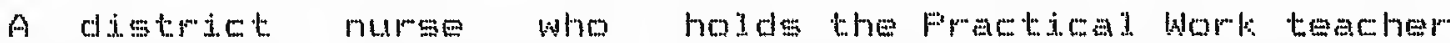
Cortificate The practical. work teacher has maponsibility for teaching the practice ot disteite numbing planning the

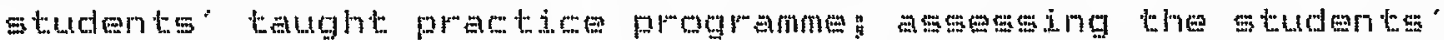
progress whoughut the coumse and evaluting competence to practics

The term community protice temoher has now been adopted by the English National Gomol for Nwming Widwirery and Health Visiting It is a generic term to inelueb not on ly practicat work teathers but aso others in the practice setwings of the communitiy who have teaching and assesment

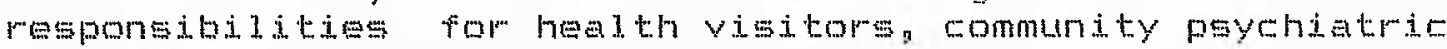
numges commonity mental. handicap numses and oteupational

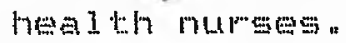

Casenad

The population for which the district nurwe has dogignated rmsponsibility and is based on a defingd population such as

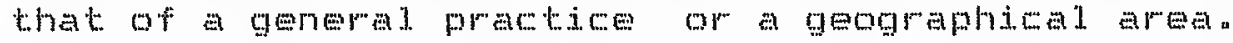

Worlo $10 \mathrm{ad}$

The whole mage of activities for which the distriet mume has professiona! pegpongibility such as nurging individuals in their home Iiacing with other agenciesg identifying heat th neras of a population. 